\title{
Revision of Archaeoteleia Masner (Hymenoptera: Platygastroidea, Scelionidae)
}

\author{
JOHN W. EARLY ${ }^{1}$, LUBOMÍR MASNER ${ }^{2} \&$ NORMAN F. JOHNSON ${ }^{3}$ \\ ${ }^{1}$ Auckland War Memorial Museum, Private Bag 92018, Auckland, New Zealand (jearly@aucklandmuseum.com) \\ ${ }^{2}$ Agriculture and Agri-Food Canada, Research Branch, K.W. Neatby Building, Ottawa, Ontario K1A 0C6, Canada \\ ${ }^{3}$ Department of Entomology, The Ohio State University, 1315 Kinnear Road, Columbus, OH 43212 (johnson.2@osu.edu)
}

\section{TABLE OF CONTENTS}

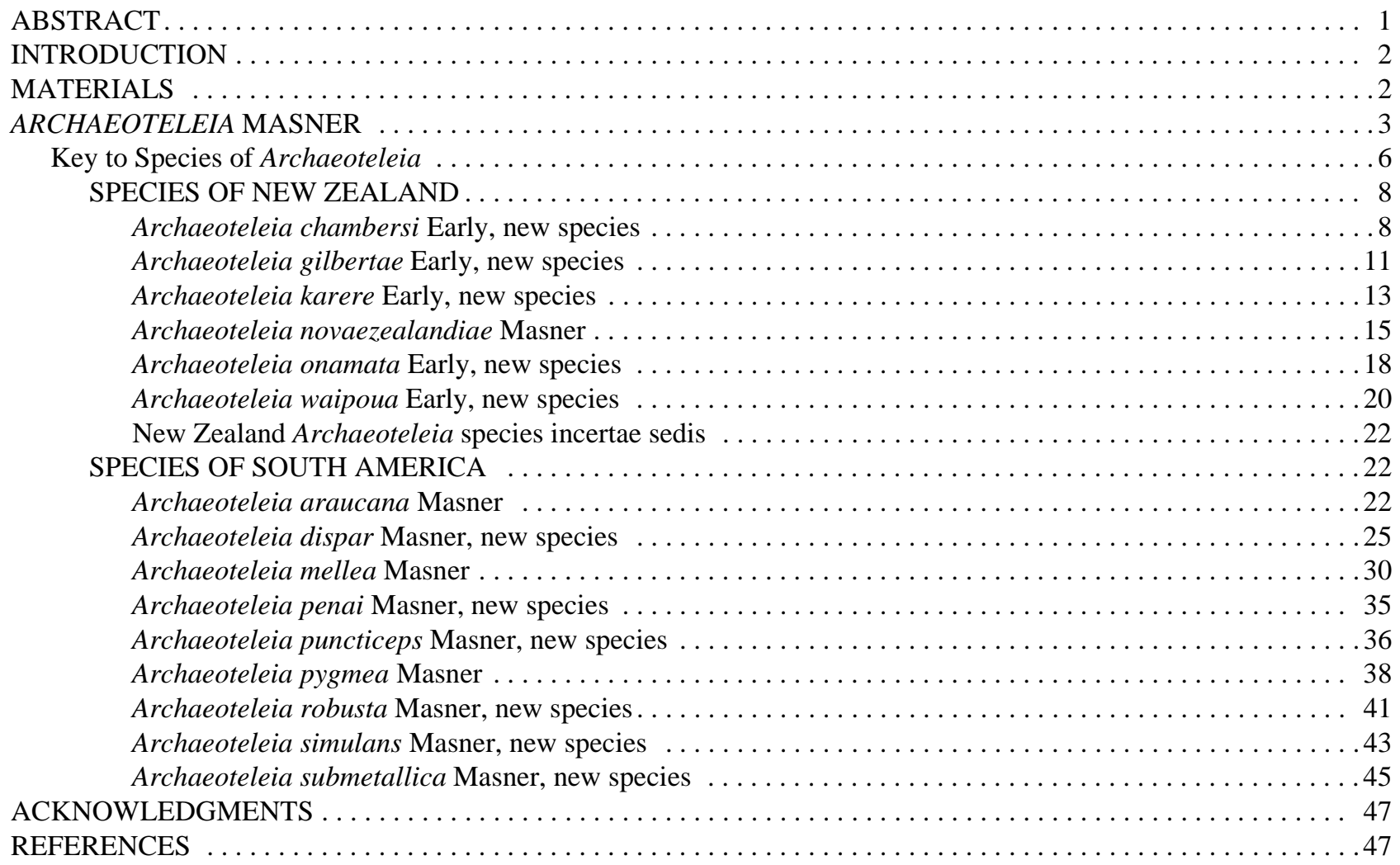

\begin{abstract}
The genus Archaeoteleia Masner is revised and redescribed. Five new species from New Zealand and six from Chile are described: A. chambersi Early, new species, A. gilbertae Early, new species, A. karere Early new species, A. onamata Early, new species, A. waipoua Early, new species, $A$. dispar Masner, new species, $A$. penai Masner, new species, $A$. puncticeps Masner, new species, $A$. robusta Masner, new species, $A$. simulans Masner, new species, and A. submetallica Masner, new species. The previously unknown females of A. mellea Masner and A. pygmea Masner are described from Chile. The genus is probably more closely related to Scelionini sensu lato than to the other putatively plesiomorphic genera Nixonia Masner (Nixoniini), Sparasion Latreille and Sceliomorpha Ashmead (Sparasionini s. str.), and Neuroscelio Dodd (Gryonini). Archaeoteleia chambersi, new species, and A. novaezealandiae Masner parasitize eggs of Gymnoplec-
\end{abstract}


tron spp. (Orthoptera: Rhaphidophoridae, Macropathinae). Both Archaeoteleia and Macropathinae have austral disjunct distributions and are considered to be Gondwanan relicts.

Key words: egg parasitoids, Rhaphidophoridae, Macropathinae, Chile

\section{INTRODUCTION}

The fossil record of the family Scelionidae (Hymenoptera: Platygastroidea) dates back to the mid Cretaceous (Nel \& Azar 2005; Johnson et al. in press). Very few of the genera, however, have disjunct distributions characteristically associated with continental drift. The genus Archaeoteleia Masner is one prominent exception, exhibiting a transantarctic distribution, being found only in New Zealand and the Valdivian forests of Chile.

In the years since Archaeoteleia was originally described by Masner (1968), numerous specimens have been collected, and the species richness of the genus is significantly greater than indicated in the published literature. The goals of this paper are to describe the new species that have been discovered, document new host records, and redescribe the known species.

\section{MATERIALS}

This work is based upon specimens in the following collections.

$\begin{array}{ll}\text { AEIC } & \text { American Entomological Institute, Gainesville, FL, D. Wahl } \\ \text { AMNZ } & \text { Auckland War Memorial Museum, New Zealand, J.W. Early } \\ \text { CNCI } & \text { Canadian National Collection of Insects, Ottawa, Canada, A. Bennett } \\ \text { LUNZ } & \text { Entomological Museum, Lincoln University, Canterbury, New Zealand, J.W.M. Marris } \\ \text { NZAC } & \text { New Zealand Arthropod Collection, Auckland, New Zealand, T.K. Crosby } \\ \text { OSUC } & \text { C.A. Triplehorn Insect Collection, Columbus, OH, N.F. Johnson } \\ \text { USNM } & \text { National Museum of Natural History, Washington, DC, T. Nuhn } \\ \text { UCDC } & \text { Bohart Museum of Entomology, University of California, Davis, CA, S. Heydon }\end{array}$

Morphological terminology follows Masner (1980) and Mikó et al. (2007). Abbreviations and terms used in text: A1, A2, ... A12: antennomere 1,2, .. 12; claval formula: distribution of the large, multiporous basiconic sensilla on the underside of apical antennomeres of the female, with the segment interval specified followed by the number of sensilla per segment (Bin 1981); epomial corners: the junction of the transverse pronotal carina, pronotal humeral carina, and vertical epomial carina (Fig. 19, ec); IOS: interocular space, shortest distance between the inner margins of the eyes; LOL: lateral ocellar line, shortest distance between inner margins of anterior and lateral ocelli (Masner \& Huggert 1989); OOL: ocular ocellar line, shortest distance from inner orbit and outer margin of lateral ocellus (Masner \& Huggert 1989); POL: posterior ocellar line, shortest distance between inner margins of lateral ocelli (Masner \& Huggert 1989); pronotal humeral carina: the horizontal portion of epomium on the pronotum (Fig. 18: phc); S1, S2, ... S6: metasomatic sternum 1, $2, \ldots 6 ; \mathrm{T} 1, \mathrm{~T} 2, \ldots \mathrm{T} 7$ : metasomatic tergum $1,2, \ldots 7$.

Figures were made using AutoMontage software. Under the Material Examined sections, passages that are placed between square brackets are comments or interpretations of label data. Two-letter area codes for New Zealand specimen localities follow Crosby et al. (1976).

Authorship of the new Chilean species is attributed to L. Masner, the New Zealand species to J.W. Early. The links labelled "Link to Distribution Map" are to dynamically produced maps of specimen data at The Ohio State University. The map will include specimen data added after publication of this revision. 


\section{ARCHAEOTELEIA MASNER}

Archaeoteleia Masner 1968: 652. Type: Archaeoteleia novaezealandiae Masner, by original designation. Original description, key to species, systematic position. Masner 1976: 5, 12 (description, keyed); Johnson 1992: 344 (cata$\log$ of world species); Austin \& Field 1997: 10, 68 (structure of ovipositor system, discussion of phylogenetic relationships, genus misplaced in Sparasionini).

Description: Medium to large, length $2.2-6.4 \mathrm{~mm}$, usually slender; legs, wings, antennae often rather elongate, flightless females more robust, with shorter appendages; usually rather pale-colored, yellow to brown, sometimes brown to very dark brown (some with pale regions actually light green when alive), female antenna sometimes with A4 or A4+A5 gradually or distinctly lighter in color than adjacent antennomeres; body sculpture varying from smooth to densely punctate or rugulose, shining to matte; usually macropterous, but with females in some species brachypterous, micropterous or apterous; external sexual dimorphism apparent in structure of antenna, T1, apex of metasoma.

Head slightly transverse when viewed dorsally; vertex rounded, hyperoccipital carina absent; occipital carina present, complete medially; lateral ocellus distinctly separated from inner orbit by distance of at least 1-1.5 ocellar diameters, OOL greater than or equal to LOL; eye moderate to large in size, glabrous or with short setae; frons convex, without frontal depression, median longitudinal carina present; head with large raised interantennal process between toruli; torulus opening laterally on interantennal process; submedian carina absent; orbital carina present, arising at anterior mandibular articulation, continuing dorsally to lateral ocellus; lower frons with dense fanlike striae; interocular space variable in width, from subequal to distinctly less than height of eye; inner orbits very weakly divergent ventrally, subparallel; clypeus roughly triangular to subpentagonal in outline, high, usually with prominent angulate lateral corners, convex, postclypeus and anteclypeus not differentiated, apical margin usually straight; malar sulcus present, continuous with posterior orbit of eye, often obscured among fanlike facial striae; gena moderately widened, convex; labrum not exposed; mandible strong, deeply bidentate, teeth transversely oriented, subequal in size; maxillary palpus 5-segmented, penultimate segment cylindrical; labial palpus 3-segmented; antenna 12-merous in both sexes; radicle differentiated from base of A1, inserted apically into A1 at a distinct angle to longitudinal axis of A1; basal portion of A1 distinctly curved medially; apex of female antenna with gradually widened, cylindrical clava composed of conical A12, subquadrate A6-A11, apically expanded A5; gustatory sensilla on female antenna arranged in longitudinal pairs on apical antennomeres; claval formula A5-A12/1-2-2-2-2-2-2-1 or A6-A12/ (1,2)-2-2-2-2-2-1; A3 always longest flagellomere, usually longer than A1, always longer than length of A2; male antenna with tyloid position variable, either on A4, A5, A4+A5, A4+A5+A6, tyloid arising at base of segments; male flagellomeres usually extremely elongate, with short pubescence.

Mesosoma in dorsal view longer than wide, in lateral view usually high, usually convex dorsally; pronotum in dorsal view with pronotal humeral carina and well-developed lateral shoulders, epomial corners distinct, often sharply defined forming strong angle or upward projection; vertical epomial carina usually absent or very weak; lateral face of pronotum weakly concave, forming shallow scrobe for reception of fore leg; netrion usually clearly delimited anteriorly by arc of deep foveae, very broad, as wide as tegula, open ventrally; anterior margin of mesoscutum meeting pronotum anteriorly, mesoscutum with arched anterior margin, narrowed behind tegulae; admedian lines sometimes well-developed; parapsidal line almost always present; notaulus variably developed, complete, abbreviated, or entirely absent; skaphion absent; transscutal articulation flanked posteriorly by well developed line of long crenulae; scutellum transverse, often constricted or impressed along midline, posterolateral corners usually protruding in form of sharp spine or hook, sometimes unarmed; axilla large, subtriangular, posterior margin foveolate, without raised flange; metanotum fairly broad, unarmed, dorsellum bounded by distinct line of foveae dorsally and ventrally; dorsal surface of propodeum with moderate pilosity, usually excavate medially in female to house horn on T1, excavate in male of one species, sometimes with weak submedian longitudinal keels, these sometimes expanded into small, weak 
tooth; mesopleuron large, prominent; mesopleural depression well-developed; mesopleural carina moderately developed to absent, lower end of carina extending to posterior margin of mesopleuron; sternaulus absent; mesopleural pit present; anterior margin of ventral portion of mesepisternum straight, not protruding between fore coxae; mesepisternum and mesepimeron separated by line of well-developed foveae; episternal foveae absent; dorsal corner of mesepimeron not produced into tooth or hook; anteroventral portion of metapleuron rounded, not separated from lateral face by carina; metapleural pit absent; posterior margin of metapleuron not produced; posterolateral corners of propodeum not projecting posteriorly; legs usually long, slender; hind leg, particularly coxa, elongate, length of hind coxa twice length of midcoxa, posterior surface not striate; femora usually not incrassate; trochantellus present on all legs; outer surface of tibia without spines; tibial spur formula 1-2-2, outer spur shorter than inner on mid, hind leg; hind tibia without longitudinal keels; tarsal formula 5-5-5; tarsomeres tapering in width apically; hind tarsus usually cylindrical, not laterally compressed; pretarsal claws simple; apex of fore wing usually reaching or surpassing apex of metasoma, largely clear, in some species with cloud of pigmentation basally between $\mathrm{R}_{1}$ (marginal vein) and $\mathrm{r}$-rs (stigmal vein), marginal cilia short; R (submarginal vein) straight, broadly separated from costal margin, extending through basal half of length of fore wing, subapically with distinct bulla, forked apically beyond bulla, usually with moderate setae, rarely with large stiff dark bristles; $\mathrm{R}_{1}$ extending to costal margin forming marginal vein, in some species continuing apically along costal margin to form postmarginal vein; postmarginal vein variable from short to several times longer than stigmal vein; membrane of wing deeply pigmented between bulla and point where $\mathrm{R}_{1}$ reaches costal margin, forming pseudostigma, pseudostigma relatively short and wide in Chilean species, long and narrow in New Zealand species; r-rs longer than $R_{1}$, slightly downturned apically, angle between $R_{1}$, r-rs nearly perpendicular in species from New Zealand, usually acute in species from Chile; no other tracheate veins in fore wing; apical portion of fore wing with pigmented lines in position of $\mathrm{Rs}, \mathrm{M}, \mathrm{Cu}$; hind wing with $\mathrm{R}$ tracheate only in its basal half, never reaching hamuli and costal margin; $\mathrm{R}$ without bristles; 3-4 hamuli present; cilia on posterior margin of hind wing subequal in length with marginal cilia of fore wing.

Metasoma usually elongate, weakly depressed, sutures between segments usually constricted to form undulating profile; submarginal ridge well-developed, laterotergites and laterosternites narrow, very weakly sclerotized, hyaline; female with 6 terga and sterna visible externally, segments 1-4 subequal in length; male with 8 terga and 7 sterna visible externally, segments $1-5$ subequal in length, segments $6-8$ gradually shortening distally, apical segments minute; female T1 with distinct horn; S1 with weak median longitudinal keel, not laterally compressed, not extending anteriorly between hind coxae; anterior margin of S2 straight; sterna without felt fields; female with base of segment 6 much narrower than apex of segment 5; female T6 with apical margin convex, without median raised field of microsetae or secretion; apical tergite of male with distinct, short, cylindrical cerci, slightly longer than wide; female with $\mathrm{T} 7+\mathrm{T} 8$ broadly separated from $\mathrm{T} 6$ by membranous telescopic tube (i.e., Scelio-type ovipositor), tube with two segments, basal segment strongly pigmented.

Diagnosis: Archaeoteleia is distinguished from most other scelionids by the 1-2-2 tibial spur formula. It shares this plesiomorphic character state with the genera Sparasion Latreille, Sceliomorpha Ashmead, Nixonia Masner, and Neuroscelio Dodd. The distinguishing characters are summarized in the following key.

1 Malar sulcus present; head with strong fanlike facial striae reaching orbits of eyes; laterotergites and laterosternites hyaline; female with ovipositor horn on $\mathrm{T} 1$ Archaeoteleia

- Malar sulcus absent; head without fanlike facial striae; laterotergites and laterosternites well sclerotized; female $\mathrm{T} 1$ without ovipositor horn

2 Antenna 14-segmented; paired gustatory sensilla of female antennal clava arranged side by side . Nixonia

- Antenna 12-segmented; paired gustatory sensilla of female antennal clava arranged longitudinally...........

3 Pronotum without sharp dorsal transverse carina; body short, squat ...................................... Neuroscelio

- Pronotum with sharp transverse carina extending from epomial carina on one side of the body to the other;

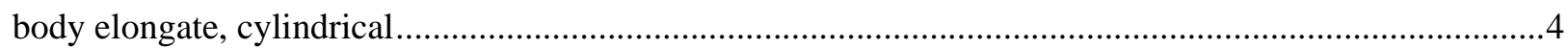


4 Radicle not differentiated from remainder of scape; base of scape U-shaped, inserting on the underside of the interantennal prominence. Sceliomorpha

- Radicle clearly differentiated by a transverse line and distinctly narrower diameter, inserted into base of scape at a distinct angle to the longitudinal axis of the scape; antenna arising frontolaterally from interantennal prominence

Sparasion

Geographic Distribution: New Zealand and the Valdivian part of Chile.

Link to Distribution Map. [http://atbi.biosci.ohio-state.edu:210/hymenoptera/eol_scelionidae.content _page?page_level=3\&page_id=taxon_page_data\&page_version=453\&page_option $1=\mathrm{M}$ ]

Biology: Two New Zealand species parasitize the eggs of Gymnoplectron spp. (Orthoptera: Rhaphidophoridae, Macropathinae).

Relationships: Ever since its original description (Masner 1968), Archaeoteleia has been considered to be a plesiomorphic group within the Scelionidae. Species possess a number of plesiomorphic character states, including paired tibial spurs on the mid and hind tibiae; maxillary palpus with 5 segments and labial palpus with 3 segments; the radial vein in the fore wing has a distinct break, or bulla, near its apex; and the antennal radicle is attached to the remainder of the scape at a sharp angle. In the first modern attempt to group scelionine genera into tribes, Kozlov (1970) failed to mention Archaeoteleia. Largely on the basis of the plesiomorphic characters, Masner (1976) placed Archaeoteleia in the tribe Sparasionini together with Sparasion, Sceliomorpha, and the fossil genus Electroteleia Brues (from Baltic amber). Kozlov and Kononova (1990) considered the monotypic tribe Nixoniini to be the most plesiomorphic extant group in the family, but in their cladogram they postulated a sister-group relationship between Nixoniini and Sparasionini. This hypothesis was based upon the proposition that in both tribes T6 and T7 are fused in the female metasoma, whereas in the male T7 and T8 are fused. In fact, this character state is not shared among all Sparasionini.

Austin \& Field (1997) extensively surveyed the structure of the ovipositor system and apical metasomatic segments in Scelionidae and Platygastridae. They reported, surprisingly, that the putatively plesiomorphic genus Archaeoteleia possesses the complex apomorphic Scelio-type ovipositor. In this system, the ovipositor is extruded from the apex of the metasoma by internal hydrostatic pressure, the sclerotized portions of the ovipositor (gonocoxae, gonapophyses, and gonoplacs) are borne at the apex of a membranous telescopic tube, and the composite sclerite T7+T8 is broadly separated from T6 and extruded from the end of the metasoma when the ovipositor is in use. Austin \& Field considered the shared possession of the complex of characters that constitute the Scelio-type ovipositor to represent strong evidence for a novel monophyletic group within Scelionidae which they called the Scelionini sensu lato. They then suggested, because it retains a number of plesiomorphic characters, that Archaeoteleia should probably be placed in a tribe separate from other Scelionini.

From this new perspective, a number of characters also support the removal of Archaeoteleia from the rest of the Sparasionini. Archaeoteleia has a strong set of fanlike carinae that arise from the anterior mandibular articulation; a fine, but well-developed malar sulcus; the labrum is small and hidden beneath the clypeus; and, in all species but one, the lateral corners of the clypeus are strongly expanded. These characters are shared with many of the so-called more "apomorphic" genera of scelionids, but are lacking in Sceliomorpha, Sparasion, Nixonia, Neuroscelio, and almost all members of the family Platygastridae.

In dried specimens of Archaeoteleia the terga are wider than the sterna and the specimens appear to have the classical scelionid submarginal ridge. Typically this is composed of narrow laterotergites that flex beneath the central tergum and articulate with an impressed submarginal groove on the corresponding sternum. In most Scelioninae, all Teleasinae, and many Platygastridae there is also a narrow, differentiated, and articulated laterosternite on each segment. In the past it has been supposed that this complex lateral articulation of the metasomatic segments may be associated with the production of hydrostatic pressure for extrusion of the ovi- 
positor (e.g., Austin et al. 2005). However, although we believe that they are present, the laterotergites and laterosternites in Archaeoteleia are extremely lightly sclerotized and nearly unpigmented. Their presence is only indicated by a different surface texture, most clearly seen in specimens that have the metasoma bloated and have been critical-point dried, and in scanning electron micrographs, by a fold along the lateral margin of each segment. This suggests that extrusion of the tubular Scelio-type ovipositor is not dependent upon the presence of a laterotergite/laterosternite locking system in the metasoma.

Murphy et al. (2007) recently examined the relationships among genera within Platygastroidea on the basis of three genes (18S, 28S, COI). They reported that Archaeoteleia groups together with Neuroscelio Dodd and, in some analyses, with Sparasion, together forming the sister group of all other Platygastroidea. These results suggested, again, that the Scelionidae is paraphyletic (as in Austin \& Field 1997), but also that the tubular ovipositor observed in Archaeoteleia was independently derived from the remainder of the Scelionini sensu lato. If these results are corroborated, then this will further strengthen the proposal that Archaeoteleia should be classified separately from other Scelionini.

\section{Key to species of Archaeoteleia}

The New Zealand and South American species form two distinct groups. Those from New Zealand have the scutellar spines small, weak, or absent (e.g., Fig. 23); the pseudostigma is elongate and narrow, not triangular (e.g., Figs. 1, 8, 20, 25); and the stigmal vein forms an angle of greater than $45^{\circ}$ with the postmarginal vein. All known species are macropterous. In contrast, the Chilean species have well-developed scutellar spines that are very prominent in brachypterous forms (Figs. 36, 58, 72); the pseudostigma is short, broad and triangular (Figs. 31, 39, 61); and the stigmal vein forms an angle of less than $45^{\circ}$ with the postmarginal vein. The species of these two groups are keyed out separately.

NEW ZEALAND SPECIES (females of A. waipoua n.sp. unknown)

1 Posterior corners of scutellum with short pointed tubercle or spine (Figs. 4, 11, 19, 27; fore wing with distinct pigmented area under marginal vein between bulla and stigmal vein (Figs. 8, 16, 25) .............2

- $\quad$ Posterior corners of scutellum rounded, without any trace of tubercle or spine (Figs. 15, 23); pigmented area under marginal vein between bulla and stigmal vein very faint or absent

2 Scutellum barely bilobate (Fig. 27); metasomatic tergites coarsely rugose (Fig. 29); mid and hind basitarsi strongly compressed laterally (Fig. 24); clypeus narrow, rounded, without sharply angulate anterolateral corners (Fig. 28); female unknown A. waipoua n.sp.

- Scutellum bilobate (Figs. 4, 11, 19); metasomatic tergites with fine longitudinal coriarious sculpture (Figs. 2); all basitarsi normal, cylindrical (Figs. 1, 8, 16); clypeus with sharply angulate anterolateral corners (Figs. 5, 9, 17)

3 Female T1 horn smooth, shining (Fig. 19); transverse pronotal carina straight, with prominent, angulate epomial corners (Fig. 19); notauli ending anteriorly behind epomial corners; pronotal shoulders narrow, maximum width about 0.5 times width of tegula; scutellum usually concolorous with mesoscutum, never clearly paler ......

A. novaezealandiae Masner

- $\quad$ Female T1 horn sculptured, finely coriarious (Figs. 4, 11); transverse pronotal carina curved around anterior margin of mesoscutum, epomial corners distinct but not prominent; notauli (or, when incomplete, their projected trajectory) ending at or between epomial corners (Figs. 4, 11); pronotal shoulders broad, at least 0.75 times width of tegula; scutellum usually distinctly paler than mesoscutum (Figs. 8, 11) 
than wide. Male: body length 3.1-3.7 mm; antenna with A5 carinate......

A. gilbertae n.sp.

- $\quad$ Female: body length 5.0-5.6 mm; metasoma 4.2-4.6 times longer than wide; T6 3.0-3.5 times longer than wide. Male: body length 4.4-4.7 mm; antenna with A5 or A4+A5 or A4-A6 carinate (Figs. 6, 7)...

A. chambersi n.sp.

Notauli complete (Fig. 23); mesopleuron below mesopleural depression covered with dense, whitish, appressed pilosity (Fig. 22); female T1 horn sculptured; body length 4.8-6.4 mm A. onamata $\mathrm{n} . \mathrm{sp}$.

- Notauli abbreviated anteriorly (Fig. 15); mesopleuron below mesopleural depression almost bare (Fig. 14); female T1 horn smooth, shining; body length $2.5-3.7 \mathrm{~mm}$

A. karere n.sp.

\section{SOUTH AMERICAN SPECIES}

Females

1 Micropterous or apterous: fore wings at most a minute scale not extending beyond metanotum (Figs.

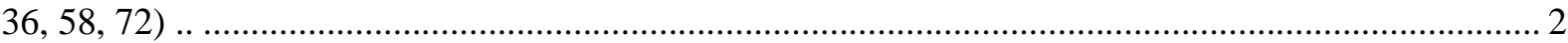

- $\quad$ Macropterous: fore wings extending at least to apex of metasoma (Figs. 30, 42, 46, 50, 54, 64, 68) ... 4

2 T6 about as long as wide, length 0.8-1.1 times maximum width (Fig. 59); T1 horn in lateral view short, almost vertical, not reaching level of mesoscutum, remote from scutellar spines (Fig. 58)

\section{A. pygmea Masner}

T6 at least twice as long as wide (Figs. 37, 72); T1 horn slanting forward, reaching above level of mesoscutum, projecting between base of scutellar spines (Figs. 36, 74)

3 T2-T5 with paired longitudinal depressions (Fig. 37); A1 slightly longer than A3; notauli complete; epomial corners not projecting upward A. dispar n.sp. T2-T5 without paired longitudinal depression; A1 at least 2 times as long as A3; notauli absent; epomial corners projecting upwards, appearing like small spines in lateral view (Fig. 74).

A. submetallica n.sp.

Length of A1 about 2 times length of A3; mesoscutum almost flat in lateral view (Fig. 66); T1 horn entirely sculptured, with median longitudinal carina on posterior face (Fig. 67); submarginal vein with very prominent, upright, strong black bristles; femora distinctly incrassate A. robusta $\mathrm{n} . \mathrm{sp}$. A1 shorter than A3; mesoscutum convex in lateral view; T1 horn smooth, not carinate; submarginal vein with fine pale setae; femora not incrassate

Mesoscutum entirely evenly sculptured, punctate or finely coriaceous, without smooth areas (Figs. 49, $53,57)$.

- $\quad$ Mesoscutum with some smooth areas (Figs. 33, 45, 71)

T6 short, about as long as wide; posterior margin of T5 straight; T1 horn small, weakly developed (Figs. 50, 53); mesopleuron entirely sculptured (Fig. 52) A. penai n.sp. T6 elongate, about 3 times as long as wide; posterior margin of T5 concave (Figs. 46, 54); T1 horn well developed, reaching level of mesoscutum (Figs. 48, 54); upper part of mesopleuron smooth (Figs. 48, 56)

Upper frons, vertex, occiput entirely punctate, sculpture similar to that of mesoscutum (Figs. 55, 57); A6, A7 paler than remaining segments of clava (Fig. 54) A. puncticeps n.sp. Upper frons with longitudinal sculpture, becoming weaker towards ocelli (Fig. 47); most of vertex and occiput usually with transverse wrinkles, differing from sculpture of mesoscutum (Fig. 49); clava uniformly dark (Fig. 46)

A. mellea Masner T1 with low hump, completely longitudinally costate (Figs. 68, 70, 71); length of A3 2.7 times length of A4 T1 with horn completely smooth in upper part (Figs. 35, 44, 45); length of A3 1.5 times length of A4 9 Body entirely black to very dark brown (Figs. 30-35); posterior two-thirds of median lobe of mesoscu- 
- Body brownish or yellowish (Figs. 42-45); entire median lobe of mesoscutum, scutellum with setigerous punctures (Fig. 45)

Males (males of A. penai n.sp., A. submetallica n.sp. unknown)

1 Postmarginal vein with well-developed tubular section that is longer than stigmal vein 2

- Postmarginal vein at most with rudimentary, short tubular section that is shorter than stigmal vein, often obscured by thick, pigmented pseudostigma

2 Notauli present (Fig. 39); A4, A5 carinate basally; netrion well defined, indicated by row of foveolae ....3

- Notauli absent (Fig. 61); only A4 with small basal carina; netrion not well defined ..... A. pygmea Masner

3 A1 longer than A3; A6-A9 straight, cylindrical; anterior margin of T1 sharply pointed, fitting into wedgeshaped excavation of propodeum

A. robusta n.sp.

- A1 shorter than A3; A6-A9 arcuate; anterior margin of T1 normal, propodeum without excavation

4 Mesoscutum entirely evenly sculptured, punctate or coriaceous, without smooth areas ..........................5

A. dispar n.sp.

- Mesoscutum with some smooth, polished areas ........................................................................... 6

5 A4, A5 carinate; upper frons, vertex, occiput entirely punctate, similar to sculpture of mesoscutum

A. puncticeps n.sp.

- A4 carinate, A5 rarely with rudimentary carina; upper frons with longitudinal sculpture, this becoming weaker towards ocelli; most of vertex, occiput smooth and shining, differing from sculpture of mesoscutum A. mellea Masner

6 Only A4 with keel; body predominantly light-colored, yellowish brown A. gracilis Masner

- Both A4 and A5 with keels; body distinctly darker, dark brown to black...... 7

7 Posterior two-thirds of mesoscutum glabrous A. araucana Masner

- Entire mesoscutum with setigerous punctures. A. simulans n.sp.

\section{SPECIES OF NEW ZEALAND}

\section{Archaeoteleia chambersi Early, new species}

Figures 1-6

Archaeoteleia novaezealandiae (!), Chambers 1982:44. Misidentification.

Description: Female. Length 5.0-5.6 mm. Color: shiny dark brown in fresh specimens, without greenishbrown areas; scutellum yellow-brown, usually paler than mesoscutum, rarely dark brown, concolorous with mesoscutum.

Head (Figs. 3-5): frons lacking swelling by inner orbits, head not or only weakly browed in dorsal view; occipital carina entire but weaker and more crenulate medially than genal carina; A1 3.9-4.9 times longer than wide; A2 2.2-2.9 times longer than wide; A3 3.8-4.2 times longer than A2; flagellum with setae dense, appressed, flagellomeres without bristled appearance.

Mesosoma (Figs. 3-4): transverse pronotal carina curved around anterior margin of mesoscutum, epomial corners distinct but not strongly raised, width between epomial corners 0.8 times width of mesoscutum; pronotal humeral carina well separated from mesoscutum, shoulders broad, at widest point about 0.8 times width of tegula; vertical epomial carina very weak or absent; lateral pronotum finely coriarious; netrion smooth or minutely aciculate; admedian lines subparallel to slightly divergent posteriorly, 1.4-1.6 times longer than separation of posterior ends; notaulus complete or incomplete, if complete would attain scutal margin at or between epomial corners; scutellum bilobate, scutellar spines distinct; dorsellum finely reticu- 
late-coriarious; mesopleural carina incomplete, indistinct posteriorly; mesopleural depression with fine longitudinal rugulae; mesepisternum below carina with moderately dense setigerous punctures; upper half of metapleuron with small glabrous area anteriorly; medial excavation of propodeum with reticulate rugulose sculpture, medial carinae raised anteriorly to form a vertical toothlike structure bearing long erect setae; fore wing with distinct pigmented area under marginal vein between bulla and stigmal vein; postmarginal vein 3.5-4.3 times longer than marginal vein.

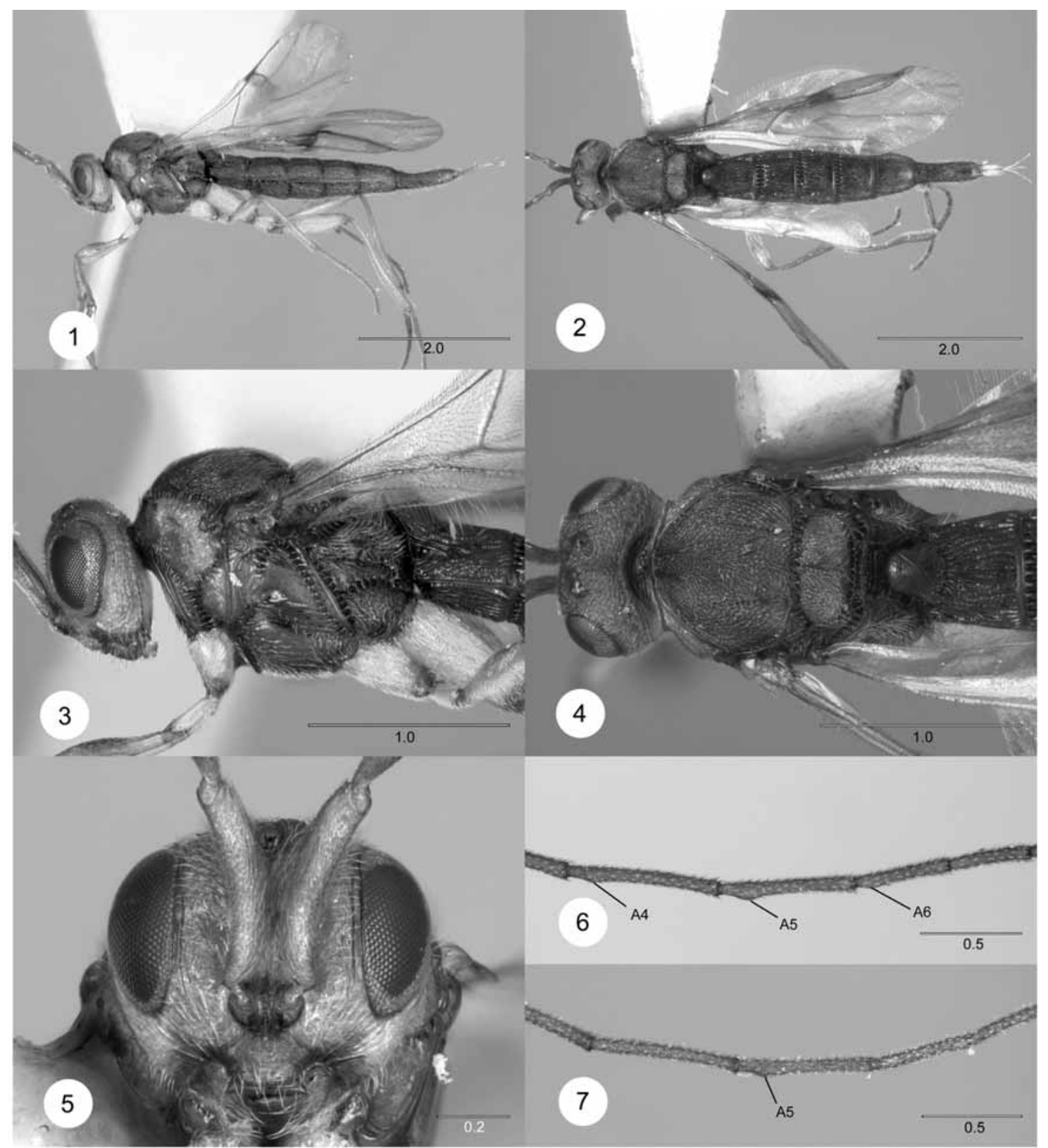

FIGURES 1-7. Archaeoteleia chambersi, n.sp. 1, Lateral habitus, female (OSUC 163300); 2, dorsal habitus, female (OSUC 163300); 3, head and mesosoma, lateral view (OSUC 163300); 4, head and mesosoma, dorsal view (OSUC 163300); 5, head, frontal view (OSUC 163300); 6, male antenna, indicating keels on A4-A6 (OSUC 163299); 7, male antenna, indicating sole keel on A5 (OSUC 163298). Scale bars in millimeters.

Metasoma (Figs. 1, 2, 4) 4.2-4.6 times longer than wide; T1 slightly wider than long, T2-T5 distinctly so, T6 3.0-3.5 times longer than wide; T1-T5 with broad longitudinal furrow laterally (Fig. 2), sometimes weaker in posterior tergites; costae of T1 strong but not more strongly impressed around base of horn; horn coriarious except for smooth and shining tip (Fig. 4); T6 entirely coriarious-punctate, with some longitudinal 
carinulae; anterior lens-shaped area of S2 often strongly angular and tooth-like in profile (Fig. 1).

Male. Differs from female as follows: Length: 4.4-4.7 mm; A1 3.5-3.9 times longer than wide; A2 1.42.3 times longer than wide; A3 4.3-5.7 times longer than A2; sex segments variable, either A4-A6, A4+A5 or only A5 with small basal carinae, carina usually largest on A5.

Dorsellum strongly foveolate anteriorly, posterior half finely punctate; propodeum with dorsal surface entirely areolate-rugose, medial excavation weak.

Metasoma 3.6-3.8 times longer than wide; $\mathrm{T} 1$ with anterior margin raised medially, toothlike in profile; T1-T5 without broad longitudinal dorsolateral furrows; anterior lens-shaped area of S2 prominent and more or less angular in profile, but not as strong as in female.

Diagnosis: Recognized by the following combination of characters: female body length 5.0-5.6 mm, male 4.4-4.7 mm; clypeus with sharply angulate anterolateral corners; epomial corners not strongly angulate; transverse pronotal carina curved weakly around anterior margin of mesoscutum; scutellum bilobate, posterior corners with spine, usually paler than mesoscutum; fore wing with pigmentation under marginal vein; female metasoma 4.2-4.6 times longer than wide, T6 3.0-3.5 times longer than wide; male antenna with sex segments A4 -6 or A4+5 or A5 only.

Distribution: Found widely in the North Island of New Zealand (ND, AK, CL, BP, TK, TO, WN) and sympatric with A. karere n.sp. at some localities.

Link to Distribution Map. [http://atbi.biosci.ohio-state.edu:210/hymenoptera/eol_scelionidae.content _page?page_level=3\&page_id=taxon_page_data\&page_version=190980\&page_option1=M]

Biology: Several specimens were reared from eggs of Rhaphidophoridae from old gold mining tunnels on the Coromandel Peninsula. The only weta in tunnels at Tokatea Track was Gymnoplectron uncata (Richards 1959) where it is presumed to be the host. Gymnoplectron fusca (Richards 1959) also inhabits tunnels in the Coromandel area and its eggs are probably parasitized as well.

Etymology: The species is named in honor of Mr. F.D. Chambers who collected the first specimens and noted differences between them and A. novaezealandiae (Chambers 1982).

Material Examined: Holotype female. NEW ZEALAND: TK, Mt Egmont, Dawson Falls, 19.III.1985, F. Chambers (AMNZ 64307). Deposited in AMNZ.

Paratypes (25 males, 15 females): NEW ZEALAND: TK, Mt Egmont, Dawson Falls, F. Chambers, 8.II.1981, 24.II.1983, 24.II.1984, 18.I.1985, 3 males, 2 females, AMNZ 64308-64310, OSUC 163737 (AMNZ, CNCI); ND, Waipoua Forest, Yakas Tr, J.B. Johnson, 17.X.2000, male, AMNZ 64311 (AMNZ); AK, Waitakere Ra, Nihotupu Pipeline, 200 m, 3-11.IX.2005, 11-25.IX.2005, 16-23.XI.2005, 1-8.XII.2005, 22-29.XII.2005, 5-12.I.2006, 12-19.I.2006, 3-10.II.2006, yellow pan trap in forest, 13 males, 5 females, AMNZ 73863, 73864, 73866-73869, 73891-73894, 74157, 74158, 74174-74177, OSUC 179079, 179080 (AMNZ, LUNZ, OSUC); CL, Kennedy Bay Rd, Tokatea Track, 400 m, 20.III.1994, J.W. Early \& R.F. Gilbert, soil in mining tunnel, emerged Rhaphidophoridae egg, male, 2 females, AMNZ 64312, 64313, OSUC 163298 (AMNZ, CNCI); CL, Wentworth R., 40 m, 19.III.1994, J.W. Early \& R.F. Gilbert, soil in mining tunnel, emerged from Rhaphidophoridae eggs, 2 males, 3 females, AMNZ 64314-64317, OSUC 163300 (AMNZ, CNCI); CL, Kauaeranga, 29.XI.1970, H.A. Oliver, Malaise trap, female, OSUC 163640 (NZAC); CL, Aldermen Is, Ruamahuanui, 140 m, B.M. Fitzgerald, forest, beaten, male, AMNZ 55474 (AMNZ); BP, Mt Te Aroha, 360 m, 22.III.1994, J.W. Early, R.F. Gilbert, forest, swept, male, AMNZ 64320 (AMNZ); BP, Mt Te Aroha, 380 m, J.W. Early, R.F. Gilbert, yellow pan trap in forest, 2 males, female AMNZ 73870-73872 (AMNZ); BP, forest above Okauia Pa, W side Kaimai Ra., 29.IV.1982, K.A.J. Wise, male, AMNZ 64318 (AMNZ); BP, Rotorua, Forest Research Inst., Feb 1981, J. Bain, Malaise trap, female, OSUC 163639 (NZAC).

Other material: Because of the variability described below, the following specimens were not included in the type series. NEW ZEALAND: TO, Monganui Station, Moawhango-iti Stream, 800 m, 17.IV.1993, J.W. Early, Nothofagus forest, male, AMNZ 64319 (AMNZ); WI, Bruce Park, SH1, 260 m, 3-6.II.2000, J.W. 
Early, rimu/tawa forest, yellow pan trap, male, AMNZ 63421 (AMNZ); WN, Tararua Ra., Dundas Hut Ridge, 4.II.1985, B.A. Holloway, beating at night, male, OSUC 163642 (NZAC); WN, Otaki Forks, 18.II.1999, J.W. Early, podocarp-broadleaf forest, swept, male, AMNZ 64322 (AMNZ).

Remarks: Archaeoteleia chambersi is the most variable and widespread of the New Zealand species. Distribution of carinae on the sex segments of the male antennae has been used to separate species of scelionids. The presence of three forms with respect to this character (A4-A6, A4+A5, and A5 only) might indicate that three species are present. The notauli vary from complete to incomplete. At the type locality (Mt. Taranaki) there is a correlation in the limited material available - both sexes have incomplete notauli and the male sex segments are A4-A6. For other localities there is no correlation between these two characters. Most specimens examined have a scutellum that is distinctly paler than the mesoscutum, but in some (from the lower North Island) the scutellum and mesoscutum are uniformly dark brown.

In the absence of any consistent differences in other characters, all specimens are included here in $A$. chambersi. It may prove to be a complex of two or more closely related species once more material is available for study.

\section{Archaeoteleia gilbertae Early, new species}

Figures 8-11

Description: Female. Length 3.4-4.0 mm. Color: shiny dark brown in fresh specimens, without greenishbrown areas; cheeks, lateral pronotum, mesopleuron above mesopleural carina and coxae pale; scutellum yellow brown, usually paler than mesoscutum.

Head (Figs. 9-11): frons lacking swelling by inner orbits, head not or only weakly browed in dorsal view; occipital carina entire, slightly weaker and more crenulate medially than genal carina; A1 4.1-4.5 times longer than wide; A2 2.0-2.5 times longer than wide; A3 3.8-4.2 times longer than A2; flagellum with setae dense, appressed, flagellomeres without bristled appearance.

Mesosoma (Figs. 10-11): dorsal pronotum with transverse pronotal carina almost straight, only weakly curved around anterior margin of mesoscutum, epomial corners distinct but not strongly angulate or raised, width between epomial corners 0.8 times mesoscutum width; pronotal humeral carina well separated from mesoscutum, shoulders broad, at widest point $0.8-1.0$ times width of tegula; vertical epomial carina very weak or absent; lateral pronotum including netrion finely coriarious; admedian lines subparallel to slightly divergent posteriorly, 1.4-2.0 times longer than separation of posterior ends; notaulus incomplete, if complete would attain scutal margin at or between epomial corners; scutellum bilobate, scutellar spines distinct; dorsellum smooth, without sculpture; mesopleural carina indistinct, not differentiated from longitudinal rugulae of the mesopleural depression; mesepisternum below depression with moderately dense setigerous punctures; upper half of metapleuron with small glabrous area anteriorly; medial excavation of propodeum with reticulate rugulose sculpture, medial carinae raised anteriorly to form a vertical toothlike structure bearing long erect setae; fore wing with distinct pigmented area under marginal vein between bulla and stigmal vein; postmarginal vein 3.0-3.2 times longer than marginal vein.

Metasoma (Figs. 8, 11) 3.4-3.7 times longer than wide; T1 slightly wider than long; T2-5 distinctly longer than wide; T6 2.3-2.6 times longer than wide; T1-5 with broad longitudinal furrow laterally, sometimes weaker in posterior tergites; costae of T1 strong but not more strongly impressed around base of horn, horn coriarious, tip shining and sometimes with weaker sculpture; T6 entirely coriarious-punctate and with some longitudinal carinulae; anterior lens-shaped area of S2 rounded to bluntly square in profile, never strongly angular or toothlike. 


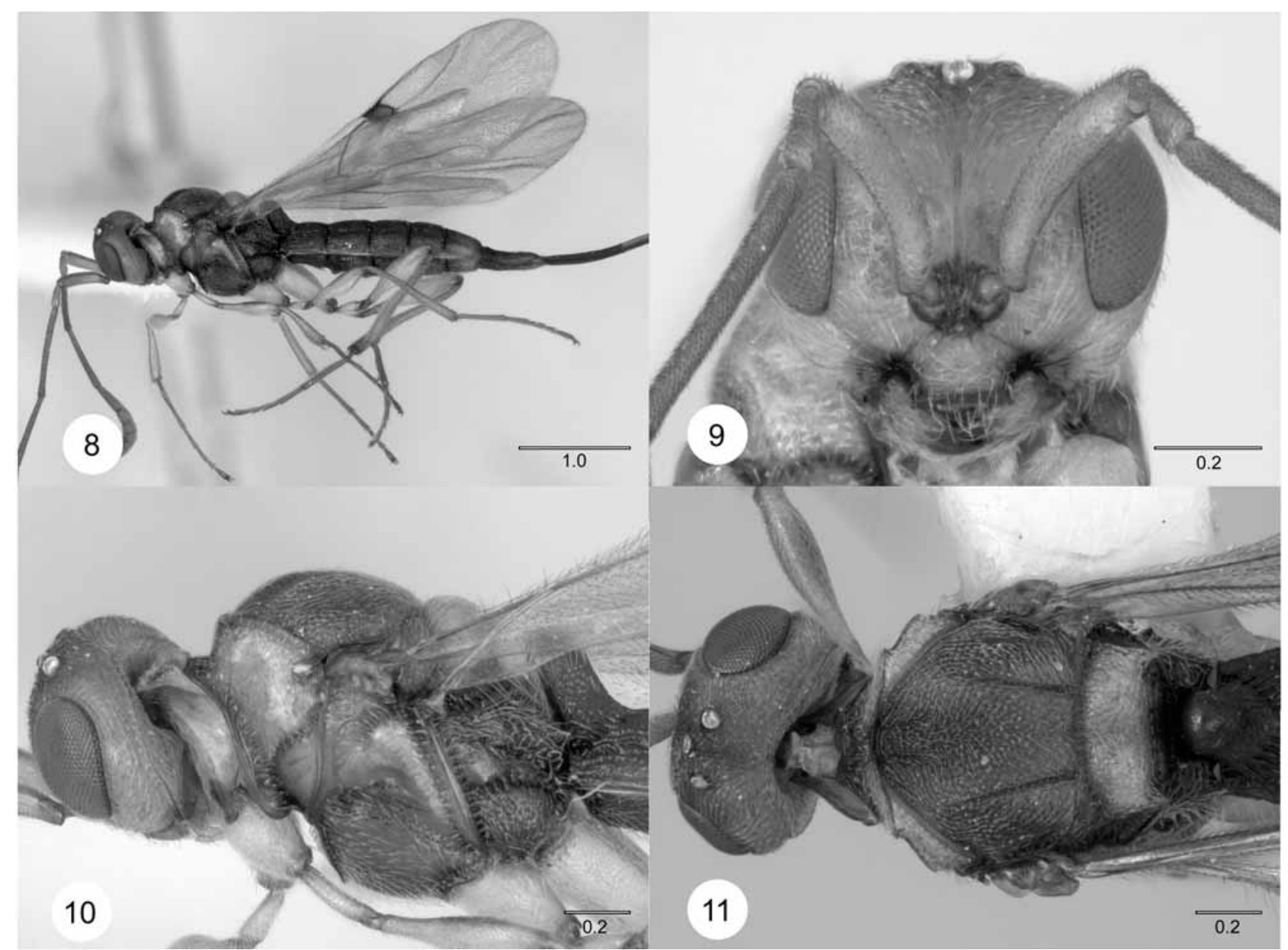

FIGURES 8-11. Archaeoteleia gilbertae, n.sp., paratype female (OSUC 179074). 8, Lateral habitus; 9, head, frontal view; 10, head and mesosoma, lateral view; 11, head and mesosoma, dorsal view. Scale bars in millimeters.

Male. Differs from female as follows: Length: 3.1-3.7 mm; A1 3.2-3.4 times longer than wide; A2 1.51.7 times longer than wide; A3 5.0-5.9 times longer than A2; sex segment A5 only with basal carina.

Dorsellum strongly foveolate anteriorly, posterior half finely punctate; propodeum with dorsal surface entirely areolate-rugose, medial excavation weak.

Metasoma 3.5-4.0 times longer than wide; T1 with anterior margin raised medially, toothlike in profile; T1-5 without broad longitudinal dorsolateral furrows. Anterior lens-shaped area of S2 rounded or weakly angular in profile.

Diagnosis. Recognized by the following combination of characters: female body length 3.4-4.0 mm, male 3.1-3.7 mm long; clypeus with sharply angulate anterolateral corners; epomial corners not strongly angulate; transverse pronotal carina curved weakly around anterior margin of mesoscutum; scutellum bilobate, posterior corners with spine, always paler than mesoscutum; fore wing with pigmentation under marginal vein; female metasoma 3.4-3.7 times longer than wide, T6 2.3-2.6 times longer than wide; male antenna with sex segment A5 only.

Etymology. This species is named for Rosemary Gilbert who assisted with the field collection of many of the specimens in this study.

Distribution. This species is found in the top of the New Zealand's South Island (NN, MB) where it may be sympatric with $A$. novaezealandiae and A. onamata $\mathrm{n} . \mathrm{sp}$.

Link to Distribution Map. [http://atbi.biosci.ohio-state.edu:210/hymenoptera/eol_scelionidae.content _page?page_level=3\&page_id=taxon_page_data\&page_version=214232\&page_option1=M] 
Material examined. Holotype female: NEW ZEALAND: NN, Roding R, 220 m, 21-26.III.2006, J.W. Early, R.F. Gilbert, Nothofagus forest, yellow pan trap, AMNZ 75111. Deposited in AMNZ.

Paratypes: NEW ZEALAND: 5 males, 5 females with same data as holotype AMNZ 75112-75121 (AMNZ); NN, Roding V., second ford, 27.VII.1967, J.S. Dugdale, sweeping, male, OSUC 163617 (NZAC); NN, Nelson, Dun Track, 20.III.1971, E.W. Valentine, swept from low growth under Weinmannia 2 males, OSUC 163615, 163616 (NZAC); NN, Canaan, Harwoods Hole Tk, 800 m, 8.IV.2003, J.W. Early, swept Nothofagus forest, 3 males AMNZ 55806-55808 (AMNZ); NN, Harwoods Hole, 800 m, 20-25.III.2006, Nothofagus forest, yellow pan trap, 8 males, female, AMNZ 75122-75130 (AMNZ); MB, Onamalutu Scenic Reserve, 100 m, 19-26.III.2006, J.W. Early, R.F. Gilbert, kahikatea forest remnant, yellow pan trap, male, AMNZ 75132 (AMNZ); MB, Pelorus Bridge, 80 m, 20-26.III.2006, J.W. Early, R.F. Gilbert, Nothofagus forest, yellow pan trap, 3 males, female, AMNZ 75133-75136 (AMNZ); MB, Wakamarina R., 80 m, 12.IV.2003, J.W. Early, Nothofagus forest, swept, male, AMNZ 53675 (AMNZ); MB, Wakamarina R., 100 m, J.W. Early, R.F. Gilbert, 18.III.2006, Nothofagus forest, swept, 11 males, 7 females, AMNZ 75137-75148, OSUC 179074, 179075 (AMNZ, CNCI, LUNZ, OSUC).

\section{Archaeoteleia karere Early, new species}

Figures 12-15

Description: Female. Length 3.0-3.7 mm. Color: upper frons, dorsal head and mesosoma, metapleuron and entire metasoma dark brown; lower frons, genae, lateral pronotum, mesopleuron and legs pale yellowish.

Head (Figs. 13-15): occipital carina weakly crenulate medially, without crenulae in genal region; striation of cheeks distinct but fine, strongest in malar region and up inner orbits; posterior gena smooth, with sparse setigerous punctures; A1 4.0-4.5 times longer than wide; A2 2.4-3.0 times longer than wide; A3 3.7-3.9 times longer than A2; flagellum with setae appressed, not conspicuously bristly in appearance.

Mesosoma (Figs. 14-15): dorsal pronotum with transverse pronotal carina bowed in front of anterior margin of mesoscutum, epomial corners sharp; pronotal humeral carina distinct, shoulders moderately broad, at widest point 0.64 times tegula width; vertical epomial carina absent; lateral pronotum glabrous medially; netrion smooth, with sparse fine setigerous punctures; admedian lines usually distinct, V-shaped, 2.8-3.0 times longer than their posterior separation; notaulus incomplete, well indicated and foveolate in basal 0.60.8 , becoming faint anteriorly and indicated by line of foveae, trajectory ending at or between epomial corners; parapsidal line weak; scutellum very weakly bilobate, a faint median longitudinal depression between the two lobes, posterior corners rounded, without spines; mesopleural carina absent or indicated anteriorly by faint aciculate line, becoming weaker posteriorly; mesepisternum below mesopleural depression with moderately dense fine setigerous punctulae; upper half of metapleuron with small glabrous triangular area; fore wings hyaline, cloud of pigmentation under marginal vein and stigmal vein usually absent, at most very faintly indicated; postmarginal vein 3.9-5.6 times longer than marginal vein, tubular through most of its length; basal vein strong, subtracheate.

Metasoma (Figs. 12, 15) 3.6-4.0 times longer than wide; T1 about as long as wide, ovipositor horn almost raised to level of mesoscutum; T2-T5 wider than long, T6 1.8-2.4 times longer than wide; T1 with complete longitudinal costae, strongest around base of horn, horn weakly coriarious laterally, posterior face highly polished from base to tip; T2-T5 coriarious, with strongly costate anterior margins, costae strongest and longest on T2, becoming progressively shorter and less well developed on posterior tergites; T2-T5 coriarious medially, sculpture strongest anteriorly, becoming weaker on posterior tergites; T6 finely coriarious, without longitudinal sculpture; S2 with anterior lens-shaped region almost flat, never conspicuously rounded or tooth-like in profile. 


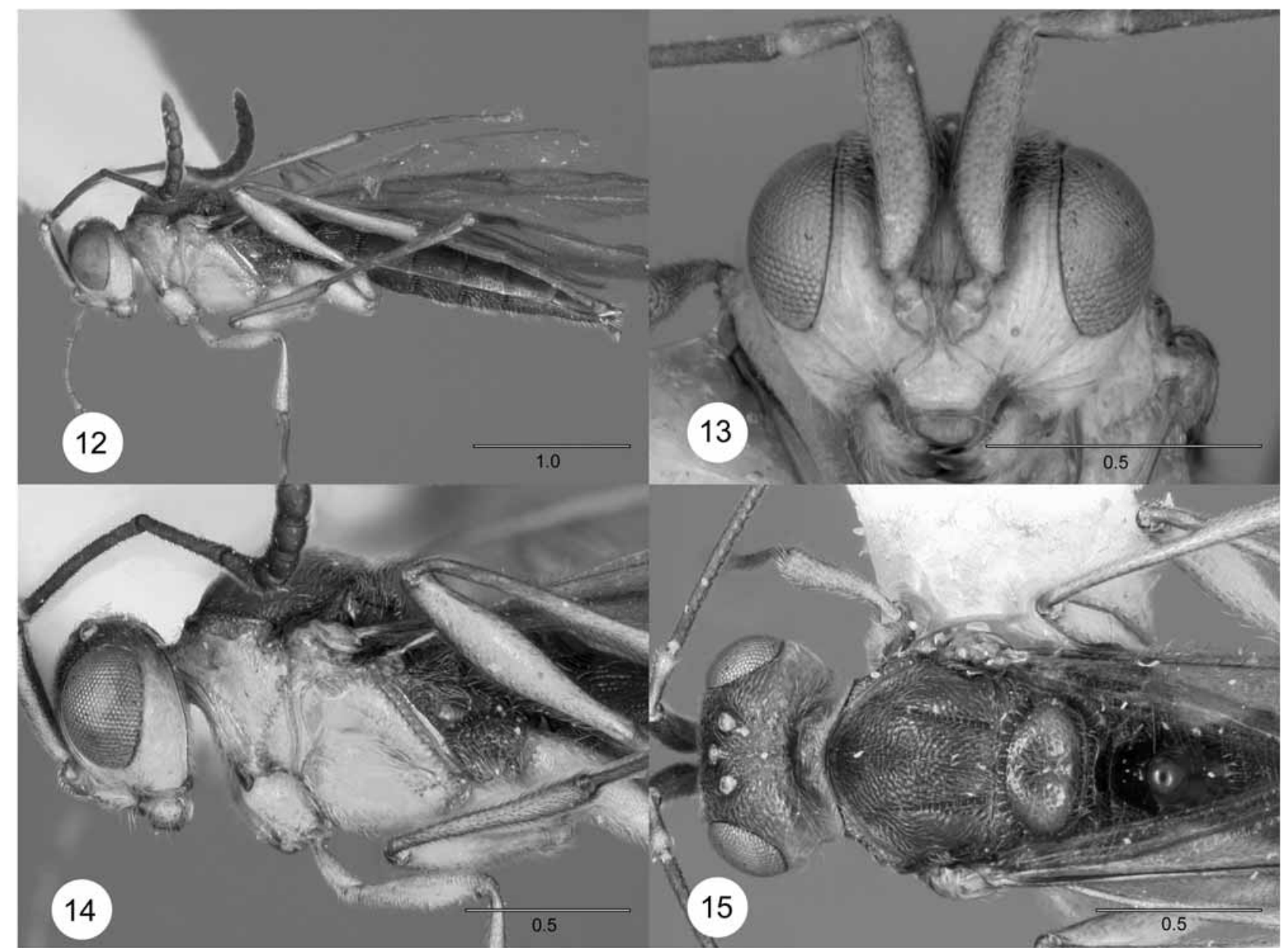

FIGURES 12-15. Archaeoteleia karere, n.sp., holotype female (AMNZ 64325). 12, Lateral habitus; 13, head, frontal view; 14, head and mesosoma, lateral view; 15, head and mesosoma, dorsal view. Scale bars in millimeters.

Male. Differs from female as follows: Length: 2.6-3.2 mm; A1 3.1-3.5 times longer than wide; A2 1.31.7 times longer than wide; A3 5.1-6.0 times longer than A2; A5 laterally expanded at apex of basal carina.

Notauli almost complete; scutellum even less distinctly bilobate; dorsellum clearly differentiated, smooth and shiny posteriorly; propodeum completely areolate-rugose, without medial excavation and carinae.

Metasoma 3.4-3.7 times longer than wide; anterior margin of $\mathrm{T} 1$ only slightly raised, anterior corners acute but not distinctly produced or spinelike.

Diagnosis: Recognized by the combination of the following characters: small size, female body length 3.2-3.7 mm, male 2.6-3.2 mm, scutellum without spines, no strong pigment cloud under marginal vein, notaulus not complete, female T6 about twice as long as wide, and male antenna with only A5 carinate, the basal carinal region being laterally expanded.

Distribution: Found only in parts of the North Island of New Zealand (AK, BP, WO, TK, TO) where it is sometimes sympatric with A. chambersi.

Link to Distribution Map. [http://atbi.biosci.ohio-state.edu:210/hymenoptera/eol_scelionidae.content _page?page_level=3\&page_id=taxon_page_data\&page_version=190982\&page_option1=M]

Biology: Hosts unknown but presumed to be eggs of a macropathine rhaphidophorid.

Etymology: In the Māori language karere means 'messenger'. Named for Mt. Messenger from which a number of specimens were taken.

Material Examined: Holotype female. NEW ZEALAND, TK, Mt Egmont, E side, 850 m, 16.XII.1983, J.W. Early, swept in kamahi forest, AMNZ 64325. Deposited in AMNZ. 
Paratypes (35 males, 13 females): NEW ZEALAND: 2 females with same data as holotype, OSUC 163656, 163657 (CNCI, LUNZ); AK, Titirangi, Atkinson Park, Zigzag Track, 40 m, 2-6.IX.2006, S.E. Thorpe, Damp gully, on plants above small stream, 4 males, female, AMNZ 75168 (AMNZ, NZAC); TK, Mt Egmont West, 29.I.1977, 24.XII.1981, F. Chambers, 3 males, AMNZ 64326-63428 (AMNZ); TK, Mt Egmont, Dawson Falls, 820 m, 3-11.XII.2005, J.W. Early, kamahi-podocarp forest, yellow pan trap, female, AMNZ 71468 (AMNZ); TK, Mt Egmont North, 950 m, 20.III.2005, J.W. Early, R.F. Gilbert, swept in forest, male, AMNZ 73895 (AMNZ); TK, Mt Egmont, Stratford Mtn House, 860 m, 4-11.XII.2005, J.W. Early, kamahi forest, yellow pan trap, 3 females, AMNZ 74165-74167 (AMNZ); TK, Egmont National Park, Kaitake Ra., Lucy's Gully, 14.IV.1983, F. Chambers, male, AMNZ 64334 (AMNZ); TK, Mt Messenger, 15.XII.1983, L. Masner, screen sweep, male (CNCI); TK, below Mt. Messenger; 15.XII.1983, L. Masner, male, OSUC 151833 (AEIC); TK, Mt Messenger, S side, 90 m, 15.XII.1983, J.W. Early, sweeping grass, sedges and ferns in damp gully, 2 males, OSUC 163659, 163660 (LUNZ); TK, Mt Messenger, 11.III.1985, F. Chambers, damp fern gully S end, 3 males, female, AMNZ 64329-64331 (AMNZ); TK, Whangamomona Saddle, 25.III.1985, F. Chambers, 2 males, AMNZ 64332, 64333 (AMNZ); TK, $21 \mathrm{~km} \mathrm{~N}$ of Ohura, 14.XII.1983, L. Masner, screen sweep undergrowth in Nothofagus forest, 2 males (CNCI); TK, Tangarakau Gorge, Morgans Grave, 200 m, 6-10.XII.2005, J.W. Early, forest, yellow pan trap, male, 2 females, AMNZ 74169-74171 (AMNZ); TK, 23 km S of Aria, Pukerewe Scen. Res., 14.XII.1983, L. Masner, screen sweep, male (CNCI); TK, Waitewhena Forest, 220-250 m, 2-10.XII.2005, J.W. Early, yellow pan trap in forest, 10 males, 2 females, AMNZ 74159-74164, OSUC 179076-179078 (AMNZ, NZAC, OSUC); WO, Pirongia, Hihikiwi Track, 350 m, 1.IX.1986, A.R. Plant, swept mossy bank under mixed bush, male, OSUC 163661 (LUNZ); BP, Kaimai Forest, Wairere Track, 350 m, 22.III.1988, A.R. Plant, swept from low foliage under 15$20 \mathrm{~m}$ canopy bush, female (LUNZ); BP, Kaimai Ra., 4.XI.1982, F.D. Chambers, male, AMNZ 64335 (AMNZ); TO, Pureora Forest Park, 2.II.1995, B.J. Sinclair, podocarp, yellow pan trap, male, OSUC 146524 (CNCI).

\section{Archaeoteleia novaezealandiae Masner}

Figures 16-19

Archaeoteleia novaezealandiae Masner 1968: 654. Original description.

Description: Female. Length 4.5-5.0 mm. Color variable, usually yellow brown; head yellow brown, antennae yellow to orange brown basally, darkening somewhat apically; coxae, pronotum and upper part of mesopleuron yellowish to greenish brown; lateral pronotum immediately above fore coxa, lower mesepisternum and lower half of metapleuron dark brown; mesoscutum and scutellum usually dark brown, sometimes faded to fulvous, notaulus always paler than background color; propodeum and metasoma pale yellow brown to chestnut, horn on $\mathrm{T} 1$ always darker than rest of metasoma.

Head (Figs. 17-19): vertex, temples and upper frons densely punctate, punctures bearing short, fine, semiappressed setae; occipital carina complete, crenulate throughout its length, sculpture denser and finer medially than in genal region; striation of cheeks and face below toruli moderate to strong, extending half way up inner orbits; posterior gena with moderately dense, short, fine, semi-appressed setae; clypeus strongly striate, with long erect setae; frons with weak swelling by inner orbits at about half eye height and upper limit of striae, giving head a browed appearance in dorsal view; A1 4.6-5.8 times longer than wide; A2 elongate, 3.1-3.6 times longer than wide; A3 3.2-3.7 times longer than A2; flagellum with moderately dense erect setae as long as A3 width so as to appear bristly; claval formula A5-A12/1-2-2-2-2-2-2-1. 


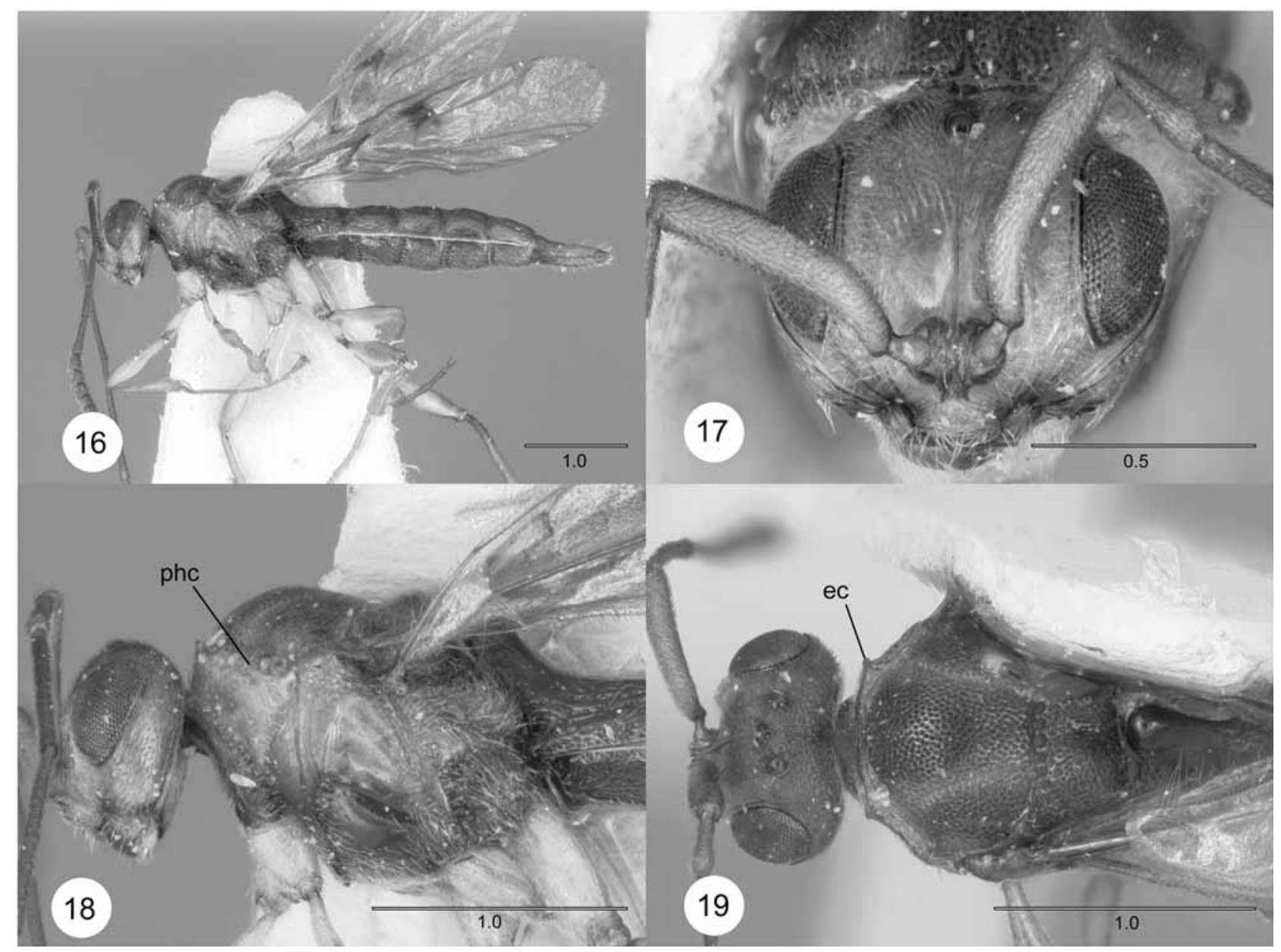

FIGURES 16-19. Archaeoteleia novaezealandiae, female (OSUC 146573). 16, Lateral habitus; 17, head, frontal view; 18, head and mesosoma, lateral view; 19, head and mesosoma, dorsal view. Scale bars in millimeters.

Mesosoma (Figs. 18-19): dorsal pronotum with transverse pronotal carina almost straight, its anterolateral corners raised, sharp and well defined; width between epomial corners 0.6 times mesoscutum width; horizontal epomial carina close to mesoscutum, and shoulders narrow, maximum width about 0.5 times tegula width; vertical epomial carina present, fine; lateral pronotum smooth, glabrous, anterior margin coarsely crenulate from base of vertical epomial carina to fore coxa; mesonotum entirely covered with dense setose punctures; admedian lines varying from distinct, smooth, broadly V- or U-shaped welts, 1.2-1.3 times longer than maximum distance between posterior ends, to admedian lines indistinct and obliterated by sculpture; notaulus crenulate, usually complete, becoming weaker anteriorly, ending behind epomial corners; parapsidal line indicated by weak sulcus or absent; scutellum strongly bilobate; scutellar spines distinct, short, sometimes weakly curved or hooked; mesopleural carina complete, smooth and shining above; mesepisternum below mesopleural carina with longitudinal rugulae, becoming finely coriaceous with sparse setigerous punctures; metapleuron setose, anterior margin crenate, lower half areolate-rugose, upper half with fine setigerous punctures, without glabrous area; medial excavation of propodeum smooth; medial carinae not raised or tooth-like in profile; fore wing slightly infuscated, with dark brown cloud of pigmentation under under marginal vein between bulla and stigmal vein; stigmal vein straight or only very weakly arched and curved basad; cubitalis obscured by cloud of pigmentation; postmarginal vein 2.8-3.3 times longer than marginal vein, quickly becoming indistinct.

Metasoma (Figs. 16, 19) 3.6-3.9 times longer than wide; T1-5 distinctly wider than long, horn raised to level of mesoscutum; T6 2.5-2.9 times longer than wide; all tergites coriarious with superimposed longitudinal sculpture of variable length and extent; $\mathrm{T} 1$ with costae well impressed from anterior corners posteriorly 
around base of horn and usually distinct throughout rest of tergite, horn coriarious basally, becoming smooth and shiny apically; T2-5 always with anterior margin strongly costate, costae often strong and complete, sometimes weak to almost absent and indicated by rugulae, always weaker medially than laterally; T6 coriarious to longitudinally rugulose, anterior margin never costate; anterior lens-shaped area of S2 sometimes prominent but always rounded in profile, never angular or toothlike.

Male. Differs from female as follows: Length 3.5-4.4 mm; A1 4.0-5.1 times longer than wide; A2 1.72.4 times longer than wide; A3 4.6-5.0 times longer than A2; A4 and A5 (rarely A5 only) with small carina in basal $0.2-0.3$; A3-A12 cylindrical, elongate, becoming progressively shorter.

Metapleuron with small glabrous area medially; dorsal propodeum completely areolate-rugose, not excavated medially but sometimes with trace of two median longitudinal carinulae not prominent in profile.

Metasoma 3.2-3.5 times longer than wide; T1 with anterior margin not distinctly raised in profile, with semicircular depression anteriorly as though skirting posterior margin of horn base, strongly costate throughout; T2-5 sculptured as for female.

Diagnosis: Recognized by the following combination of characters: clypeus with sharply angulate anterolateral corners; epomial corners prominent and strongly angulate; transverse pronotal carina between epomial corners straight, not curved around anterior margin of mesoscutum; scutellum bilobed, posterior corners armed with short spine, dark and concolorous with mesoscutum; fore wing with pigment cloud under marginal vein; male sex segments A4+5.

Distribution: This species is restricted to the South Island of New Zealand from the Nelson area in the north, and down the west coast from Karamea to Franz Josef. At the type locality (NN, Roding Valley) it is sympatric with A. onamata n.sp. and A. gilbertae n.sp.

Link to Distribution Map. [http://atbi.biosci.ohio-state.edu:210/hymenoptera/eol_scelionidae.content _page?page_level=3\&page_id=taxon_page_data\&page_version=4041\&page_option $1=\mathrm{M}]$

Biology: Archaeoteleia novaezealandiae is a solitary egg parasitoid of an undescribed species of cave weta, Gymnoplectron sp. One specimen was reared from a collection of five eggs found in the damp, friable sand and clay on the floor near the mouth of a limestone cave (Ananui Cave, Nile River, BR). Recognizable fragments were also found in old parasitized eggs of the same Gymnoplectron sp. in an abandoned mining tunnel (Woods Creek, near Greymouth, BR), where live specimens have been found on the walls. In these tunnels, the weta hosts deposit eggs singly, 3-15 mm deep, in a similar substrate on the floor or small ledges where sufficient (at least $20 \mathrm{~mm}$ depth) substrate accumulates. Because of a shortage of suitable areas for oviposition, these sites are apparently used repeatedly by numerous females. Sometimes it is possible to see holes left when the weta's ovipositor is withdrawn, but these may not persist for long due to the substrate's friability. While they do, eggs may be more vulnerable to parasitism by A. novaezealandiae.

Archaeoteleia novaezealandiae is not an obligate cave dweller and probably only enters caves when searching for hosts. It can also be collected by sweeping low vegetation in the forest in suitable areas. The Gymnoplectron species from which it was reared is also a facultative cave dweller and free living populations are known (P.M. Johns, pers. comm.).

Archaeoteleia novaezealandiae probably parasitizes several species of Macropathinae because its distribution extends further south than that of the known host species. Other Gymnoplectron spp known from those places (P.M. Johns, pers. comm.) are presumed to be its hosts.

Material Examined: Holotype female: NEW ZEALAND: NN, Roding Valley, limestone cave, 6.VIII.1960, E.W. Valentine. Deposited in NZAC.

Paratypes: 10 males, 5 females with same locality data as holotype, OSUC 146572, 163602-163609, 203619, 203620 (NZAC, CNCI).

Other material: NEW ZEALAND: BR, Ananui Cave, Nile R., 3.IV.1983, J.W. Early, weta egg in mud on cave floor, wasp emerged 8-13.vi.1983, female, OSUC 163596 (LUNZ); BR, Ananui Cave, Nile R., 3.iv.1983, J.W. Early, R.M. Emberson, found dead on cave floor, male, 3 females, OSUC 163590, 163593, 
163594, 163600 (LUNZ); BR, Dunganville, Woods Ck Track, 150 m, 24.IV.1984, J.W. Early, wall of abandoned mining tunnel, 2 males, OSUC 163592, 163595 (LUNZ); BR, Lake Rotoiti, Nelson Lakes NP, 19.XII.1983, L. Masner, screen sweeping, male, OSUC 146574 (CNCI); NN, Nelson, 18.V.1924, E.S. Gourlay, male, OSUC 163610 (NZAC); NN, Oparara Arch Tk, 210 m, 3.IV.1988, J.W. Early, M.L. Barrell, swept in podocarp-Nothofagus forest, 2 males, OSUC 163597, 163599 (LUNZ); NN, Oparara R. x creek, NW Nelson For. Park, 8-9.II.1995, B.J. Sinclair, male, OSUC 146576 (CNCI); WD, L. Kaniere, 140 m, 30.XII.1983, J.W. Early, swept in kamahi forest, male, OSUC 163591 (LUNZ); WD, Westland NP, Franz Josef, 210 m, 2.I.1984, J.W. Early, swept in podocarp-broadleaf forest, male, OSUC 163601 (LUNZ); WD, the Metro of Nile River Cave, 1.IX.1971, R.M. Emberson, female, OSUC 146573 (CNCI).

Remarks: Much of the color variation is due to fading. The pale areas (neck, collar, upper half of lateral pronotum and mesopleuron, notauli, coxae) of live specimens are greenish. This fades to pale yellowish brown, often within a year after death. Similarly, the dark brown dorsal mesosoma and metasoma often become chestnut to orange brown.

\section{Archaeoteleia onamata Early, new species}

Figures 20-23

Description: Female. Length 5.6-6.4 mm. Color: central upper frons, vertex and occiput pale golden brown to dark brown, sometimes almost black, particularly ocellar triangle; frons along inner orbits, genae, clypeus and mandibles pale; mesonotum medium golden brown to dark brown; pronotum, lateral mesosoma, coxae, trochanters and femora pale greenish to yellow; ovipositor horn of $\mathrm{T} 1$ always dark brown to almost black, always the darkest part of the body; tergites dark brown medially, orange brown laterally; sternites paler, yellowish brown.

Head (Figs. 21-23): vertex, temples and upper frons very finely coriaceous-punctate, setae short and very fine; occipital carina complete, finely crenulate medially but with only a few fine punctures in genal region; cheeks with dense, fine setigerous punctures, striation weak but strongest basally near mandibular articulation; striation of lower face most pronounced in malar region and on clypeus; central carina of frons very weak, fine, sometimes incomplete; frons with smooth shallow depression on side for reception of scape, without swelling by inner orbits, head not browed in dorsal view; A1 4.0-4.3 times longer than wide; A2 2.4-3.4 times longer than wide; A3 4.2-5.0 times longer than A2; flagellum not conspicuously bristly, with few erect setae, setae mostly appressed and short, less than half width of A3; claval formula A5-12/1-2-2-2-2-2-2-1.

Mesosoma (Figs. 22-23): dorsal pronotum with transverse pronotal carina bowed in front of anterior margin of mesoscutum, epomial corners distinct but not raised or sharp; pronotal shoulders broad, at maximum width 0.75 times as wide as tegulae; vertical epomial carina absent; lateral pronotum with small narrow glabrous area medially; netrion punctulate, with short, fine, semi-appressed setae posteriorly directed; mesoscutum with dense, fine setulose punctures; admedian lines always clearly defined, long, 3.0-4.4 times longer than separation of posterior ends; notaulus complete, finely crenulate, strongest posteriorly, becoming weaker and less distinct anteriorly, subparallel and diverging only slightly anteriorly, ending before epomial corners; parapsidal line clearly indicated; scutellum virtually not bilobate, without spines; mesopleural carina absent; anterior margin and mesepisternum below depression with dense setigerous punctulae, setae very fine, whitish, appressed and obliquely posteroventrally directed; mesopleural depression and area above entirely smooth and almost glabrous; upper half of metapleuron largely smooth and glabrous, lower half not distinctly swollen, densely finely punctulate and hairy like lower mesopleuron; medial excavation of propodeum smooth, flanked by carinae raised anteriorly to sharp tooth-like spine bearing long erect setae; fore wing hyaline, without infuscation under marginal vein between bulla and stigmal vein; stigmal vein distinctly curved basad; postmarginal vein long, 4.0-5.0 times longer than marginal vein, becoming indistinct gradually. 


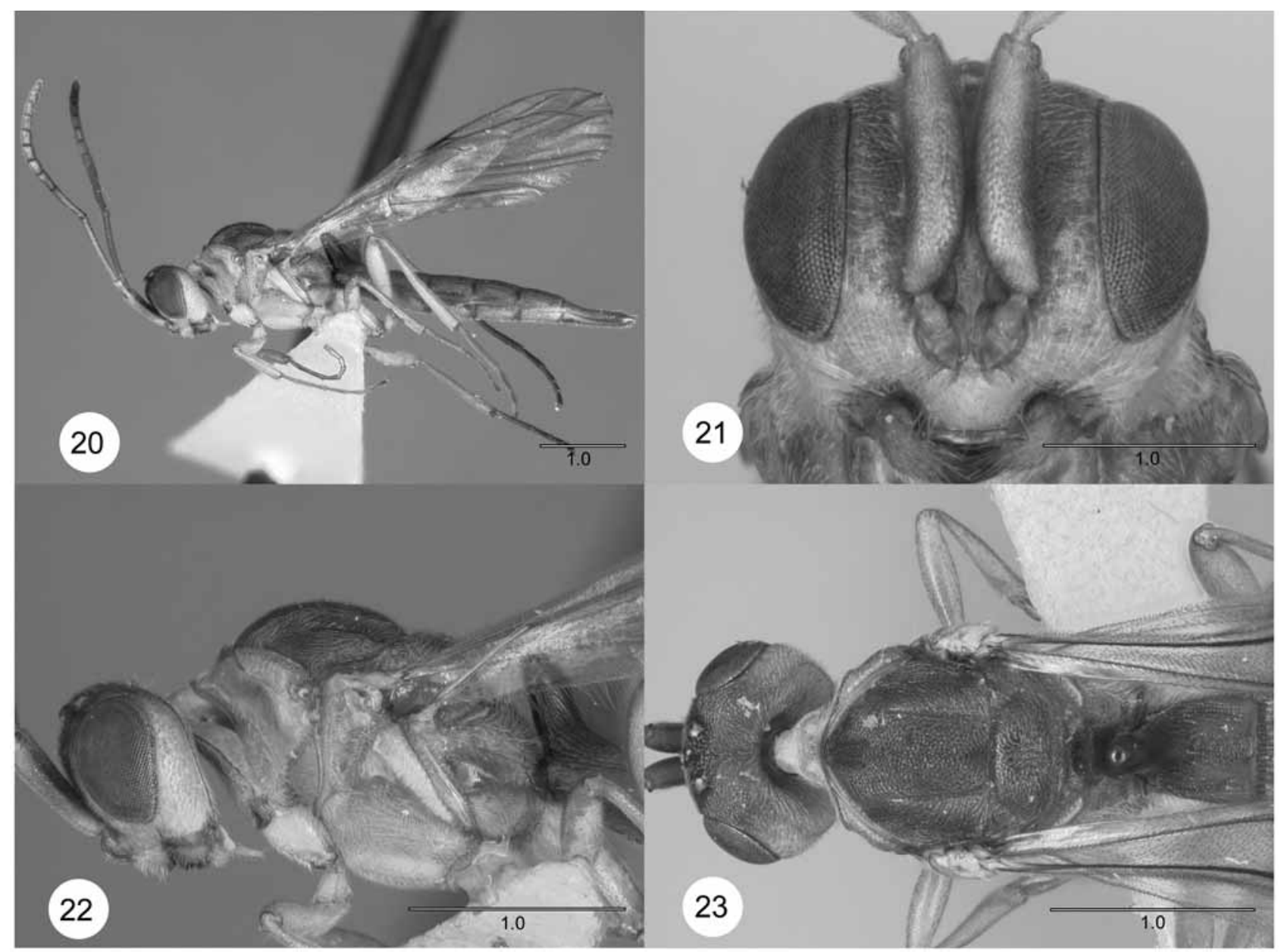

FIGURES 20-23. Archaeoteleia onamata, n.sp., paratype female (OSUC 163297). 20, Lateral habitus; 21, head, frontal view; 22, head and mesosoma, lateral view; 23, head and mesosoma, dorsal view. Scale bar in millimeters.

Metasoma (Fig. 20, 23) 5.0-5.5 times longer than wide; T1 and T5 about as long as wide, T2-4 only slightly wider than long, T6 3.7-4.1 times longer than wide; sculpture very fine; T1 with longitudinal costulae sometimes not well impressed around base of ovipositor horn and interrupted by coriaceous wrinkling, horn finely coriaceous, smooth and shining only on tip; T2-5 with vague shallow longitudinal depression laterally, anterior margins costulate, costulae sometimes complete medially on T2 and T3 but usually only present laterally with broad finely coriaceous medial region.

Male. Differs from female as follows: Length 4.8-5.0 mm; upper frons, vertex, occiput, dorsal mesosoma and metasoma dark brown, always darker than female; A1 2.9-3.0 times longer than wide; A2 1.4-1.7 times longer than wide; A3 5.7-6.0 times longer than A2; only A5 distinctly carinate but A4 often with small vestige of a basal carina.

Propodeum with indistinct weak medial depression flanked anteriorly by delicate propodeal carinae which are not distinctly raised or tooth-like.

Metasoma 4.1-4.2 times longer than wide; T1 longer than wide, anterior margin raised.

Diagnosis: Recognized by the following combination of characters: large body size, female body length 5.6-6.4 mm, male 4.8-5.0 mm; notaulus complete; scutellum barely bilobate and without spines at posterior corners; fore wing without pigment cloud under marginal vein; mesepisternum below mesopleural depression covered with dense, fine pilosity, male antenna with A5 carinate, A4 sometimes with small carina.

Distribution: Found primarily in parts of the north of the South Island of New Zealand (SD, NN, BR, NC). It is sympatric with A. novaezealandiae and A. gilbertae in one locality (NN, Roding Valley), and also at the type locality with A. gilbertae. 
Link to Distribution Map. [http://atbi.biosci.ohio-state.edu:210/hymenoptera/eol_scelionidae.content _page?page_level=3\&page_id=taxon_page_data\&page_version=190983\&page_option1=M]

Biology: Hosts unknown but presumed to be eggs of a large macropathine rhaphidophorid.

Etymology: The word onamata in the Māori language means 'from ancient times' and reflects our belief that this is the most plesiomorphous species of the genus.

Material Examined: Holotype female. NEW ZEALAND: NN, Abel Tasman National Park, Canaan, 720 m, 22.XII.1983, J.W. Early, swept in Nothofagus forest, AMNZ 64336. Deposited in AMNZ.

Paratypes: NEW ZEALAND: 3 males with same data as holotype, OSUC 163672-163674 (LUNZ); NN, Abel Tasman N.P., Harwood's Track, 720 m, 3.II.1981, J.W. Early, sweeping ferns and ground cover in Nothofagus forest, male, female OSUC 163691, 163692 (LUNZ); NN, Harwood's Hole, 21-25.II.1993, L. Le Sage, Malaise trap in Nothofagus forest, male, OSUC 146521 (CNCI); NN, Harwood's Hole, 800 m, 6-7.II.1995, B.J. Sinclair, sphagnum in Nothofagus forest, yellow pan trap, male, OSUC 146523 (CNCI); NN, Canaan, Harwood's Hole Tk., 8.IV.2003, J.W. Early, swept in Nothofagus forest, 3 females, AMNZ 55809-55811 (AMNZ); NN, Abel Tasman N.P., Castle Rock - Torrent Bay Track, 4.II.1981, J.W. Early, sweeping ferns and ground cover on forest floor, male, female, OSUC 163693, 163694 (LUNZ); NN, NW Nelson Forest Park, Mt Arthur Tableland, 1000 m, 17-18.II.1995, B.J. Sinclair, Nothofagus forest, yellow pan trap, 2 males, OSUC 146520 (CNCI); MB, Penk Saddle bet. Penk R and Dillon Ck, 1160 m, 8.II.2001, I.R. Millar, grassy/scrub clearing in mountain beech forest, yellow pan trap, male, AMNZ 73861 (AMNZ); BR, Nelson Lakes N.P., N slope Mt Robert, 860 m, 23-26.III.1980, A. Newton \& M. Thayer, Nothofagus spp, intercept trap, 2 males, female (CNCI); BR, L. Rotoiti, 610 m, 4.II.1978, A.K. Walker, to Coleman lantern "Station C", male, OSUC 163685 (NZAC); BR, L. Rotoiti, XII.1980, 24.XII.1982, A.K. Walker, pan trap in Nothofagus forest, 5 males, OSUC 163686-163690 (NZAC); BR, L. Rotoiti, 615 m, 19,20.XII.1983, J.W. Early, swept in Nothofagus forest, male, OSUC 163675 (LUNZ); 4 males, 3 females with same data but L. Masner, screen sweep (CNCI); BR, L. Rotoiti, 18-23.XII.1983, J.W. Early \& L. Masner, yellow pan trap in Nothofagus forest, 3 males, female, OSUC 163297, 163676 (CNCI, LUNZ); SD, Queen Charlotte Sound, Bay of Many Coves, 2931.XII.1985, 5-11.I.1987, 27.XII.1989-4.I.1990, J.W.M. Marris, yellow pan trap in kanuka bush, 2 males, 7 females, AMNZ 73862, OSUC 163677-163684 (AMNZ, LUNZ); NC, Arthurs Pass, Bealy River Tr, 800 m, 11-12.II.1995, B.J. Sinclair, yellow pan trap, male, OSUC 146522 (CNCI).

Other material: NEW ZEALAND: BR, Nelson Lakes N.P., Mt. Robert, 1200 m, 18-23.XII.1983, L. Masner, Malaise trap, female, OSUC 151834 (AEIC). BR, L. Brunner Moana Scenic Res., 14-15.II.1995, B.J. Sinclair, yellow pan trap, male, OSUC 146525 (CNCI).

\section{Archaeoteleia waipoua Early, new species}

Figures 24-29

Description: Male. Length $4.1 \mathrm{~mm}$. Color: head and mesosoma brown; metasoma dark brown; legs pale yellowish brown; body without greenish brown areas.

Head (Figs. 26-28): occipital carina crenulate and irregular, poorly defined; frons lacking swelling, head not appearing browed in dorsal view; eye relatively small, outer orbits well separated from occipital carina so that postgena wider than eye in lateral view; clypeus compressed, rounded, very narrow, smooth, anterior margin without sharp lateral corners; A1 5.6 times longer than wide; A2 short, 1.2 times longer than wide; A3 7.8 times longer than A2; A4 and A5 with small basal carina.

Mesosoma (Figs. 26-27): dorsal pronotum with transverse pronotal carina curved around anterior margin of mesoscutum; pronotal humeral carina separated from mesoscutum by distance of about tegula width, shoulders broad, maximum width 0.91 times tegula width; vertical epomial carina weak, most distinct at ventral end; lateral pronotum entirely coriarious-punctate; netrion almost entirely crenulate; admedian lines weak, 
almost obscured by sculpture; notaulus incomplete, clear and distinct in posterior half, becoming weak and absent anteriorly; mesoscutellum very weakly bilobate; scutellar spines small, bladelike; dorsellum sculptured in posterior half; mesopleural carina complete, weak; mesepisternum below mesopleural carina smooth and shining, with only sparse setae; propodeum not medially excavate, entirely areolate-rugose, medial carina distinct and prominently angulate in lateral view; postmarginal vein 3.0 times longer than marginal vein, mostly indicated by pigmentation, basal tubular section shorter than marginal vein; mid and hind basitarsi laterally compressed, higher than wide (Fig. 24).

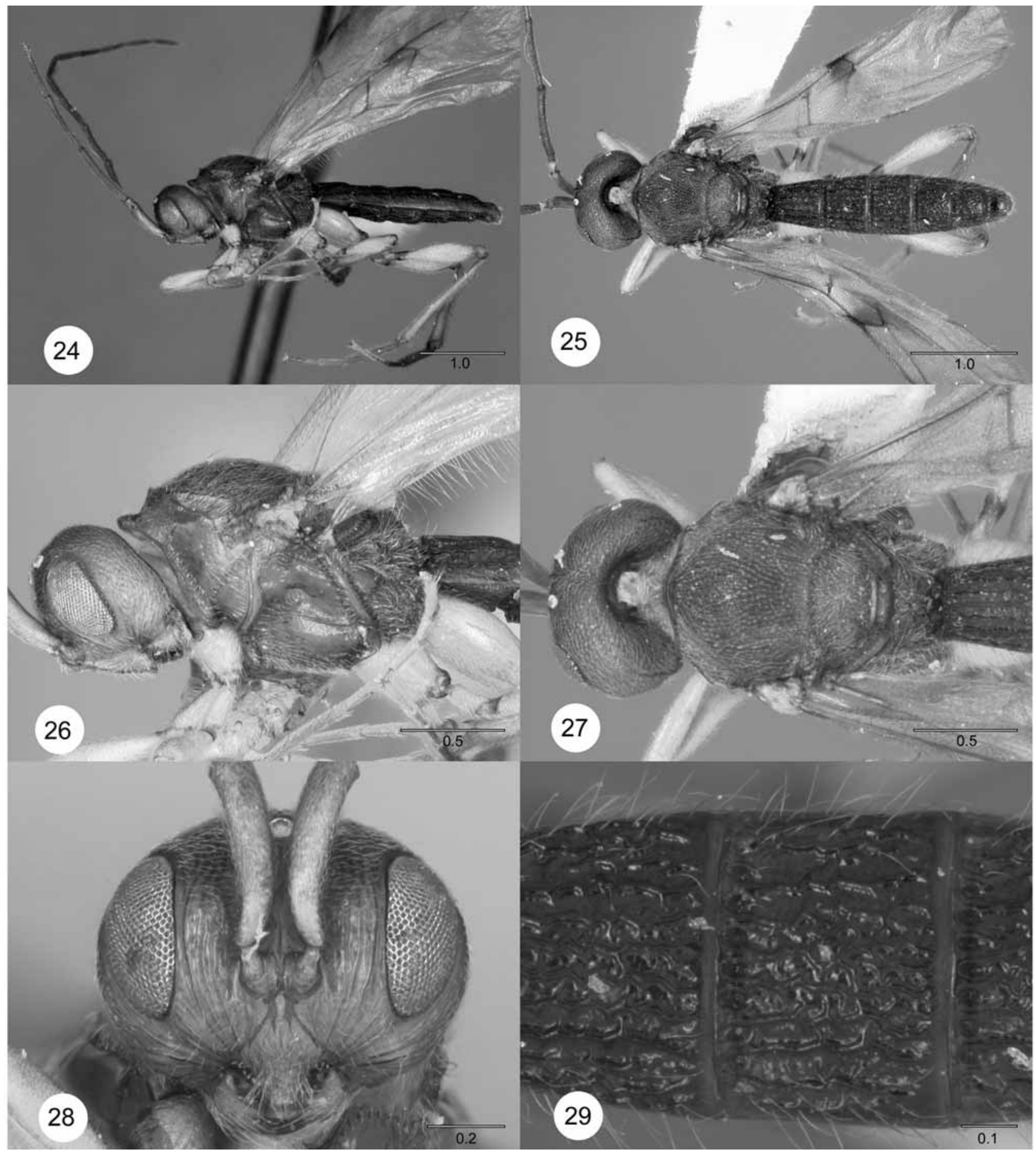

FIGS. 24-29. Archaeoteleia waipoua, n.sp., holotype male (AMNZ 64323). 24, Lateral habitus; 25, dorsal habitus; 26, head and mesosoma, lateral view; 27, head and mesosoma, dorsal view; 28, head, frontal view; 29, metasoma T3, dorsal view. Scale bars in millimeters. 
Metasoma (Figs. 24, 25, 29) 3.9 times longer than wide, strongly sculptured, with coarse longitudinal costae particularly on T1, sculpture becoming less coarse posteriorly; anterior margin of T1 not raised; anterior lens-shaped region of S2 strongly angular in profile.

Female unknown.

Diagnosis: Recognized by the following combination of characters: fore wing with pigment cloud under marginal vein; metasomal tergites with coarse longitudinal costae; clypeus narrow, compressed and without angulate corners; mid and hind basitarsi compressed.

Distribution: Known only from a single specimen from the Waipoua forest, northern North Island of New Zealand, where it is found sympatrically with A. chambersi.

Link to Distribution Map. [http://atbi.biosci.ohio-state.edu:210/hymenoptera/eol_scelionidae.content _page?page_level=3\&page_id=taxon_page_data\&page_version=190988\&page_option1=M]

Etymology: Named for the type locality, a Māori word of uncertain meaning, and is to be regarded as a noun in apposition.

Material Examined: Holotype male. NEW ZEALAND: ND, Waipoua State Forest near Forest HQ, 290 m, 11-14.IV.1980, podocarp-broadleaf, A. Newton, M. Thayer, AMNZ 64323. Deposited in AMNZ.

\section{New Zealand Archaeoteleia species incertae sedis}

Two female specimens from the North Island (TK, Mt Egmont; $21 \mathrm{~km} \mathrm{~N}$ of Ohura) are very close to $A$. novaezealandiae but differ in several small ways. They are somewhat smaller (3.8, $4.0 \mathrm{~mm}$ long), lack strongly angulate epomial corners at the end of the transverse pronotal carina, and have slightly weaker sculpture on the metasomal tergites than South Island specimens. We exclude them from A. novaezealandiae but prefer not to erect a new species until more material, including males, is obtained.

\section{SPECIES OF SOUTH AMERICA}

\section{Archaeoteleia araucana Masner}

Figures 30-35

Archaeoteleia araucana Masner 1968: 657. Original description. Loiácono \& Díaz 1977: 96, description; Sarazin 1986 : 972, type information.

The original description (Masner 1968) may be supplemented as follows:

Head (Figs. 32-34): LOL subequal to OOL; eye with few, extremely minute, scattered hairs; median keel on frons lacking; claval formula A6-A12/2-2-2-2-2-2-1.

Mesosoma (Figs. 32, 33): transverse pronotal carina weakly arcuate, anterolateral corners angular, not spikelike; vertical epomial carina very strong, complete, complete row of foveae along anterior margin of side of pronotum; horizontal epomial carina weakly developed, obliterated in anterior half, pronotal shoulders poorly defined, with row of foveolae along mesoscutal margin; lateral portion of pronotum with large central smooth, glabrous field; netrion very well-indicated by foveolae, micropilose; admedian lines very long, clearly indicated; notaulus deeply incised, complete, finely foveolate, nearly parallel to subparallel; parapsidal line faintly indicated; scutellum transverse, length 0.5 times length of mesoscutum, largely smooth, shining, with scattered small setigerous punctures, scutellar spines short, straight, horizontal; mesopleural carina absent; mesopleuron largely smooth, glabrous, mesepisternum with few scattered hairs; acetabular carina fine; posterior margin of mesopleuron with complete chain of deep foveolae reaching ventrally to coxal cavity; metapleuron with arcuate foveolate longitudinal line at meson, below this with long setae, surface rather 
densely punctate, above predominantly glabrous, with only very few small, scattered setae, shining, with row of foveolae along anterior margin; median portion of propodeum shallowly excavate, median keels weakly pronounced; fore wing broadly exceeding apex of metasoma; hind coxa relatively small, smooth.

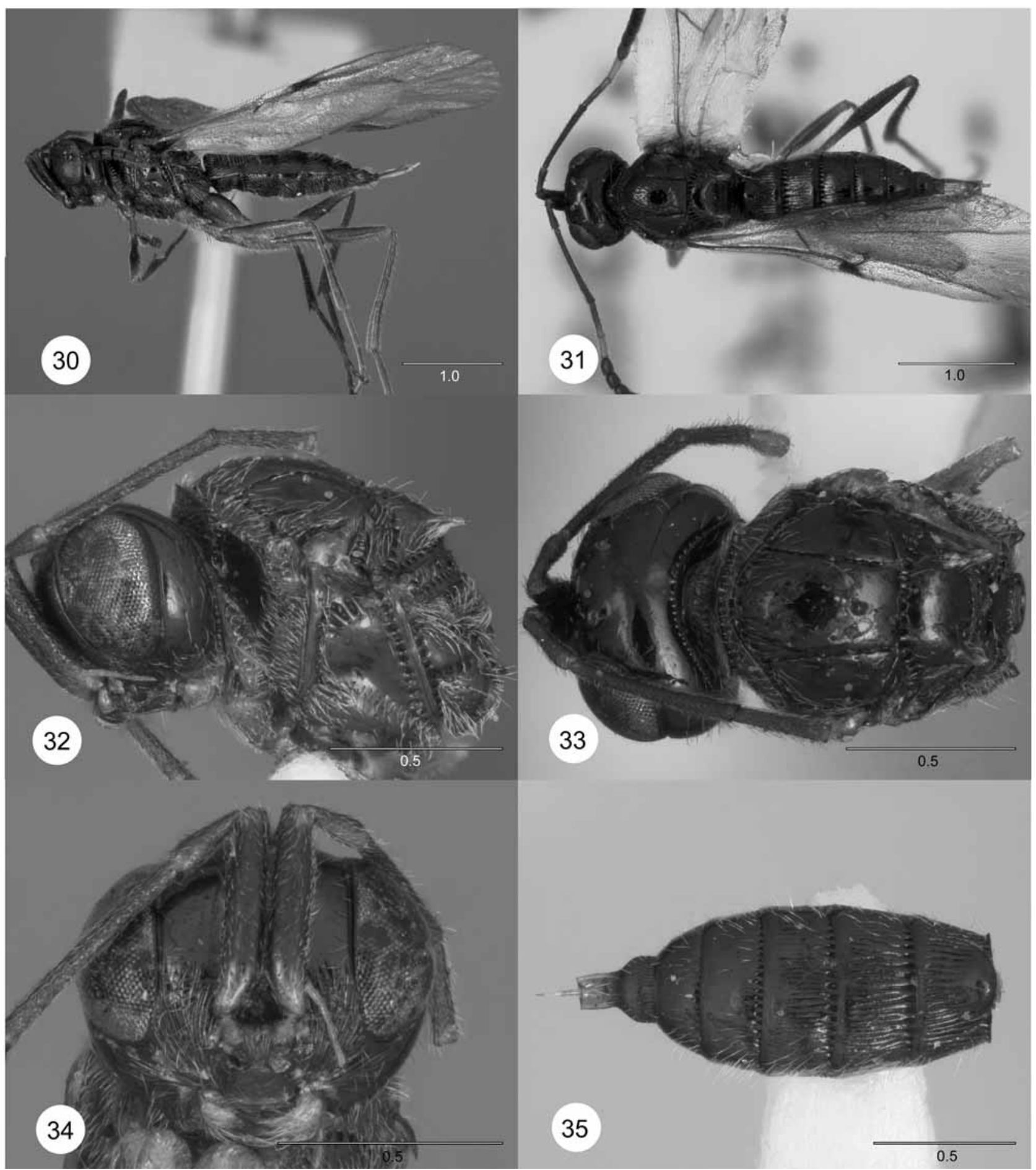

FIGURES 30-35. Archaeoteleia araucana. 30, Lateral habitus, paratype female (OSUC 146467); 31, dorsal habitus, paratype female (OSUC 146467); 32, head and mesosoma, lateral view, holotype female (CNC 10475); 33, head and mesosoma, dorsal view, holotype female (CNC 10475); 34, head, frontal view, holotype female (CNC 10475); 35, metasoma, dorsal view, holotype female (CNC 10475). Scale bars in millimeters.

Metasoma (figs 30, 31, 35) relatively short, broad, length 2.3 times greatest width; T1 horn in lateral view not exceeding height of dorsellum, dorsal portion of horn totally smooth; length of T2 0.5 times width, longitudinally rugulose, with fine microsculpture in furrows between rugulae; length of T3 0.4 times width, with 
longitudinal striae medially in basal half or predominantly smooth, with scattered punctures; length of T4 0.4 times width, with only short basal costae or costae extending over its basal half; length of T5 0.3 times width, nearly smooth; length of T6 equal to width.

Diagnosis: Most similar to A. simulans and A. gracilis, all of which have the mesoscutum with areas devoid of sculpture. Archaeoteleia araucana is distinguished by its dark color and apically smooth horn on T1.

Link to Distribution Map. [http://atbi.biosci.ohio-state.edu:210/hymenoptera/eol_scelionidae.content _page?page_level=3\&page_id=taxon_page_data\&page_version=4038\&page_option 1=M]

Material Examined: Holotype female: CHILE: Pichinahuel, Cord. de Nahuelbuta, Malleco Prov., Araucanía Reg., L. Peña, CNC 10475. Deposited in CNCI.

Paratypes: CHILE: Araucanía, Pichinahuel, Cord. de Nahuelbuta, Malleco Prov., 1.X.1959, L. Peña, female, OSUC 192707 (CNCI).

Bío-Bío, Butamalal, Prov. de Arauco, 31.I.1954, L.E. Peña, male, OSUC 146465 (CNCI); Caramavida, Prov. de Arauco, 10.II.1953, L.E. Peña, male, OSUC 146468 (CNCI); Pichinahuel, 1100-1400m, Cord. de Nahuelbuta, Prov. de Arauco, 1-10.I.1959, L. Peña, male, OSUC 146466 (CNCI); Pichinahuel, 1100-1400m, Cord. de Nahuelbuta, Prov. de Arauco, 12.II.1953, L. Peña, male, OSUC 146463 (CNCI); Pichinahuel, 11001400m, Cord. de Nahuelbuta, Prov. de Arauco, 20-28.I.1959, L. Peña, male, OSUC 192701 (CNCI); Pichinahuel, 1100-1400m, Cord. de Nahuelbuta, Prov. de Arauco, 10-20.I.1959, L. Peña, male, female OSUC 192702, 192706 (CNCI); Pichinahuel, 1100-1400m, Cord. de Nahuelbuta, Prov. de Arauco, 12.II.1953, L. Peña, male, OSUC 192704 (CNCI);

Los Lagos, Antillanca, Prov. de Osorno, 18.II.1955, L.E. Peña, male, OSUC 146464 (CNCI); Enco, 1100-1600m, Prov. de Valdivia, 6.III.1955, L.E. Peña, female, OSUC 146467 (CNCI).

Other material: CHILE: Araucanía, 10km S Pucón, 900 m, Nothofagus grove on ash, Villarrica N.P., Cautín Prov., 15.XII.1984-10.II.1985, J. Peck, S. Peck, male, OSUC 146478 (CNCI); 12 km E Malalcahuello, 1350 m, Prov. de Malleco, 13-31.XII.1982, A. Newton, M. Thayer, female, OSUC 146470 (CNCI); Parque Nacional Conguillio, 1150 m, Cautín, 5.II.1988, L. Masner, male, OSUC 151835 (AEIC); Conguillío National Park, 1150 m, Araucaria / Nothofagus, Cautín Prov., 4-5.II.1988, L. Masner, male, OSUC 146483 (CNCI); Conguillío National Park, 38³8'56"S 71³9'49"W, 1214m, UCR AToL C05-010, Araucaria / Nothofagus forest, 11-24.II.2005, male, OSUC 174425 (CNCI); Conguillío National Park, 38³9'01"S 71³9'45"W, 1239m, UCR AToL C05-011, Nothofagus / Chusquea forest, $3.9 \mathrm{~km} \mathrm{~S}$ north entrance, 11.II.2005, male, OSUC 174426 (CNCI); Contulmo National Monument, 350 m, mixed evergreen forest, Purén, Malleco Prov., 11.XII.1984-13.II.1985, J. Peck, S. Peck, male, OSUC 146476 (CNCI); Juble, 1100 m, W of Cordillera de Las Raices, 19-21.XII.1976, L. Peña, male, OSUC 146471 (CNCI); N of Malalcahuello, 1570 m, Prov. de Malleco, 13-31.XII.1982, A. Newton, M. Thayer, female, OSUC 146475 (CNCI); Nahuelbuta National Park, 1200-1500 m, Araucanía / Nothofagus forest, 40 km W Angol, 9.XII.1984-17.II.1985, J. Peck, S. Peck, female, OSUC 146477 (CNCI); Nahuelbuta National Park, 1200-1500m, Araucanía / Nothofagus forest, 9.XII.1984-17.II.1985, J. Peck, S. Peck, male, OSUC 146469 (CNCI); Nahuelbuta National Park, 3748'10"S 7301'27"W, 1327m, UCR AToL C05-004, Araucaria / Chusquea forest, 8.II.2005, female, OSUC 174428 (CNCI); Nahuelbuta National Park, 3748'54"S 7300'44"W, 1288m, UCR AToL C05-007, open scrub Nothofagus forest, 9.II.2005, male, OSUC 174424 (CNCI); Nahuelbuta National Park, 3749'30"S 7258'24"W, 1168 m, 9-10.II.2005, L. Masner, 3 males, OSUC 203614-203616 (CNCI); Nahuelbuta National Park, 3749'30"S 7258'24"W, 1168 m, UCR AToL C05-001, meadow \& Nothofagus, 10-24.II.2005, 2 males, female OSUC 174427, OSUC 203617, OSUC 203618 (CNCI); Nahuelbuta National Park, 3749'42"S 7300'39"W, 1138 m, 8-9.II.2005, L. Masner, 4 males, 10 females, OSUC 203600-203613 (CNCI); Parque Nacional Nahuelbuta, 1300 m, Prov. de Malleco, 31.I-3.II.1979, L. Peña, male, OSUC 146472 (CNCI); Parque Nacional Nahuelbuta, 1300 m, Prov. de Malleco, L.E. Peña, female, OSUC 151829 (AEIC); Parque Nacional Nahuelbuta, 37.809 ${ }^{\circ} \mathrm{S} 73.016^{\circ} \mathrm{W}, 1200$ m, Prov. de Malleco, 9-12.I.2000, D. Webb, D. Yeates, 
female, OSUC 146491 (CNCI); Parque Nacional Nahuelbuta, 37.809 S 73.016º W, 3680 ft, 6-9.I.2000, D. Webb, D. Yeates, male, OSUC 146492 (CNCI); Pichinahuel, 1300 m, Cord. de Nahuelbuta, Malleco, 1315.I.1977, L.E. Peña, male, OSUC 151830 (AEIC); Pichinahuel, Cord. de Nahuelbuta, Malleco Prov., 1.X.1959, L. Peña, female, OSUC 163612 (CNCI); Pichinahuel, Cord. de Nahuelbuta, Malleco Prov., 1520.I.1977, L. Peña, male, OSUC 146473 (CNCI); Río Blanco, CuraCautín, Prov. de Malleco, 1-5.II.1959, Peña, male, OSUC 146474 (CNCI); Río Blanco, CuraCautín, Prov. de Malleco, II.1964, L.E. Peña, female, OSUC 151831 (AEIC); Río Blanco, Prov. de Cautín, 5-20.I.1996, T. Cekalovic, male, OSUC 146488 (CNCI); Villarrica Volcano, 39²3.27'S 71 ${ }^{\circ} 57.82^{\prime} \mathrm{W}, 1390 \mathrm{~m}$, stunted Nothofagus pumilo forest, road to ski center, Villarrica N.P., Cautín Prov., 27.XII.1996-3.II.1997, A. Newton, M. Thayer, female, OSUC 146489 (CNCI); Villarrica, 39 ${ }^{\circ} 10.052^{\prime} \mathrm{S} 71^{\circ} 58.892^{\prime} \mathrm{W}, 440 \mathrm{~m}$, canopy, Flor del Lago Ranch, 12.I.2003, Arias, et al., 2 females, OSUC 174429-174430 (CNCI).

Bío-Bío, Las Escaleras, Prov. de Concepción, 4.I.1995, T. Cekalovic, female, OSUC 146490 (CNCI); Pata de Gallina, E of Contulmo, Arauco Prov., II.1989, P. Salinas, 2 males, female, OSUC 146487, 163613163614 (CNCI); Contulmo, Arauco, II.1989, P. Salinas, 2 males, female, OSUC 55597-55599 (OSUC).

Los Lagos, Petrohué, Nothofagus forest, 9.I.1986, N. A. Deans, male, OSUC 163611 (LUNZ); 30 km W La Unión, 600 m, Prov. de Valdivia, 10-11.II.1988, L. Masner, male, OSUC 151837 AEIC); Antillanca, 1300 m, Nothofagus tree line, Puyehue N.P., Osorno Prov., 16.II.1988, L. Masner, male, OSUC 146479 (CNCI); coast, Pucatrihue, Prov. de Osorno, 25-31.I-10.II.1980, L. Peña, male, OSUC 146480 (CNCI); Las Lajas, W of La Unión, Prov. de Valdivia, 9-13.I.1990, L.E. Peña, male, OSUC 146486 (CNCI); Las Trancas, 500 m, Nothofagus, 30 km W La Unión, Valdivia Prov., 8-11.II.1988, L. Masner, male, OSUC 146484 (CNCI); nr. Lake Chapo, 200 m, Nothofagus tree line, Llanquihue Prov., 18.II.1988, L. Masner, male, OSUC 146482 (CNCI); Puntra River, 100 m, Nothofagus forest, Route 5, Chiloé Isl., 24.II.1988, L. Masner, male, OSUC 146485 (CNCI); W of La Unión, Prov. de Osorno, III.1987, L.E. Peña, male, OSUC 146481 (CNCI).

\section{Archaeoteleia dispar Masner, new species}

Figures 36-41

Description: Female. Length 3.0-4.8 mm. Color: body light brown; A1-A5 bright yellow, A6-A12 almost black; legs, including coxae, bright yellow; gena, ventral and lateral portions of mesosoma dark brown, metasomatic sternites darker than tergites.

Head (Figs. 36, 37, 40): vertex, temples, upper frons densely punctate, setose; patches of longitudinal rugulosity along inner orbits, middle portion of frons below anterior ocellus with fine, dense punctures, with fine, appressed pilosity; upper gena rugose punctate, sculpture more finely expressed in smaller specimens; eye sparsely setose; vertex between posterior ocelli and occipital carina slightly concave medially; LOL subequal to OOL; occipital carina sharp, acute, complete, simple to deeply crenulate; frons medially with strong keel reaching about half distance to anterior ocellus; striae on lower frons reaching inner orbits, striae on lower gena well developed; clypeus transversely striate, punctate dorsally, anterolateral corners strongly projecting; antennal toruli confluent with dorsal margin of clypeus; A1 4.6-5.5 times longer than wide; A2 2.5-2.7 times longer than wide; A3 1.9-2.3 times as long as A2; flagellum with fairly long, semierect setae; claval formula A6-A12/2-2-2-2-2-2-1.

Mesosoma (Figs. 36, 37): transverse pronotal carina almost straight, bladelike sharp, median tooth not pronounced, anterolateral corners only moderately angular, not spinelike; vertical epomia absent; horizontal epomia turned downward posteriorly, distinctly separated from mesoscutum, pronotal shoulders very broad, with rough rugulosity; side of pronotum glabrous, almost entirely smooth and shining; netrion distinctly delimited by arc of foveolae; mesoscutum strongly reduced, moderately convex, deeply punctured, with fine, scattered pilosity; admedian lines absent; notaulus deep, broad, coarsely foveolate; parapsidal line absent; 
transscutal articulation deep, strongly foveolate; scutellum strongly transverse, striplike, length $0.5-0.6$ times length of mesoscutum, deeply punctate, with appressed pilosity, apical margin distinctly crenulate, slightly invaginated medially; scutellar spines strong, straight, sharply pointed, at about $45^{\circ}$ angle to longitudinal axis of body or greater; mesopleural carina absent; mesopleuron predominantly glabrous, smooth, mesepisternum ventrally predominantly smooth, shining, almost glabrous, with row of deep crenulae above mid coxa; acetabular carina distinct, crenulate; posterior margin of mesopleuron with complete chain of deep foveolae reaching ventrally to coxal cavity; metapleuron predominantly glabrous, with only very few small, scattered setae, shining, with row of foveolae along anterior margin and arcuate foveolar line at meson, roughly rugulose above hind coxa, smooth and shining medially; propodeum moderately setose, posteromedially almost without sculpture, nearly smooth, submedian keels weakly developed or absent; tegula minute, but present; fore wing represented in form of scale behind tegula, twice as long as tegula in largest specimens; hindwing represented by small scale, more elongate in larger specimens, not reaching past propodeal spiracles; legs: robust, but not shortened; pretarsal claws strong; hind coxa unusually large, robust, only slightly shorter than hind femur, twice as long as mid coxa, reaching posteriorly nearly as far as apex of T2, posterior surface of distal portion with transverse wrinkles.

Metasoma relatively elongate, spindlelike, length 4.1-4.8 times width; length of T1 1.4 times width, dorsal surface of horn with transverse rugulosity, posterior part of tergite with irregular, rough rugulosity, near horn transversely oriented, near posterior margin longitudinally oriented; T2-T5 each with pair of longitudinal deep depressions; length of T2 0.7-0.8 times width; length of T3 0.6 times width; length of T4 0.6 times width; T2-T4 with exceptionally coarse, irregular rugulosity, becoming concentric in middle of sclerite, with sparse, semi-appressed setae, without bristles; length of T5 0.5-0.6 times width, depressions shallower, shorter; T6 distinctly elongate, length 2.3-2.8 times width, with finer irregular rugulosity, fairly dense semierect pilosity; small specimens with posterior surface of T1, entire T2-T4 predominantly longitudinally rugose, $\mathrm{T} 5$ with irregular rugulosity and punctures.

Male. Length: 2.8-4.6 mm. Color: light honey-brown with pleural and ventral region of mesosoma distinctly darker; wings slightly yellowish, not clear, with appreciable dark cloud under marginal vein; antenna and legs concolorous with body.

Head (Figs. 38, 39, 41): vertex, temples, frons rugose punctate, frons with dense appressed pilosity, upper gena entirely rugose punctate, sculpture finer in smaller specimens; eye with scattered hairs; vertex behind ocelli with moderate median longitudinal depression; LOL distinctly shorter than OOL, lateral ocelli far from inner orbits, ocellar triangle very compact; occipital carina sharp, complete, finely crenulate; median keel distinct, reaching midpoint between antennal insertion and anterior ocellus; facial striae strong, reaching inner orbit, extending to lower third of eye; clypeus very high, higher than wide, anterolateral corners strongly projecting, lower half with transverse rugae, upper half almost smooth; toruli contiguous with upper margin of clypeus; A1 3.9-4.0 times as long as wide; A2 1.3 times as long as wide; A3 4.4 times as long as A2; A5-A9 gently to distinctly arched, elongate; A4 and A5 with distinct keels, keel longer on A4, in smaller specimen keels subequal in length.

Mesosoma (Figs. 38, 39): transverse pronotal carina complete, well developed, anterolateral corners angular, but not spinelike, no middle tooth; vertical epomial carina absent; horizontal epomial carina well developed, pronotal shoulder fairly broad, rugose punctate; side of pronotum partly smooth, with scattered punctures at margins; netrion well developed; mesonotum entirely covered by fine appressed pilosity, middle lobe of mesoscutum mesally with transverse rugulae, laterally densely rugospunctate; admedian lines rudimentary; notaulus complete, deeply incised, with fine foveolae; parapsidal line evanescent; transscutal articulation broad, with large foveolae; scutellum almost rectangular, densely punctate, length 0.5 times length of mesoscutum; scutellar spines short, straight, acute, pointing diagonally backwards; mesopleural carina not developed, but replaced by 3-4 longitudinal furrows on mesepisternum; upper portion of mesopleuron entirely smooth, shining, glabrous, mesepisternum below partly smooth, with scattered punctures; acetabular 
carina fine; chain of foveolae on posterior margin of mesopleuron complete, extending ventrally to coxal cavity; metapleuron largely glabrous, with only scattered fine hairs, with rough irregular rugulosity above hind coxa, area topped by arcuate of foveolae medially, upper metapleuron with smooth glabrous mirror, carina between metapleuron and propodeum sharply raised; propodeum with irregular, rough rugulosity, relatively sparse pilosity, median keels not developed, but with two irregular rudiments in area of keels; fore wing slightly to strongly exceeding tip of metasoma, basal vein strongly pigmented, delicate infuscated cloud below marginal vein, postmarginal vein distinctly tracheate, length 2.5 times length of stigmal vein, stigmal vein distinctly arched and slightly to distinctly hooklike at apex, Rs, M, Cu well-defined by nebulous streaks; hind basitarsus relatively strong, hind coxa very large, on posterior surface with irregular rugulosity and several transverse wrinkles above apex.

Metasoma (Figs. 38, 39) distinctly elongate, length 3.3-3.6 times width; length of T1 equal to width; length of T2 0.6 times width; length of T3 0.6 times width; length of T4 0.6 times width; length of T5 0.5 times width; all five basal tergites with longitudinal costae, some irregular rugulae at sides; width of T6 0.6 times length; tergites beyond T6 extremely small, length of T7 0.3 times width, length of T8 0.6 times width.

Diagnosis: The female is differentiated from the other flightless species, A. pygmea and A. submetallica, by the presence of short stubs of wings, deeply incised and foveolate notaulus, well-developed and foveolate transscutal articulation, and the elongate metasoma with pairs of longitudinal sublateral depressions on T2T5. The male is distinguished from most Chilean species by the elongate, tracheate postmarginal vein, a character shared with A. pygmea and A. robusta. From those two species the male may be distinguished by the well-developed notauli (absent in A. pygmea) and the gentle, but distinct bowlike curving of antennomeres 58 (straight and cylindrical in the other two species).

Etymology: The specific epithet dispar, Latin for unlink or different, stresses the strong secondary sexual dimorphism of the males and females.

Link to Distribution Map. [http://atbi.biosci.ohio-state.edu:210/hymenoptera/eol_scelionidae.content _page?page_level=3\&page_id=taxon_page_data\&page_version=190981\&page_option1=M]

Material Examined: Holotype female: CHILE: Los Lagos, Chiloé Is., Ahoni Alto, 70 m., 22.II.1988, primary forest, pan trap, L. Masner, OSUC 163624. Deposited in CNCI.

Paratypes: CHILE: Aisén, Parque Nacional Río Simpson, 70 m, 33 km E Puerto Aisén, 22.II.1988, J. Peck, S. Peck, male, OSUC 146498 (CNCI).

Araucanía, Lago Caburgua, 21 km NE Pucón, 600 m, 15.XII.1984-10.II.1985, J. Peck, S. Peck, female, OSUC 146496 (CNCI).

Los Lagos, N of Correntoso, El Chingue, Prov. de Llanquihue, IV-V.1989, L.E. Peña, male, OSUC 146499 (CNCI); 30 km W La Unión, 600 m, Prov. de Valdivia, 10.II.1988, G.B. Edwards, female, OSUC 146497 (CNCI); 34 km W La Unión, 700 m, Prov. de Valdivia, 17.XII.1984-7.II.1985, J. Peck, S. Peck, female, OSUC 146495 (CNCI); 37 km SE Chaiten, 60 m, Prov. de Palena, 28.XII-30.I.1985, J. Peck, S. Peck, female, OSUC 146494 (CNCI); Ahoni, 70 m, primary forest, Isla Chiloé, IV.1988, L. Masner, Malaise trap, male, AMNZ 75763. Chepu, $42^{\circ} \mathrm{S}, 120 \mathrm{ft}$, mixed forest, Isla Chiloé, female, OSUC 163623 (CNCI); Chiloé Is., Ahoni Alto, 70 m., 22.II.1988, primary forest, pan trap, L. Masner, OSUC 146500, 163625 (CNCI); Las Trancas, 500 m, 30 km W La Unión, Prov. de Valdivia, 7.II.1988, L. Masner, male, OSUC 146501 (CNCI); Parque Nacional Chiloé, 42²0'S 747'W, sea level, Isla Chiloé, 11-12.XII.2002, L. Masner, male, OSUC 146504 (CNCI); Piopio, Isla Chiloé, 3-15.II.1995, A. Ugarte, male, OSUC 146503 (CNCI); Río Puntra \& Rt.5, 100m, Isla Chiloé, 24.II.1988, L. Masner, male, OSUC 146502 (CNCI). 


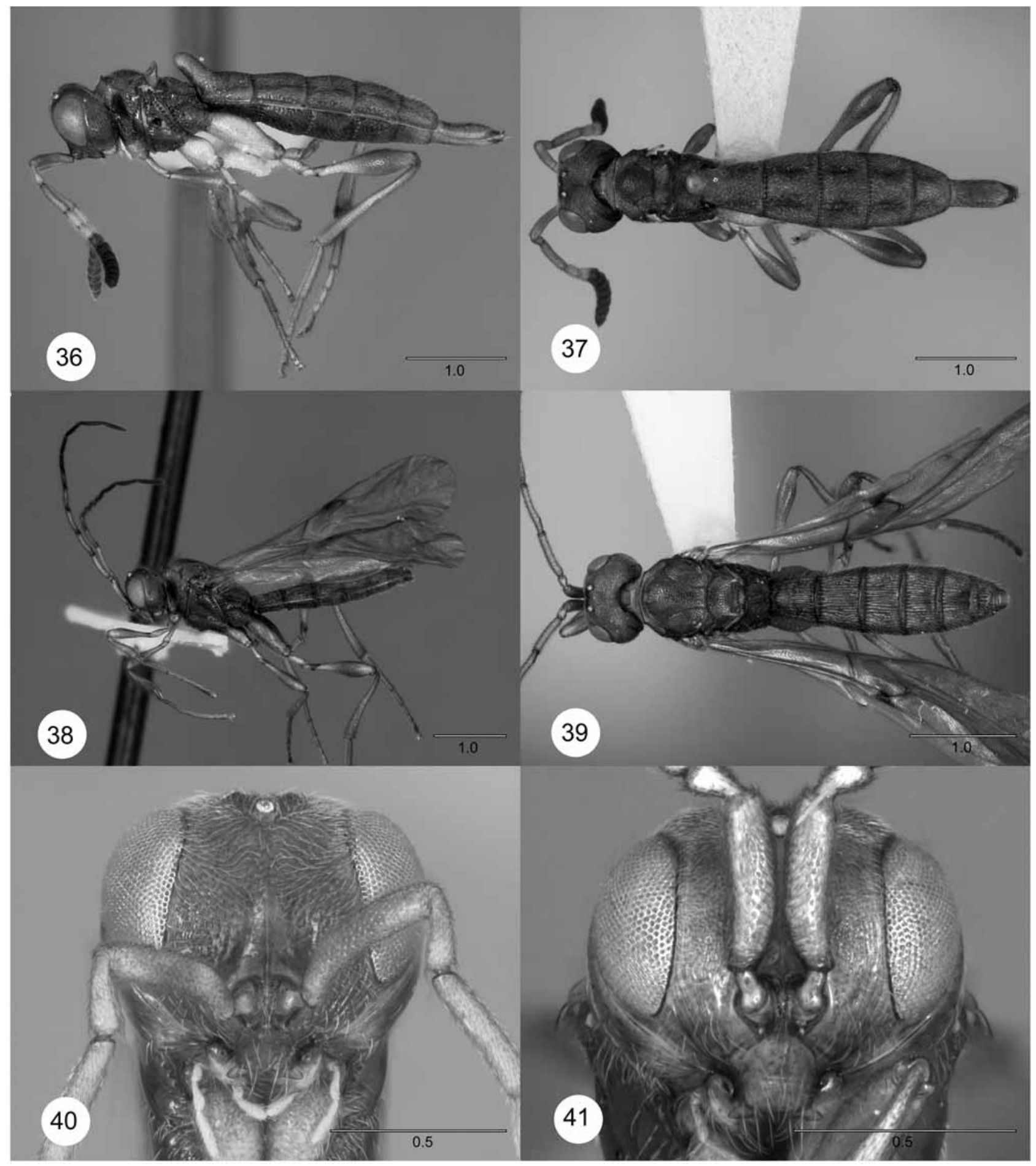

FIGURES 36-41. Archaeoteleia dispar n.sp. 36, Lateral habitus, paratype female (OSUC 146494); 37, dorsal habitus, paratype female (OSUC 146494); 38, lateral habitus, paratype male (OSUC 146499); 39, dorsal habitus, paratype male (OSUC 146499); 40, head, frontal view, paratype female (OSUC 146494); head, frontal view, paratype male (OSUC 146499). Scale bars in millimeters.

\section{Archaeoteleia gracilis Masner}

Figures 42-45

Archaeoteleia gracilis Masner 1968: 659. Original description. 
The original description (Masner 1968) may be supplemented as follows:

Head (Figs. 43-45): entirely smooth, shining, almost glabrous; eye glabrous; LOL slightly greater than OOL; occipital carina complete, finely crenulate; median keel weakly developed in lower half of frons; frontal striae along inner orbits not reaching midpoint of height of eye; clypeus smooth, lateral corners strongly protruding; toruli contiguous with upper margin of clypeus; A1 4.7 times as long as wide; A2 3.3 times as long as wide; A3 3.4 times as long as A2; claval formula A5-A12/1-2-2-2-2-2-2-1.

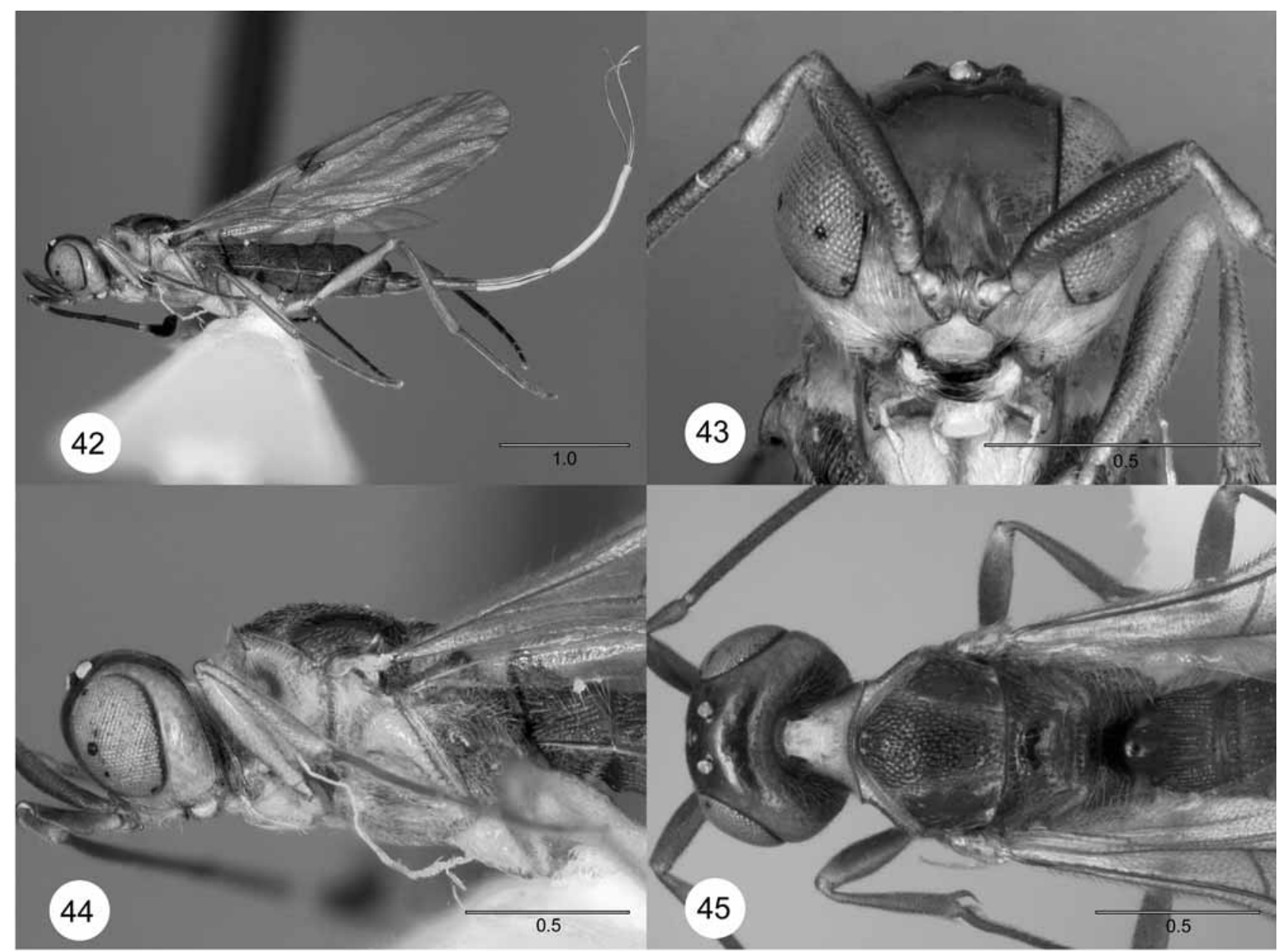

FIGURES 42-45. Archaeoteleia gracilis, female (OSUC 146517). 42, Lateral habitus; 43, head, frontal view; 44, head and mesosoma, lateral view; $\mathbf{4 5}$, head and mesosoma, dorsal view. Scale bars in millimeters.

Mesosoma (Figs. 44-45): transverse pronotal carina very sharply raised, arcuate; vertical epomial carina present; horizontal epomial carina present, pronotal shoulders moderately developed; side of pronotum with extensive smooth, shining field; netrion well developed, demarcated by anterior arc of deep foveae, finely sculptured, setose; lateral lobe of mesoscutum smooth, shining, almost completely glabrous, contrasting with heavy, even punctures on midlobe of mesoscutum; admedian lines well expressed; notauli subparallel; parapsidal line present, delicate; posterior margin of mesopleuron with complete chain of deep foveolae reaching ventrally to coxal cavity; metapleuron predominantly glabrous, with only very few small, scattered setae, shining, with row of foveolae along anterior margin and arcuate foveolar line at meson, roughly rugulose above hind coxa, smooth and shining medially; scutellum transverse, length 0.5 times length of mesoscutum, nearly smooth, setose scutellar spines straight, rather short, directed posteriorly; mesopleural carina indicated by two or three parallel, closely spaced rugulae; mesepisternum with distinct rugose punctation in epicnemial corner; acetabular carina fine; posterior margin of mesopleuron with complete foveolate chain extending ventrally to coxal cavity; metapleuron rugulose, densely setose ventrally, above medial line of foveae with narrow smooth, glabrous area, otherwise setose; propodeal keels well developed; fore wing 
strongly exceeding tip of metasoma, basal vein strongly pigmented, delicate infuscated cloud below marginal vein, postmarginal vein distinctly tracheate, length 3.3 times length of stigmal vein, stigmal vein nearly straight, Rs, M, Cu well-defined by nebulous streaks; hind basitarsus narrow, apex of hind coxa not extending beyond apex of S2, on posterior surface with irregular rugulosity and several transverse wrinkles above apex.

Metasoma (Figs. 42, 45) generally more elongate than A. simulans, length 3.4 times greatest width; T1 with very distinct horn, gently sloping anteriorly, most of surface smooth, without sculpture, in lateral view top of horn reaches top of scutellum, length 0.8 times width; length of T2 0.7 times width; length of T3 0.5 times width; length of T4 0.7 times width; length of T5 0.6 times width; sculpture of tergites, particularly T3$\mathrm{T} 5$, finely longitudinally rugulose, anterior margin of T2-T4 with row of very large foveolae; length of T6 1.0-1.4 times width, with fine scattered setigerous punctures.

Male. Very similar to female; length 2.6-2.9 mm; only A4 with keel.

Diagnosis: Distinguished from A. araucana by the punctate scutellum and median lobe of mesoscutum, this contrasting with the smooth lateral lobes of the mesoscutum..

Link to Distribution Map. [http://atbi.biosci.ohio-state.edu:210/hymenoptera/eol_scelionidae.content _page?page_level=3\&page_id=taxon_page_data\&page_version=4039\&page_option 1=M]

Material Examined: Holotype female: CHILE: Aisén, Puerto Cisnes, II.1961, L. Peña. Deposited in AEIC.

Paratypes: CHILE: male, female with same data as holotype, OSUC 151828 (AEIC), OSUC 146506 (CNCI); Bío-Bío, Contulmo, Arauco, 2.II.1953, L.E. Peña, male, OSUC 146507 (CNCI).

Other material: CHILE: Aisén, Puerto Cisnes, 44²5'S 7240'W, 16-28.II.1961, L.E. Peña, male, OSUC 146508 (CNCI).

Araucanía, $4.5 \mathrm{~km}$ W Los Portones entrance, 3749.25'S 7259.82'W, 1300 m, P.N. Nahuelbuta, Prov. de Malleco, 21.XII.1996-7.II.1997, A. Newton, M. Thayer, female, OSUC 146518 (CNCI); Monumento Natural Contulmo, 350 m, Puren, Malleco Prov., 11.XII.1984-13.II.1985, male, OSUC 146515 (CNCI); Nahuelbuta

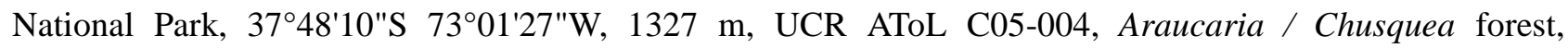
8.II.2005, male, OSUC 174431 (CNCI); Nahuelbuta National Park, 3749'42"S 7300'39"W, 1138 m, 89.II.2005, L. Masner, 5 males, 4 females, OSUC 203541-203549 (CNCI); Parque Nacional Nahuelbuta, 37.809 ${ }^{\circ}$ 73.016W, 3680 ft, 6-9.I.2000, D.K. Yeates, D. Webb, female, OSUC 146519 (CNCI).

Bío-Bío, Laraquete, S of Concepción, 10-25.I.1993, P. Salinas, female, OSUC 146517 (CNCI); Pata de Gallina, E of Contulmo, Arauco Prov., II.1989, P. Salinas, 2 males, female, OSUC 146514, 163618, 163619 (CNCI); playa, nr. Contulmo, Prov. de Arauco, 10-25.I.1993, P. Salinas, male, OSUC 146516 (CNCI).

Los Lagos, Lago Chapo, 200 m, Llanquihue, 16-19.II.1988, L. Masner, female, OSUC 55600 (OSUC); Ahoni Alto, Isla Chiloé, XII.1988-III.1989, L.E. Peña, female, OSUC 146513 (CNCI); Las Trancas, 500 m, 30 km W La Unión, Prov. de Valdivia, 25.II.1988, L. Masner, female, OSUC 146511 (CNCI); nr. Mafil, 150 m, Prov. de Valdivia, 26.II.1988, L. Masner, female, OSUC 146510 (CNCI); Parque Nacional Puyehue, 250 m, nr. Anticura, Prov. de Osorno, 14.II.1988, L. Masner, female, OSUC 146509 (CNCI); Río Puntra \& Rt.5, 100 m, Isla Chiloé, 24.II.1988, L. Masner, male, OSUC 146512 (CNCI).

Comments: The three species A. gracilis, A. simulans, and A. araucana are all very similar. Archaeoteleia gracilis has extremely long, slender legs and antennae, and of these three, has the longest metasoma. This species, together with A. mellea, are the only species so far known south of Chiloé Island.

\section{Archaeoteleia mellea Masner}

Figures 46-49

Archaeoteleia mellea Masner 1968: 656. Original description. Loiácono \& Díaz 1977: 96, description. 
The original description was based on a series of males. This may be supplemented now with data from the females.

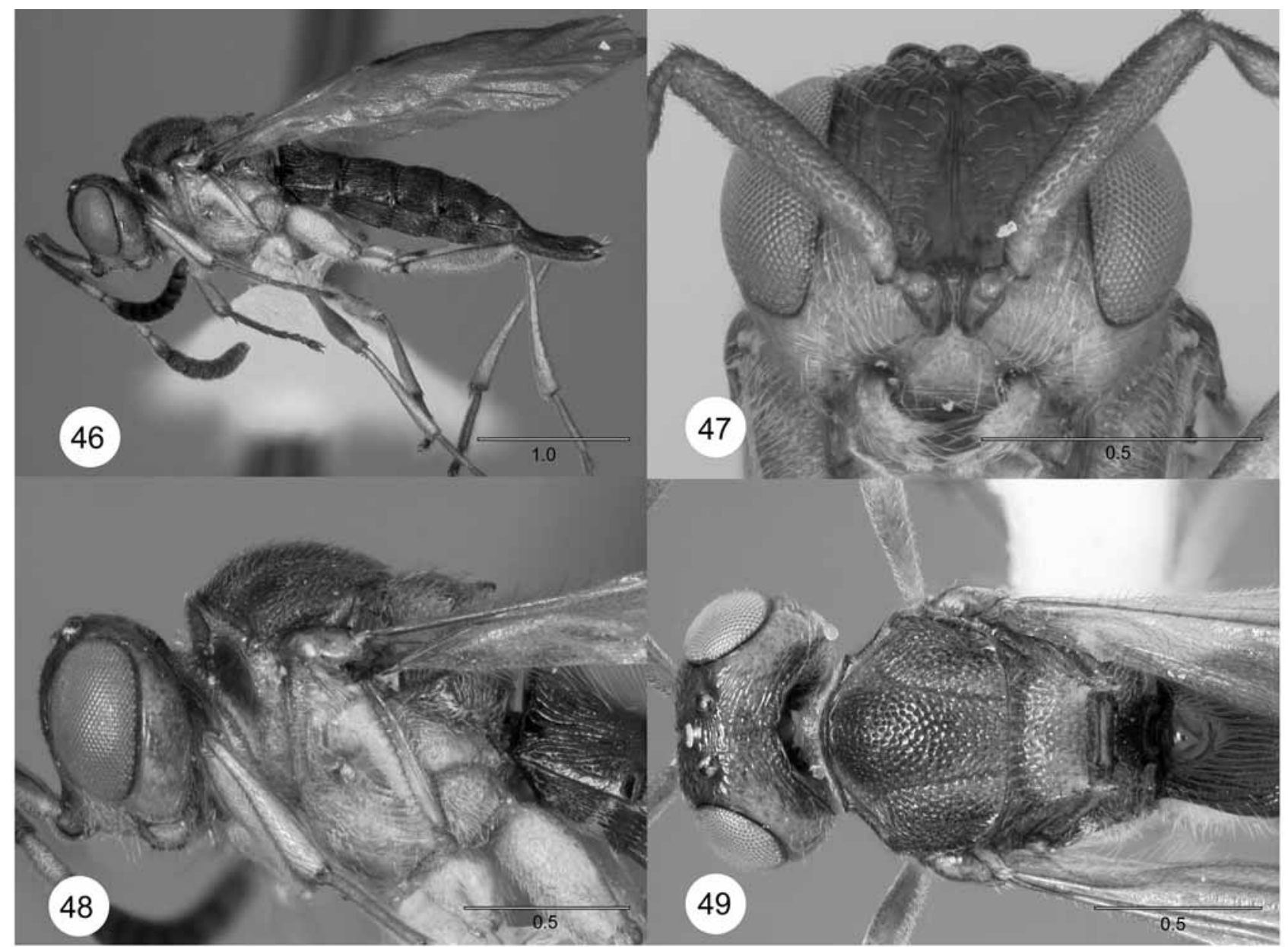

FIGURES 46-49. Archaeoteleia mellea, female (OSUC 163003). 46, Lateral habitus; 47, head, frontal view; 48, head and mesosoma, lateral view; 49, head and mesosoma, dorsal view. Scale bars in millimeters.

Description: Female. Length: 3.2-4.0 mm. Color generally light brown, sometimes varying to dark brown to black; A1-A5, legs, including coxae, mandibles, most of side of pronotum, mesopleuron, metapleuron lighter, yellowish brown; A6-A12, upper part of head, horn on T1 dark brown; wings clear, with only slight infuscation below marginal and stigmal veins; pseudostigma (begins at bulla, fills in space above venation) above marginal vein very dark brownish black, lighter in smaller specimens; dorsal portion of body, particularly metasoma, sometimes very dark brown to brownish black;

Head (Figs. 47-49): vertex, occiput, upper frons predominantly smooth, highly shining, with only few scattered setigerous fine punctures, in some specimens with occiput, vertex, upper frons with longitudinal rugulae on frons, transverse rugulae in ocellar triangle, diagonal rugulae on occiput; upper gena smooth, shining, almost glabrous; eye glabrous; LOL distinctly shorter than OOL, lateral ocellus located far from inner orbit; occipital carina strong, complete, finely crenulate at least medially, in some specimens crenulae strongly developed; frontal keel strong, continuing onto upper frons as shallow depression to anterior ocellus; facial striae strong, reaching inner orbit and extending dorsally to midpoint of eye; clypeus not particularly high, smooth, anterolateral corners weakly projecting; toruli confluent with dorsal margin of clypeus; A1 4.6-5.2 times as long as wide; A2 2.6 times as long as wide; A3 3.3 times as long as A2; flagellum with short setae; claval formula A5-A12/1-2-2-2-2-2-2-1.

Mesosoma (Figs. 48-49): transverse pronotal carina sharp, complete, almost straight, anterolateral corners angular, but not spikelike; vertical epomial carina sharp, complete, reaching anterior margin of lateral 
pronotum, from junction to ventral margin of lateral face with chain of large foveolae; horizontal epomial carina very sharp, shoulders narrow, punctured; lateral pronotum smooth, shining, glabrous; netrion well-defined by row of foveolae, with fine setigerous punctures; mesonotum entirely covered with dense, fine setigerous punctures, pilosity appressed; admedian lines absent; notaulus complete, deeply incised, foveolate; parapsidal line strongly developed, elevated; scutellum subrectangular, with same sculpture as mesoscutum, except somewhat sparser; scutellar spines sharp, slightly curved apically toward midline, slightly shorter than length of scutellar disk, in lateral view directed almost directly posteriorly; mesopleural carina not developed, but several horizontal grooves present on mesepisternum; mesopleuron largely smooth, shining, glabrous, upper portion, perfectly smooth, sometimes with horizontal striae reducing size of smooth area, mesepisternum predominantly smooth, shining, with only very few scattered hairs; acetabular carina fine, complete; row of foveolae along posterior margin of mesopleuron complete, reaching mid coxal cavity; metapleuron with more pilosity than mesepisternum, lower half of metapleuron above hind coxa distinctly more setose, with scattered fine punctures, arched line of deep foveolae mesally leaving fairly large smooth, glabrous, mirrorlike part of metapleuron above foveolae, carinae between metapleuron and propodeum present, complete; propodeum sides densely pilose, median keels well-developed, distinctly diverging ventrally, propodeum deeply excavate medially, excavation glabrous, with fine punctures; fore wing almost clear, slightly surpassing tip of metasoma; stigmal vein short, forming $45^{\circ}$ angle with costal margin, subequal in length to marginal vein, apex distinctly slanted backwards; postmarginal vein not developed, in one specimen with nebulous streak in position of postmarginal vein, $\mathrm{Cu}$, Rs, $\mathrm{M}$ nebulous, pigmented, basal vein strongly pigmented; legs slender, hind femur only slightly enlarged; spurs delicate; hind coxa either smooth or with weak transverse wrinkles.

Metasoma (Figs. 46, 49) moderately elongate, length 3.2-4.2 times width; length of T1 0.8 times width, horn only moderately developed, in lateral view not exceeding level of middle of propodeum, dorsal surface of horn smooth and shining, T1 otherwise longitudinally costate; length of T2 0.5 times width, entirely longitudinally costate; length of T3 0.5 times width, with row of deep foveolae along anterior margin, otherwise entirely longitudinally costate, sculpture irregular medially; length of T4 0.5 times width, with row of deep foveolae along anterior margin, longitudinally rugulose; length of T5 0.4 times width, posterior margin slightly excavate; T6 distinctly elongate, length 2.7-3.2 times width, with coarse longitudinal rugulosity, semierect setae, sometimes sculpture more confused.

Diagnosis: Archaeoteleia mellea is closest to A. penai and A. puncticeps, but has a complete, sharp, vertical epomial carina; the head is smooth and shining or with wrinkles (not punctation), extensively smooth and shining, and the male has a keel only on A4. Unlike A. puncticeps, in that it has some parts of body distinctly darker than the rest, especially the dorsum of the mesosoma and the metasoma.

Link to Distribution Map. [http://atbi.biosci.ohio-state.edu:210/hymenoptera/eol_scelionidae.content _page?page_level=3\&page_id=taxon_page_data\&page_version=4040\&page_option 1=M]

Material Examined: Holotype male: CHILE: Aisén, Puerto Cisnes, II.1961, L. Peña. Deposited in AEIC.

Paratypes: CHILE: Aisén, Puerto Cisnes, 4445'S 7240'W, 16-28.II.1961, II.1961, L.E. Peña, 5 males, OSUC 146526, 146528 (CNCI), OSUC 151823, 151825, 151826 (AEIC).

Los Lagos, Neltume, Prov. de Valdivia, 3.III.1955, L.E. Peña, male, OSUC 146527 (CNCI); Dalcahue, Chiloé Isl., 17.I-14.II.1962, L.E. Peña, male, OSUC 151827 (AEIC).

Other material: CHILE: Araucanía, 10 km S Pucón, 900 m, Nothofagus grove on ash, Villarrica N.P., Cautín Prov., 15.XII.1984-10.II.1985, J. Peck, S. Peck, 2 males, 5 females, OSUC 146561, 203578-203582, 203584 (CNCI); $4.5 \mathrm{~km} \mathrm{~W}$ Los Portones entrance, 3749.25'S 7259.82'W, 1300 m, P.N. Nahuelbuta, Prov. de Malleco, 21.XII.1996-7.II.1997, A. Newton, M. Thayer, male, OSUC 146567 (CNCI); Conguillío National Park, 1150 m, Araucaria / Nothofagus, Cautín Prov., 4-5.II.1988, L. Masner, male, OSUC 146553 (CNCI); Conguillío National Park, 1150 m, Nothofagus, Cautín Prov., 4-5.II.1988, L. Masner, 21 males, 10 females, OSUC 192933-192940, 203327-203331, 203368, 203369, 203424-203439 (CNCI); Conguillío National Park, 38³8'56"S 71³9'49"W, 1214 m, UCR AToL C05-010, Araucaria / Nothofagus forest, 11-24.II.2005, 
male, OSUC 174438 (CNCI); Cordillera de Nahuelbuta, 1100m, Cabreria, 20-21.I.1977, L.E. Peña, male, OSUC 146566 (CNCI); Flor del Lago, 300 m, Nothofagus forest, 15 km NE Villarrica, Cautín Prov., 14.XII.1984-10.II.1985, J. Peck, S. Peck, male, OSUC 146530 (CNCI); La Princesa Waterfall, 1000 m, Nothofagus forest, 20 km E Curacautín, Malleco Prov., 12.XII.1984-16.II.1985, J. Peck, S. Peck, 2 females, OSUC 146558, 203583 (CNCI); Lago Caburgua, 600 m, mixed forest remnant, $21 \mathrm{~km}$ NE Pucón, Cautín Prov., 15.XII.1984-10.II.1985, J. Peck, S. Peck, male, female, OSUC 146532, 203560 (CNCI); Lake Villarrica, 310m, Valdivian forest, Bellavista, Cautín Prov., 15-30.XII.1982, A. Newton, M. Thayer, 2 females, OSUC 146529, 163003 (CNCI); Monte Verde, Carahue, Prov. de Cautín, 29.I-2.II.1993, L.E. Peña, 4 males, female, OSUC 146544, 203534-203536, 203559 (CNCI); Monumento Natural Contulmo, 350 m, Puren, Malleco Prov., 11.XII.1984-13.II.1985, J. Peck, S. Peck, female, OSUC 146559 (CNCI); Nahuelbuta National Park, 1200-1500 m, Araucaria / Nothofagus forest, 40 km W Angol, 9.XII.1984-17.II.1985, J. Peck, S. Peck, male, OSUC 146531 (CNCI); Nahuelbuta National Park, 3748'10"S 7301'27"W, 1327 m, UCR AToL C05-004, Araucaria / Chusquea forest, 8.II.2005, male, OSUC 174434 (CNCI); Nahuelbuta National Park, 3748'54"S 7300'44"W, 1288 m, UCR AToL C05-007, open scrub Nothofagus forest, 9.II.2005, female, OSUC 174439 (CNCI); Nahuelbuta National Park, 3749'42"S 7300'39"W, 1138 m, 8-9.II.2005, L. Masner, male, OSUC 203540 (CNCI); Parque Nacional Nahuelbuta, 1200-1500 m, 40 km W Angol, 8.XII.1984-17.II.1985, J. Peck, S. Peck, male, female, OSUC 203585, 203586 (CNCI); Parque Nacional Nahuelbuta, $37.809^{\circ} \mathrm{S} 73.016^{\circ} \mathrm{W}, 3680$ ft, 9-12.I.2000, D. K. Yeates, D. W. Webb, male, OSUC 146568 (CNCI); Purén, 350 m, mixed evergreen forest, Contulmo N.M., Malleco Prov., 11.XII.1984-13.II.1985, J. Peck, S. Peck, male, OSUC 203561 (CNCI); Río Blanco, Prov. de Cautín, 5-20.I.1996, T. Cekalovic, 4 males, OSUC 203596-203599 (CNCI); Villarrica Volcano, 39²3.27'S 7157.82'W, $1390 \mathrm{~m}$, stunted Nothofagus pumilo forest, road to ski center, Villarrica N.P., Cautín Prov., 27.XII.1996-3.II.1997, A. Newton, M. Thayer, male, OSUC 146542 (CNCI);

Bío-Bío, Las Trancas, 1250 m, 19.5 km ESE Recinto, Prov. de Ñuble, 8-11.II.1988, L. Masner, male, OSUC 192692 (CNCI); Pata de Gallina, E of Contulmo, Arauco Prov., II.1989, P. Salinas, 2 males, 2 females, OSUC 146543, 203520, 203521, 203556 (CNCI);

Los Lagos, $0.6 \mathrm{~km}$ W route to Miraflores, $42^{\circ} 46.74 ' \mathrm{~S} 73^{\circ} 47.70^{\prime} \mathrm{W}, 130 \mathrm{~m}$, secondary Valdivian rainforest with few conifers, Chiloé Isl., 12-21.XII.2002, Newton, Thayer, et al., male, female OSUC 146564, 203538 (CNCI); $11 \mathrm{~km} \mathrm{~W}$ Quemchi, $42^{\circ} 10.40^{\prime} \mathrm{S} 73^{\circ} 35.73^{\prime} \mathrm{W}, 140 \mathrm{~m}, 2002-066$, Valdivian forest remnant with thick bamboo understory, Chiloé Prov., 10-21.XII.2002, Clarke, Newton, Thayer, male, OSUC 146541 (CNCI); $14.5 \mathrm{~km}$ W Puaucho, 40³7'S 7345'W, 175 m, Prov. de Osorno, 11-28.XI.1994, R. Leschen, male, OSUC 146546 (CNCI); 2.5 km SSW Puerto Fui, L. Pirehuico, Prov. Valdivia, 160 m, 25-28.XI.1988, A. Ashworth, male, OSUC 146562 (CNCI); 30 km W La Unión, 600 m, Prov. de Valdivia, 10-11.II.1988, L. Masner, male, OSUC 151836 (AEIC); 34 km WNW La Unión, 700 m, mixed evergreen forest, Valdivia Prov., 17.XII.19847.II.1985, J. Peck, S. Peck, 2 females, OSUC 146540, 203539 (CNCI); 34 km WNW La Unión, 700 m, Valdivia Prov., 17.XII.1984-7.II.1985, J. Peck, S. Peck, 2 males, 6 females, OSUC 203562-203569 (CNCI); 37 km SE Chaitén, 60 m, riverside / 2nd forest, Palena Prov., 28.XII.1984-30.I.1985, J. Peck, S. Peck, 5 males, 1 female, OSUC 146560, 203570-203574 (CNCI); 37 km SE Chaitén, 700 m, mixed evergreen forest, Palena Prov., 17.XII.1984-7.II.1985, J. Peck, S. Peck, 3 females, OSUC 203575-203577 (CNCI); 4 km E Anticura, 430 m, Prov. de Osorno, 19-24.XII.1982, A. Newton, M. Thayer, male, OSUC 146534 (CNCI); 6 km NW Choshuenco, Puente Blanco, Prov. Valdivia, 180 m, 3-6.XII.1987, A. Ashworth, female, OSUC 146563 (CNCI); 8 km S Ancud, forest remnant litter, Chiloé Isl., 1.II.1985, J. Peck, S. Peck, female, OSUC 146535 (CNCI); Aguas Calientes Hot Springs, 600 m, Nothofagus forest, Puyehue N.P., Osorno Prov., 18.XII.1984-8.II.1985, J. Peck, S. Peck, 2 females, OSUC 146538, 203533 (CNCI); Ahoni, 70m, primary forest, Isla Chiloé, II.1988, 21.II.1988, 22.II.1988, 23.II.1988, IV.1988, V.1988, L. Masner, 55 males, 36 females, OSUC 146551, 163631, 163633, 192474-192484, 192665-192675, 192925-192932, 203464-203485, 203487-203519, 203526-203528 (CNCI); Ahoni, Isla Chiloé, 3-15.II.1995, A. Ugarte, 3 males, OSUC 
146548, 203557, 203558 (CNCI); Ahoni, primary forest, Chiloé Isl., XII.1988-III.1989, L.E. Peña, female, OSUC 203537 (CNCI); Ahoni, primary forest, Chiloé Isl., IX.1988, L.E. Peña, 2 males, 2 females, OSUC 203552-203555 (CNCI); Alerce Costero National Monument, 40¹1'38"S 73²6'02"W, 938 m, UCR AToL C05-026, mature Fitzroyia forest, W of La Unión, 19.II.2005, male, OSUC 174432 (CNCI); Anticura, 40³9'53"S 72¹0'02"W, 447m, UCR AToL C05-022, Nothofagus / Chusqueia forest, Puyehue N.P., Repucura Path, 17.II.2005, male, OSUC 174435 (CNCI); El Chingue, 200m, Nothofagus forest, nr. Correntoso, Llanquihue Prov., 18.II.1988, L. Masner, 9 males, OSUC 203446-203454 (CNCI); El Chingue, Lago Chapo, Prov. de Llanquihue, IV-V.1990, VI-IX.1990, L.E. Peña, 3 males, 2 females, OSUC 146556, 203524, $203593-$ 203595 (CNCI); Lago Chapo, 200 m, Prov. de Llanquihue, 16-19.II.1988, L. Masner, male, OSUC 55601 (OSUC); Laguna Sargazo, 150 m, vegetation along track, Alerce Andino N.P., 18.I.1986, N. A. Deans, 3 males, OSUC 163626-163628 (LUNZ); Lake Chapo, 200m, Nothofagus forest, Llanquihue Prov., 1619.II.1988, L. Masner, 49 males, 7 females, OSUC 146536, 192435-192445, 192447-192457, 192965192991, 192994, 192995, 192997-193000 (CNCI); Las Lajas, W of La Unión, Prov. de Valdivia, 9-13.I.1990, L.E. Peña, male, OSUC 146557 (CNCI); Las Trancas, 500m, Nothofagus, 30 km W La Unión, Valdivia Prov., 7.II.1988, 7-11.II.1988, 7-12.II.1988, 8-11.II.1988, 11-24.II.1988, 25.II.1988, L. Masner, 117 males, 35 females, OSUC 146550, 163632, 163634, 192676-192679, 192681-192691, 192693, 192941-192964, 203209-203281, 203304, 203332-203367 (CNCI); Las Trancas, 500m, Nothofagus, 30 km W La Unión, Valdivia Prov., II.1990, P. Salinas, 2 males, OSUC 203550, 203551 (CNCI); Las Trancas, Dept. de La Unión, I.1995, A. Ugarte, female, OSUC 146549 (CNCI); Mirador, 40¹0'12"S 73³0'00"W, 1004 m, UCR AToL C05-027, recovering Fitzroyia forest, Alerce Costero N.M., 19-20.II.2005, female, OSUC 174436 (CNCI); N of Correntoso, El Chingue, Prov. de Llanquihue, IV-V.1989, IV-V.1990, L.E. Peña, 4 males, 6 females, OSUC 146555, 203522, 203523, 203525, 203587-203592 (CNCI); nr. Lake Chapo, 200m, Nothofagus forest, Llanquihue Prov., 16-19.II.1988, 18.II.1988, L. Masner, 113 males, 13 females, OSUC 192485-192489, 192491-192499, 192558-192586, 192588-192600, 192640-192654, 192656-192695, 203282-203303, 203305-203309, 203311-203326, 203445, 203463 (CNCI); nr. Máfil, 150 m, forest floor, Valdivia Prov., 26.II.1988, L. Masner, male, OSUC 192694 (CNCI); Parque Nacional Chiloé, 42²0'S 747'W, sea level, Isla Chiloé, 11-12.XII.2002, L. Masner, male, OSUC 146565 (CNCI); Piopio, Isla Chiloé, 3-15.II.1995, A. Ugarte, male, OSUC 146547 (CNCI); Puntra River, 100 m, Nothofagus forest, Route 5, Chiloé Isl., 24.II.1988, L. Masner, 7 males, 2 females, OSUC 146554, 203455, 203456-203462 (CNCI); Puyehue National Park, 250 m, Nothofagus forest, nr. Anticura, Osorno Prov., 12-13.II.1988, 12-14.II.1988, 14.II.1988, L. Masner, 4 males, OSUC 203529-203532 (CNCI); S side of Huillinco Lake, 42 $41.81^{\prime}$ S $73^{\circ} 55.88^{\prime} \mathrm{W}, 45 \mathrm{~m}$, \#2002-072, Valdivian rainforest with emergent Saxegothaea conspicua, road to Bellavista, 1.3km S road to Cucao, Chiloé Prov., 12-22.XII.2002, Chani, Newton, Thayer, male, OSUC 146539 (CNCI); Terao, 4242'22"S 7339'12"W, 10 m, UCR AToL C05-016, beach / shrub forest, 10km S Chonchi, Chiloé Isl., 13.II.2005, male, OSUC 174433 (CNCI); Terao, 4243'01"S 73³8'47"W, 45 m, UCR AToL C05-013, 10 km S Chonchi, Chiloé Is1., 12-13.II.2005, male, OSUC 174437 (CNCI); Terao, 50m, 2nd growth forest, nr. Chonchi, Chiloé Isl., 21-23.II.1988, L. Masner, 51 males, 39 females, OSUC 146537, 146552, 192458-192473, 192696-192700, 203201-203208, 203370-203423, 203440-203444 (CNCI); of La Unión, Prov. de Osorno, III.1987, L.E. Peña, male, OSUC 146533 (CNCI).

Río Cruces, S of Concepción, XII.1994, P. Salinas, male, OSUC 146545 (CNCI).

Remarks: Archaeoteleia mellea is a common crepuscular species: numbers of individuals were caught near Lago Chapo by L. Masner in yellow pan traps. The peak of activity fell between 8-10 P.M. (in February, therefore still with some light at that latitude). From 10 P.M. to midnight very few specimens were collected. 


\section{Archaeoteleia penai Masner, new species}

Figures 50-53

Description: Female. Length 2.9-2.95 mm. Color: generally ochraceous; antennal clava almost black; legs, A1-A5, lower frons, side of pronotum, most of mesopleuron, legs including coxae, yellowish; propodeum and tip of horn on T1 dark brown.

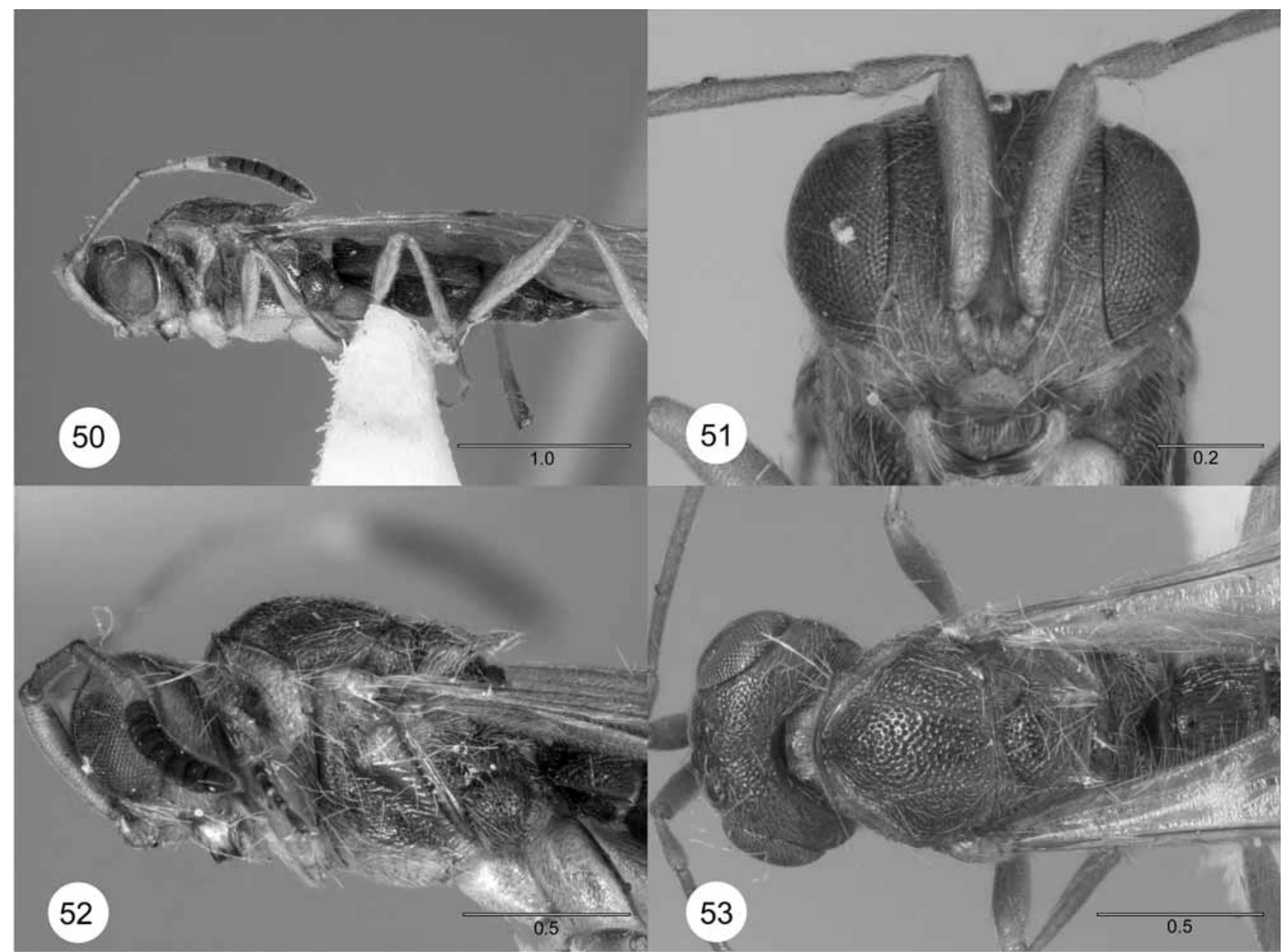

FIGURES 50-53. Archaeoteleia penai, n.sp., paratype female (OSUC 146581). 50, Lateral habitus; 51, head, frontal view; 52, head and mesosoma, lateral view; 53, head and mesosoma, dorsal view. Scale bars in millimeters.

Head (Figs. 51-53): vertex, occiput, entire frons, upper gena rugose punctate with fine, appressed pilosity; eye glabrous; LOL greater than OOL, ocellar triangle broad; occipital carina well-developed, moderately foveolate medially, weakly so at sides, complete; central keel very short, delicate; facial striae fine, dense, reaching inner orbits; clypeus slightly higher than wide, predominantly smooth, anterolateral corners weakly projecting; rim of torulus confluent with dorsal margin of clypeus; A1 5.2 times as long as wide; A2 3.2 times as long as wide; A3 3.7 times as long as A2; flagellum with fairly short setae; claval formula A6-A12/2-2-22-2-2-1.

Mesosoma (Figs. 52-53): transverse pronotal carina sharp, gently arcuate, anterolateral corners angular, but not spikelike raised; vertical epomial carina absent or only a rudiment present dorsally; horizontal epomial carina sharp, pronotal shoulders relatively broad, deeply punctate; lateral pronotum almost entirely sculptured, punctured; netrion well developed, with fine appressed pilosity, densely punctured; mesonotum moderately convex, almost glabrous, with only few short appressed setae, evenly and densely thimblelike punctured; admedian lines present, very short; notaulus complete, deeply incised; parapsidal line absent; transscutal articulation distinct, margined posteriorly by foveolae; scutellum transverse, length 0.5 times length of mesoscu- 
tum, densely punctate, setose; scutellar spines sharp, slightly shorter than scutellar disk, pointed, directed posteriorly; mesopleural carina absent; mesopleuron entirely sculptured, without smooth areas, mesepimeron, mesepisternum with subhorizontal dense rugulae; acetabular carina fine, crenulate; posterior margin of mesopleuron with chain of foveolae extending ventrally to mid coxal cavity; lower half of metapleuron densely punctured, upper portion with small smooth area, entire metapleuron only sparsely hairy; propodeum rugose punctate, with shallow medial excavation, finely punctured; median keels fine, complete; fore wing widely surpassing apex of metasoma, almost clear, without cloud of pigmentation below stigma; $\mathrm{M}$, basal vein well indicated; $\mathrm{Cu}, \mathrm{M}$, Rs vaguely infuscate; marginal vein very thick, subtriangular, markedly darkened; postmarginal vein completely absent; stigmal vein forming 45 angle, not hooked apically, very weakly arched; legs long and slender; inner surface of hind coxa with strong diagonal striae.

Metasoma (Figs. 50, 53) relatively short; length 3.2 times width; T1 relatively short, length 0.7 times width, with only slight smooth horn anteromedially, in lateral view horn not exceeding upper margin of propodeum, $\mathrm{T} 1$ otherwise longitudinally costate; length of T2 0.5 times width; length of T3 0.5 times width; length of T4 0.5 times width; T2-T4 longitudinally costate; length of T5 0.6 times width; length of T6 equal to width; T5-T6 predominantly punctured.

Male unknown.

Diagnosis. Closest to A. mellea and A. puncticeps, but distinguished by its small, gracile body and the relatively long and slender appendages. The length of T6 is equal to its width, and the horn on $\mathrm{T} 1$ is relatively weakly developed, not surpassing the upper margin of the propodeum. The most salient combination of features to separate A. penai from all other species is the thimblelike sculpture of the mesonotum, entirely sculptured mesopleuron, small hump on T1, and the short, nipplelike T6.

Etymology. Named in memory of Luís E. Peña, distinguished Chilean entomologist and naturalist, and the collector of both specimens.

Link to Distribution Map. [http://atbi.biosci.ohio-state.edu:210/hymenoptera/eol_scelionidae.content _page?page_level=3\&page_id=taxon_page_data\&page_version=190985\&page_option1=M]

Material examined. Holotype female: CHILE: Maule, Las Cruces, Cordillera Parral, Oct. 1958, L. Peña, OSUC 146580. Deposited in CNCI.

Paratype: CHILE: One female with same data as holotype, OSUC 146581 (CNCI).

\section{Archaeoteleia puncticeps Masner, new species}

Figures 54-57

Description: Female. Length $3.75 \mathrm{~mm}$. Color: entire body, including top of horn, yellowish brown; antennal clava gradually darkened toward apex, A6 yellow, A7 darker, A9-A12 dark brown, antenna otherwise yellowish brown.

Head (Figs. 55-57): vertex, occiput, frons, gena entirely and evenly rugose punctate, with no parts of head left smooth, head covered with dense, appressed, fine pilosity; eye very sparsely setose; LOL slightly greater than OOL; occipital carina indistinctly crenulate; frontal keel delicate, disappearing dorsally amidst dense sculpture; facial striae fine, extending to middle of inner orbit; clypeus smooth, lateral corners strongly protruding; toruli contiguous with upper margin of clypeus; A1 5.0 times as long as wide; A2 2.4 times as wide as long; A3 3.1 times as long as A2; claval formula A5-A12/1-2-2-2-2-2-2-1.

Mesosoma (Figs. 56-57): transverse pronotal carina distinctly arched, anterolateral corners not pronounced; vertical epomial carina absent; horizontal epomial carina strongly approximated to mesoscutum, leaving very narrow pronotal shoulders; lateral pronotum with delicate, reticulate microsculpture, fine pilosity; netrion well developed, demarcated by anterior arc of deep foveae; mesonotum evenly, thimblelike punctured; admedian lines absent; notaulus complete, foveolate; parapsidal line fairly well impressed, rather long; 
transscutal articulation well indicated, crenulate laterally; scutellum transverse, length 0.5 times length of mesoscutum, punctate, setose; scutellar spines straight, not curved toward midline; mesopleural carina absent; upper portion of mesepisternum with large, smooth glabrous area, lower portion of mesepisternum with irregular rugulosity in epicnemial area; row of foveolae along posterior margin of mesopleuron complete, reaching mid coxal cavity; metapleuron rugulose, densely setose ventrally, above medial line of foveae with narrow smooth, glabrous area, otherwise setose; propodeum with longitudinal keels, sparsely setose; fore wing barely surpassing apex of metasoma, almost clear, with distinct cloud of pigmentation below stigma; M, basal vein well indicated; $\mathrm{Cu}, \mathrm{M}$, Rs vaguely infuscate; marginal vein very thick, subtriangular, markedly darkened; postmarginal vein absent; stigmal vein forming 45 angle, hooked apically, weakly arched; hind basitarsus long, narrow; hind coxa of normal size, posterior surface punctured.

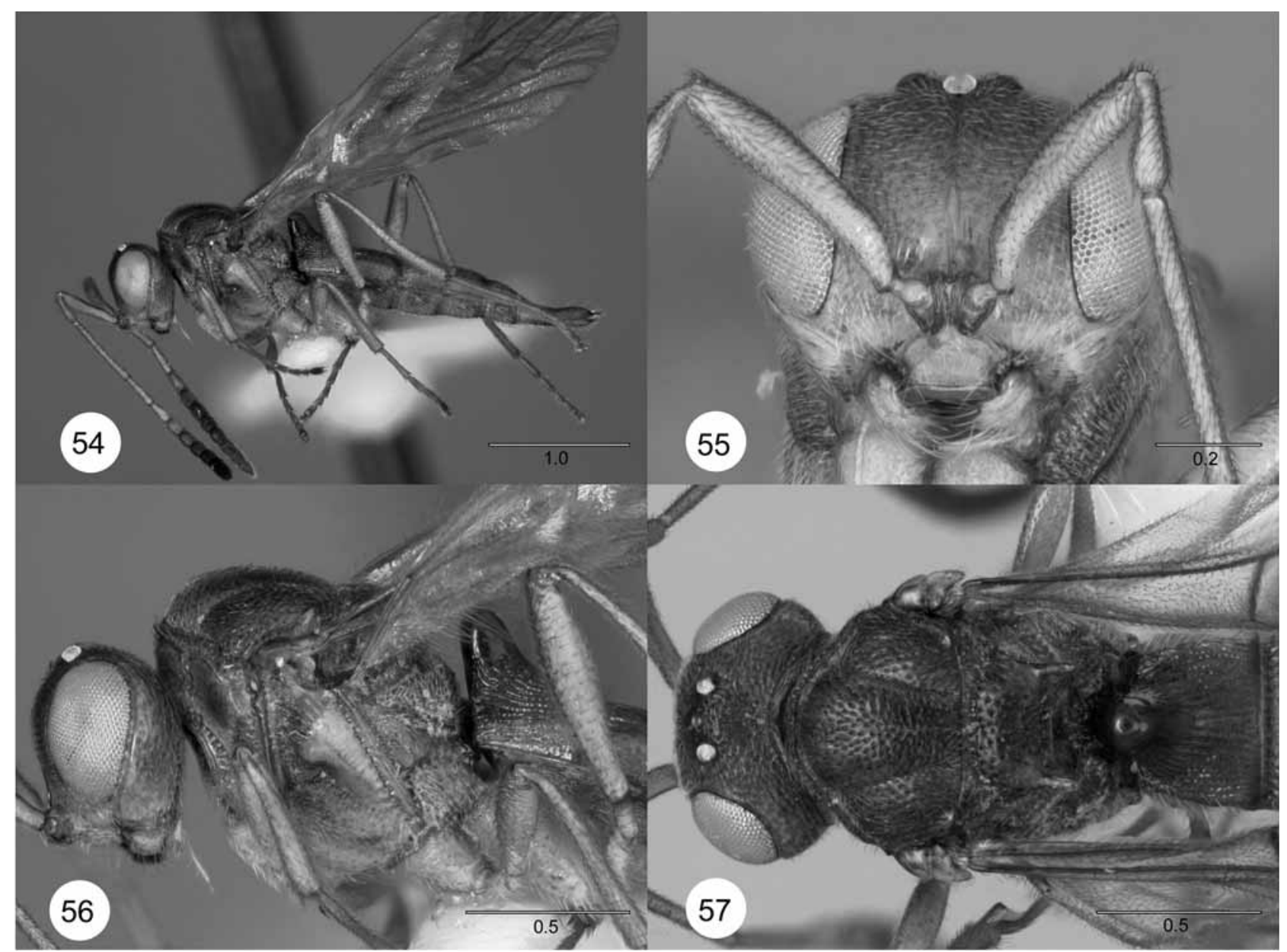

FIGURES 54-57. Archaeoteleia puncticeps, n.sp., paratype female (OSUC 146578). 54, Lateral habitus; 55, head, frontal view; 56, head and mesosoma, lateral view; 57, head and mesosoma, dorsal view.

Metasoma (Figs. 54, 57) slender, elongate, length 3.8 times width; length of $\mathrm{T} 1$ very slightly greater than width, in lateral view top of horn reaching level of scutellum, apex of horn smooth, T1 otherwise longitudinally rugulose, with microsculpture in furrows between rugulae; length of T2 0.8 times width; length of T3 0.7 times width; length of T4 0.6 times width; length of T5 0.5 times width, with fine longitudinal rugosity, posterior margin distinctly excavate; T3-T5 with distinct basal row of foveolae; T6 distinctly elongate, length 3.2 times width, with fine longitudinal rugulae in anterior half, otherwise smooth with scattered punctures.

Male. Very similar to female and to the male of A. mellea, except both A4 and A5 with longitudinal keels, keel on A5 shorter than on A4, keel on A4 does not exceed basal one-third of segment; length of A1 3.9 times width; length of A2 1.7 times width; length of A3 1.8 times length of A1.

Diagnosis. Distinguished from A. penai and A. mellea by the uniformly yellowish brown color of the 
body; the entire head is rugose punctate, without smooth areas; the vertical epomial carina is absent; the metasoma is more elongate; and male A5 with keel. The side of the pronotum is smooth or very delicately sculptured, unlike the punctured surface of $A$. penai.

Etymology. The specific epithet puncticeps refers to the sculpture of the head.

Link to Distribution Map. [http://atbi.biosci.ohio-state.edu:210/hymenoptera/eol_scelionidae.content _page?page_level=3\&page_id=taxon_page_data\&page_version=190984\&page_option1=M]

Material examined. Holotype female: CHILE: Bío-Bío, Arauco, E of Contulmo, Pata de Gallina, II.1989, P. Salinas, pan trap, OSUC 174391. Deposited in CNCI.

Paratypes: CHILE: Araucanía, 4.5 km W Los Portones entrance, 3749.25'S 7259.82'W, 1300 m, P.N. Nahuelbuta, Prov. de Malleco, 21.XII-7.II.1997, A. Newton, M. Thayer, female, OSUC 146579 (CNCI); E of Guardería Pinchinahuel, 3748.20'S 7301.41'W, 1290 m, P.N. Nahuelbuta, Prov. de Malleco, 5-24.XII.2002, A. Newton, M. Thayer, female, OSUC 174440 (CNCI).

Bío-Bío, Laraquete, S of Concepción, 10-25.I.1993, P. Salinas, female, OSUC 146578 (CNCI); Pata de Gallina, E of Contulmo, Arauco Prov., 10-25.I.1993, II.1989, P. Salinas, 104 males, 40 females, OSUC 146577, 163635, 163636, 174392, 203621-203678, 203681-203747 (CNCI).

\section{Archaeoteleia pygmea Masner}

Figures 58-63

Archaeoteleia pygmea Masner 1968: 660. Original description. Sarazin 1986: 978 (type information).

The original description was based solely on males. It may be supplemented by data from the females:

Female. Length 2.2-3.1 mm. Color: castaneous brown, never with submetallic tinge; antenna abruptly bicolored, A1-A5 bright yellow, A6-A12 nearly black; legs, including coxae, entirely yellow; dorsal part of pronotum, including epomial corners, yellow; lower portion of pronotum, mesopleuron, metapleuron, S1-S2 dark brown to nearly black.

Head (Figs. 58, 59, 62): vertex, occiput, upper frons rugose punctate, punctures bearing short, appressed setae; sculpture along inner orbits with longitudinal rugulosity, central part of frons punctate; upper gena almost smooth, shining; LOL greater than OOL; occipital carina fine, complete, not distinctly crenulate; frons with strong median keel running slightly over half distance from interantennal process to median ocellus; striae of cheeks and face strong, reaching inner orbits; clypeus strongly transversely striate, anterolateral corners strongly projecting, with long erect setae; toruli contiguous with upper margin of clypeus; A1 5.3 times as long as wide; A2 2.7 times as long as wide; A3 1.1 times as long as A2; claval formula A6-A12/2-2-2-2-22-1.

Mesosoma (Figs. 58, 59): transverse pronotal carina extremely sharp, bladelike, produced medially into broad point, with anterolateral corners sharply produced, pointed; vertical epomial carina absent; horizontal epomial carina close to mesoscutum, and shoulders narrow, maximum width about 0.5 tegula width; lateral pronotum predominantly smooth, highly shining, largely glabrous, area above fore coxa with irregular, large, transverse rugulae; netrion vaguely indicated; mesoscutum highly convex, with dense, fine pilosity, interspersed with few, long erect setae, densely punctured, interstices smooth, without microsculpture; admedian lines absent; notaulus absent; parapsidal line absent; transscutal articulation well indicated, crenulate laterally; length of scutellum 0.8-0.9 times length of mesoscutum; scutellar spines curved posteriorly; mesopleural carina running almost in middle of mesopleuron, smooth and shining above; mesopleuron almost entirely glabrous, smooth, shining, without microsculpture, with row of deep foveolae along posterior margin; mesepisternum below mesopleural carina almost glabrous, smooth and shining; acetabular carina present, crenulate; metapleuron densely hairy, with rough rugulosity and deep punctures, without glabrous area; pro- 
podeum with shallow excavation medially, punctured, with distinctly finer sculpture than lateral propodeum; submedial carinae present, not projecting, not sharp, abbreviated posteriorly; tegula absent; wings entirely absent; legs relatively short, robust; pretarsal claws very strongly developed.

Metasoma (Figs. 58, 59) short, broadened medially, length 2.1 times greatest width, without bristles amid shorter, semidecumbent pilosity; length of T1 0.5 times width, T1 hump low, distinctly below level of mesoscutum, not higher than propodeum, laterally with longitudinal rugulae, apex of horn smooth, behind horn with confused rugulae; length of T2 0.6 times width, longitudinally rugulose, without interspersed deep punctures; length of T3 0.4 times width; length of T4 0.4 times width; length of T5 0.3-0.4 times width; length of T6 $0.8-1.1$ times width, densely setose.

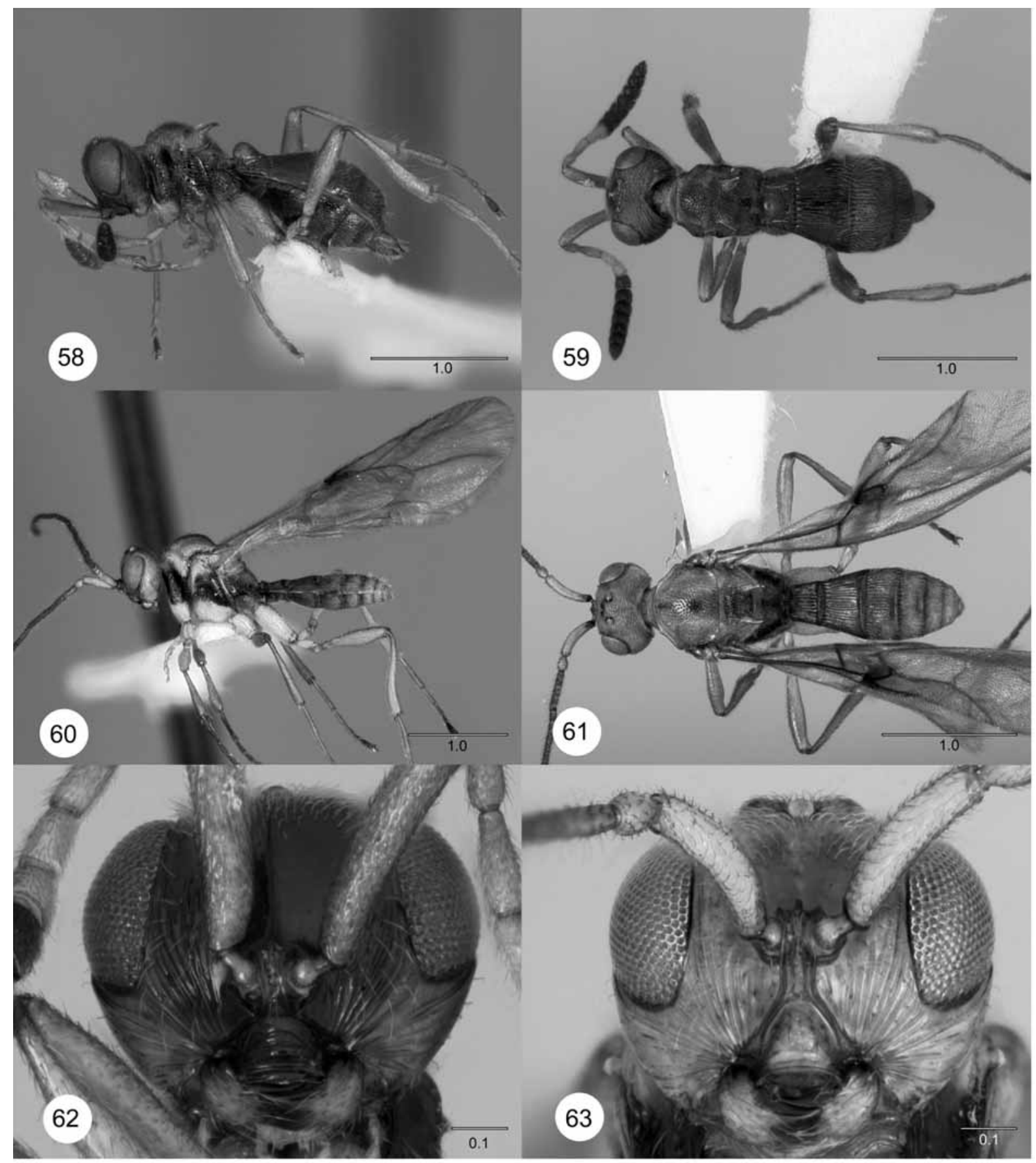

FIGURES 58-63. Archaeoteleia Pygmea. 58, Lateral Habitus, Female (OSUC 146604); 59, Dorsal Habitus, Female (OSUC 146604); 60, lateral habitus, male (OSUC 163136); 61, dorsal habitus, male (OSUC 163136); 62, head, frontal view, female (OSUC 146604); 63, head, frontal view, male (OSUC 163136). Scale bars in millimeters. 
Male. The original description may be supplemented as follows: antennal toruli broadly separated from top of clypeus (Fig. 63); "epistomal suture" dorsoventral, running down to clypeal triangle, in form of distinct raised keel; scutellar spine as long as length of disk of scutellum, curved inward toward midline of body, slender, long, subparallel (Figs. 60, 61); no keels on propodeum; fore wing with faint pigmented cloud beneath marginal and stigmal veins (Figs. 60, 61).

Diagnosis. The macropterous male is distinguished from all other species of Archaeoteleia by the position of the toruli. These are distinctly separated from the dorsal margin of the clypeus (Fig. 63). The brachypterous female is most similar to A. submetallica, from which it may be separated by the shorter metasoma and the absence of a metallic hue to the body.

Link to Distribution Map. [http://atbi.biosci.ohio-state.edu:210/hymenoptera/eol_scelionidae.content _page?page_level=3\&page_id=taxon_page_data\&page_version=4042\&page_option 1=M]

Material examined. Holotype male: CHILE: Los Lagos, Chiloé, Isl. Aulén, 6.II.1952, L. Peña. Deposited in CNCI.

Paratype: CHILE: Bío-Bío: Contulmo, Arauco, 2.II.1953, L.E. Peña, male, OSUC 146582 (CNCI).

Other material: CHILE: Araucanía, Contulmo National Monument, 240m, mixed humid forest w/ Cusquea, 10km W Purén, Malleco Prov.,12.XII.1982, A. Newton, M. Thayer, female, OSUC 146583 (CNCI); E of Guarderia Pinchinahuel, 3748.20'S 7301.41'W, 1290m, P.N. Nahuelbuta, Prov. de Malleco, 524.XII.2002, A. Newton, M. Thayer, female, OSUC 146604 (CNCI); Flor del Lago, 15 km NE Villarrica, Cautín Prov., 14.XII.1984-10.II.1985, J. Peck, S. Peck, male, OSUC 203784 (CNCI); Flor del Lago, 300m, Nothofagus forest, 15 km NE Villarrica, Cautín Prov., 14.XII.1984-10.II.1985, J. Peck, S. Peck, male, OSUC 146589 (CNCI); Lago Caburgua, $600 \mathrm{~m}$, mixed forest remnant, $21 \mathrm{~km}$ NE Pucón, Cautín Prov. (old), 15.XII.1984-10.II.1985, J. Peck, S. Peck, 19 males, 1 female, OSUC 146585, 203763-203771, 203773203778, 203780-203783 (CNCI); Monte Verde, Carahue, Prov. de Cautín, 29.I-2.II.1993, L. E. Peña, 3 males, OSUC 146597, 203819, 203820 (CNCI); Monumento Natural Contulmo, 350m, Puren, Malleco Prov., 11.XII.1984-13.II.1985, J. Peck, S. Peck, 22 males, 1 female, OSUC 146586, 203785, 203795-203815 (CNCI); Nahuelbuta National Park, 3749.29'S 7301.90'W, 1360 m, Nothofagus dombeyi \& pumilo / large Araucaria, bamboo + shrub understory, road to Piedra del Aguila, Malleco Prov., 6-24.XII.2002, M. Thayer, et al., female, OSUC 146603 (CNCI); Sendero Lemu Mau, 3800.74'S 7311.13'W, 410 m, Mon. Nat. de Contulmo, Prov. de Malleco, 8-24.XII.2002, A. Newton, et al., female, OSUC 146600 (CNCI).

Bío-Bío, Laraquete, S of Concepción, 10-25.I.1993, P. Salinas, 5 males, OSUC 203821-203825 (CNCI); Pata de Gallina, E of Contulmo, Arauco Prov., 10-25.I.1993, II.1989, P. Salinas, 25 males, OSUC 146588, 163621, 203878-203900 (CNCI).

Concepción, Hualpen, Prov. Concepción, 5.III.1977, T. Cekalovic, female, OSUC 146587 (CNCI); Concepción, Las Escaleras, 24.IX.1989, T. Cekalovic, female, OSUC 174513 (UCDC).

Los Lagos, $11 \mathrm{~km}$ W Quemchi, 42 ${ }^{\circ} 10.40^{\prime} \mathrm{S} 73^{\circ} 35.73^{\prime} \mathrm{W}, 140 \mathrm{~m}, 2002-066$, Valdivian forest remnant with thick bamboo understory, Chiloé Prov., 10-21.XII.2002, Clarke, Newton, Thayer, female, OSUC 146601 (CNCI); 3 km S Muicolpue, 200 m, mixed forest litter, Mansa Bay, Osorno Prov., 3.II.1985, J. Peck, S. Peck, male, OSUC 146592 (CNCI); 8 km S Ancud, forest remnant litter, Chiloé Isl., 1.II.1985, J. Peck, S. Peck, female, OSUC 146584 (CNCI); Ahoni, 70m, primary forest, Isla Chiloé, 21-23.II.1988, 22.II.1988, 23.II.1988, II.1988, IV.1988, V.1988, VIII-X.1988, L. Masner, 22 males, OSUC 146591, 203786, 203787, 203859-203877 (CNCI); Ahoni, forest, Chiloé Isl., 22.II.1988, L. Masner, 3 males, OSUC 203856-203858 (CNCI); Ahoni, Isla Chiloé, 3-15.II.1995, V.1988, A. Ugarte, 31 males, OSUC 203788, 203789, 203826203854 (CNCI); Ahoni, Isla Chiloé, III.1988, L.E. Peña, male, OSUC 203855 (CNCI); Anticura, 40³9'53"S $72^{\circ} 10^{\prime} 02^{\prime \prime W}, 447$ m, UCR AToL C05-022, Nothofagus / Chusqueia forest, Puyehue N.P., Repucura Path, 17.II.2005, 4 males, OSUC 174442, 203791, 203910, 203911 (CNCI); Coinco, Isla Chiloé, 8.II.1994, T. Cekalovic, female, OSUC 146602 (CNCI); Correntoso, nr. Puerto Montt, X-XI.1989, L.E. Peña, female, OSUC 163620 (CNCI); El Chingue, Lago Chapo, Prov. de Llanquihue, IV-V.1990, L.E. Peña, 3 males, 
OSUC 146596, 163136, 203907 (CNCI); Isla Quinchao, Hullar Bajo, 16.II.1996, T. Cekalovic, female, OSUC 174512 (UCDC); Las Trancas, 500 m, Nothofagus, 30 km W La Unión, Valdivia Prov., 7-11.II.1988, 1124.II.1988, L. Masner, 3 males, OSUC 146593, 203792, 203909 (CNCI); Mirador, 40¹0'12"S 73³0'00"W, 1004 m, UCR AToL C05-027, recovering Fitzroyia forest, Alerce Costero N.M., 19-20.II.2005, male, OSUC 203914 (CNCI); N of Correntoso, El Chingue, Prov. de Llanquihue, IV-V.1989, VI-VIII.1989, L. E. Peña, 9 males, OSUC 146595, 203790, 203901-203906 (CNCI), OSUC 55602 (OSUC); nr. Lake Chapo, 200 m, Nothofagus forest, Llanquihue Prov., 16-19.II.1988, L. Masner, 2 males, OSUC 146594, 203908 (CNCI); Piopio, Isla Chiloé, Chile, 3-15.II.1995, A. Ugarte, 2 males, OSUC 146599, 203817 (CNCI); Puyehue National Park, 250 m, Nothofagus forest, nr. Anticura, Osorno Prov., 12-14.II.1988, 14.II.1988, L. Masner, 3 males, 1 female, OSUC 146590, 203793, 203794, 203816 (CNCI); Terao, 4243'01"S 73³8'47"W, 45m, UCR AToL C05-013, 10km S Chonchi, Chiloé Isl., 12-13.II.2005, 2 males, OSUC 174441, 203913 (CNCI);

Río Cruces, S of Concepción, XII.1994, P. Salinas, 2 males, OSUC 146598, 203818 (CNCI).

\section{Archaeoteleia robusta Masner, new species}

Figures 64-67

Description: Female. Length $3.6 \mathrm{~mm}$. Color: body generally dark brown; prothorax, including side of pronotum, tegula, clypeus, mandible (except tips), radicle, palpi, fore legs, trochanters and tibiae lighter, light brown to yellow.

Head (Figs. 65-67): vertex, frons, gena rugose punctate, covered with fine dense appressed micropilosity, with only very few stiff bristles; eye distinctly setose; LOL less than OOL; occipital carina well developed, complete, distinctly crenulate, particularly at sides; median keel short, delicate, not reaching beyond midpoint of height of frons; facial striae well developed, reaching almost to level of middle of inner orbit; clypeus broadly triangular, with transverse rugulosity; toruli contiguous with upper margin of clypeus; antenna overall relatively short and stout: A1 6.0 times as long as wide; A2 2.3 times as long as wide; A3 1.6 times as long as A2; flagellum with short setae; claval formula A6-A12/1-2-2-2-2-2-1.

Mesosoma (Figs. 66-67): transverse pronotal carina sharp, perfectly straight, with anterolateral corners acute, but not projecting spinelike; vertical epomial carina present, sharp, originating at anterolateral corner, extending toward fore coxa; horizontal epomial carina sharp, running far from mesoscutum, pronotal shoulders very broad, rugose punctate with dense appressed pilosity, several stiff black erect bristles; lateral pronotum deeply concave, predominantly with large smooth shining glabrous area, leaving only dorsoposterior margin with deep punctation; netrion well defined; mesoscutum in lateral view almost flattened, very broad, densely rugose punctate, with dense appressed micropilosity, and scattered erect black bristles; admedian lines short; notaulus complete, deeply incised, distinctly crenulate; parapsidal line present; transscutal articulation deep, distinctly foveolate; scutellum broad, 0.4 times length of mesoscutum, much wider than long, with same sculpture as mesoscutum, with only few stiff bristles; scutellar spines strong, about as long as disk of scutellum, directed posteriorly; mesopleural carina reduced to rudiment, situated anteriorly; mesopleural depression in upper part smooth, shining, glabrous, with several longitudinal keels below tegula, mesepisternum predominantly punctured, with scattered setae; acetabular carina fine, complete; line of foveae along posterior margin of mesopleuron present, but not extending ventrally as far as mid coxa; metapleuron only sparsely setose, predominantly rugose punctate, with several transverse rugae near propodeum; propodeum with scattered setae, irregularly rugulose, deeply excavate medially, medial excavation almost smooth, glabrous, median carinae present, sharply defined, not raised in profile; macropterous, fore wing relatively short, narrow, not surpassing apex of metasoma, reaching posteriorly only to T5, generally moderately infuscate, distinct cloud of pigmentation sometimes present; $\mathrm{R}$ between tegula and marginal vein with 10 long, erect, stiff black bristles; postmarginal vein tubular, clearly longer than short stigmal vein; stigma short, curved; basal vein pigmented; M, 
$\mathrm{Cu}$, Rs moderately pigmented as nebulous veins; legs exceptionally short, stout, especially femora; tibial spurs of mid leg, hind leg unusually long, strong; hind femur strongly incrassate; hind coxa only slightly longer than mid coxa, without transverse wrinkles at apex, deeply punctured.

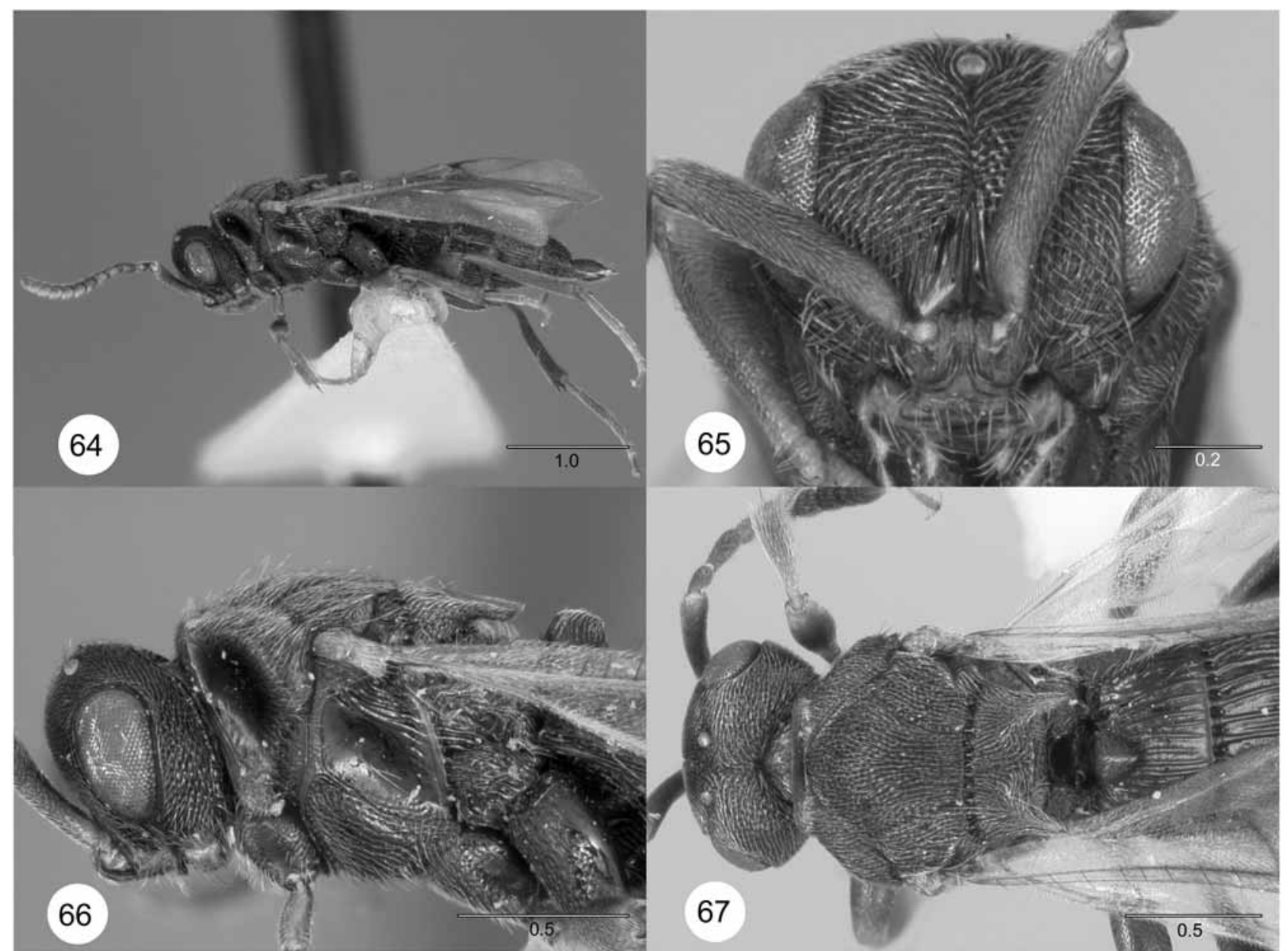

FIGURES 64-67. Archaeoteleia robusta, n.sp., paratype female (OSUC 146605). 64, Lateral habitus; 65, head, frontal view; 66, head and mesosoma, lateral view; 67, head and mesosoma, dorsal view. Scale bars in millimeters.

Metasoma (Figs. 64, 67) short, robust, length 2.6 times width; T1 trapezoidal, length 0.6-0.7 times width, longitudinally costate, trapezoidal, horn short, almost upright, with sharp crest along midline, with deep punctures, without costae; length of T2 0.5 times width; length of T3 0.5 times width; length of T4 0.4 times width; length of T5 0.4 times width; T2-T5 generally longitudinally costate, mid portion of T3-T5 gradually smoother, without costae; length of T6 1.2-1.5 times width, with abundant setigerous punctures.

Male. Very similar to female, even in normally secondary sexual characters; differing as follows: length $3.1 \mathrm{~mm}$; eye slightly smaller; keels present on A4, A5; length of A1 5.6 times width; length of A2 2.1 times width; length of A3 0.6 times length of A1; fore wing variable in length, extending to end of T4 or to tip of metasoma; metasoma with strong, sharp, pyramidal, setose point on anteromedian margin of $\mathrm{T} 1$, propodeum with corresponding excavation; length of metasoma 2.2-2.4 times width.

Diagnosis. Distinct among all Archaeoteleia by the flattened mesoscutum, scutellum and scutellar spines; presence of strong, acute vertical epomial carina; and the stout, strong legs. This species is comprised of robust, stout individuals. The only other species with A1 longer than A3 is male A. pygmea. From that species, A. robusta is distinguished by the darker body color, the presence of black stiff bristles on the mesosoma, the projection of the anteromedial portion of $\mathrm{T} 1$ in the male (very similar to the horn in the female), and the presence of notauli.

Etymology. The specific epithet robusta refers to the body shape. 
Link to Distribution Map. [http://atbi.biosci.ohio-state.edu:210/hymenoptera/eol_scelionidae.content _page?page_level=3\&page_id=taxon_page_data\&page_version=190986\&page_option1=M]

Material examined. Holotype female: CHILE: Chiloé I., Ahoni Alto, XII.1988-III.1989, L.E. Peña, Malaise trap, primary forest. Deposited in CNCI.

Paratypes: CHILE: Araucanía, $3 \mathrm{~km}$ W Victoria, 100 m, mixed Nothofagus forest, Malleco Prov., 13.XII.1984-12.II.1985, J. Peck, S. Peck, female, OSUC 146614 (CNCI); Contulmo National Monument, 350 m, mixed evergreen forest, Purén, Malleco Prov., 11.XII.1984-13.II.1985, J. Peck, S. Peck, female, OSUC 146606 (CNCI); Sendero Lemu Mau, 3800.74'S 7311.13'W, 410 m, Mon. Nat. de Contulmo, Prov. de Malleco, 8-24.XII.2002, A. Newton, et al., female, OSUC 146612 (CNCI).

Bío-Bío, Carampangue, Prov. de Arauco, 22.I.1978, T. Cekalovic, female, OSUC 146615 (CNCI).

Los Lagos, $11 \mathrm{~km}$ W Quemchi, $42^{\circ} 10.40^{\prime} \mathrm{S} 73^{\circ} 35.73^{\prime} \mathrm{W}, 140 \mathrm{~m}, 2002-066$, Valdivian forest remnant with thick bamboo understory, Chiloé Prov., 10-21.XII.2002, Clarke, Newton, Thayer, female, OSUC 146610 (CNCI); Los Lagos, Ahoni, 70m, primary forest, Isla Chiloé, Los Lagos Reg., Chile, 22.II.1988, III.1988, IV.1988, L. Masner, 5 females, OSUC 146608, 203916-203919 (CNCI); Ahoni, primary forest, Chiloé Isl., IX.1988, X.1988, XII.1988-III.1989, L.E. Peña, 4 females, OSUC 203921, 203923-203925 (CNCI); Chiloé National Park, $42^{\circ} 37.36$ 'S $74^{\circ} 06.82^{\prime} \mathrm{W}, 1 \mathrm{~m}$, low dune evergreen forest with large ferns and shrubby understory, Dunas de Cucao trail, Chiloé Prov., 11-22.XII.2002, A. Newton, M. Thayer, female, OSUC 146611 (CNCI); Petrohué Waterfall, $150 \mathrm{~m}$, mixed moist forest, Vicente Pérez Rosales N.P., Llanquihue Prov., 23.XII.1984-4.II.1985, J. Peck, S. Peck, female, OSUC 146613 (CNCI); Terao, 4242'22"S 73³9'12"W, 10 m, UCR AToL C05-016, beach / shrub forest, $10 \mathrm{~km} \mathrm{~S} \mathrm{Chonchi,} \mathrm{Chiloé} \mathrm{Isl.,} \mathrm{13.II.2005,} \mathrm{female,} \mathrm{OSUC}$ 203934 (CNCI); Terao, 4243'01"S 73³8'47"W, 45 m, UCR AToL C05-013, 10 km S Chonchi, Chiloé Isl., 12-13.II.2005, 8 females, OSUC 203926-203933 (CNCI); Terao, 50 m, 2nd growth forest, nr. Chonchi, Chiloé Isl., 20.II.1988, 23.II.1988, L. Masner, 1 male, 3 females, OSUC 146609, 203915, 203920, 203935 (CNCI); Valdivia, 3947'S, 7316'W, Isla Teja, Prov. de Valdivia, 7.II.1966, M. Erwin, female, OSUC 146605 (CNCI).

Maule, Altos de Vilches, 1300 m, Nothofagus forest, $70 \mathrm{~km}$ E Talca, 5.XII.1984-20.II.1985, J. Peck, S. Peck, male, OSUC 146607 (CNCI); Prov. Curicó, Los Niches 10 km E Curicó, 6-17.IV.1998, J.E. Barriga, Malaise trap, 2 females, OSUC 174514, 174515 (UCDC).

Comments: There is an almost negligible amount of variation among the 31 females available. Only 2 males are known, an unusual inversion of the typical collecting sex ratio.

\section{Archaeoteleia simulans Masner, new species}

Figures 68-71

Description: Female. Length $2.55 \mathrm{~mm}$. Color: generally ebony black; with the exception of A5, mandible (except for very tip), palpi, tegula, legs including coxae, yellowish; hind coxa slightly darker than remainder of legs; wings clear, without cloud of pigmentation below marginal, stigmal veins.

Head (Figs. 69-71): vertex, occiput, frons (except facial striae), upper gena smooth, without microsculpture, with minimum appressed minute setae; upper frons, interocellar space glabrous; eye glabrous; LOL slightly greater than OOL; occipital carina fine, but complete, with minuscule crenulation; frons without median keel, but shallow depression present above antennal insertion; facial striae dense, reaching inner orbit, reaching not beyond lower third of height of eye, very short posterior to malar sulcus; clypeus triangular, smooth, anterolateral corners minute; rim of torulus confluent with dorsal margin of clypeus; antenna remarkably slender: A1 5.4-6.0 times as long as wide; A2 2.3 times as long as wide; A3 3.6-3.8 times as long as wide; flagellum with fairly short setae; claval formula A6-A12/2-2-2-2-2-2-1. 
Mesosoma (Figs. 70-71): transverse pronotal carina sharp, slightly arcuate, curved forward medially, anterolateral corners angular, but not spikelike; vertical epomial carina present, distinct in upper half, somewhat irregular ventrally; horizontal epomial carina complete, sharp, pronotal shoulders well developed, with row of foveolae both along the horizontal carina and adjacent to mesoscutum, moderately developed, nearly smooth between foveolae; lateral pronotum with large glabrous field, with very delicate microsculpture; netrion well defined by foveolae, considerable micropilosity; mesoscutum with middle lobe smooth and shining, entire surface, particularly posterior two-thirds, regularly covered with setigerous punctures, setae semidecumbent, lateral lobe of mesoscutum almost entirely glabrous, with only few setigerous punctures near posterior notaulus; admedian lines present, fine; notaulus complete, rather narrow, finely foveolate, subparallel; parapsidal line absent or faintly indicated; transscutal articulation well developed, posterior flanking foveolae large; scutellum without microsculpture, with only few setigerous punctures; scutellar spines short, pointed, slightly incurved, distinctly shorter than length of scutellar disk; mesopleural carina absent; dorsal portion of mesopleuron smooth, glabrous, mesepisternum smooth, with fairly dense appressed pilosity; acetabular carina sharply raised; chain of foveolae along posterior margin of mesopleuron well developed, extending ventrally to mid coxal cavity; metapleuron with dense pilosity, both upper and lower parts almost smooth, without microsculpture; propodeum with fine pilosity, almost without medial depression, but median keels well-developed; wings almost clear, widely surpassing tip of metasoma; basal vein, $\mathrm{M}, \mathrm{Cu}$, Rs nebulous, with delicate infuscation under marginal vein; postmarginal vein stublike, extremely short; stigmal vein short, slightly curved apically; legs extremely long and slender, femora very weakly incrassate.

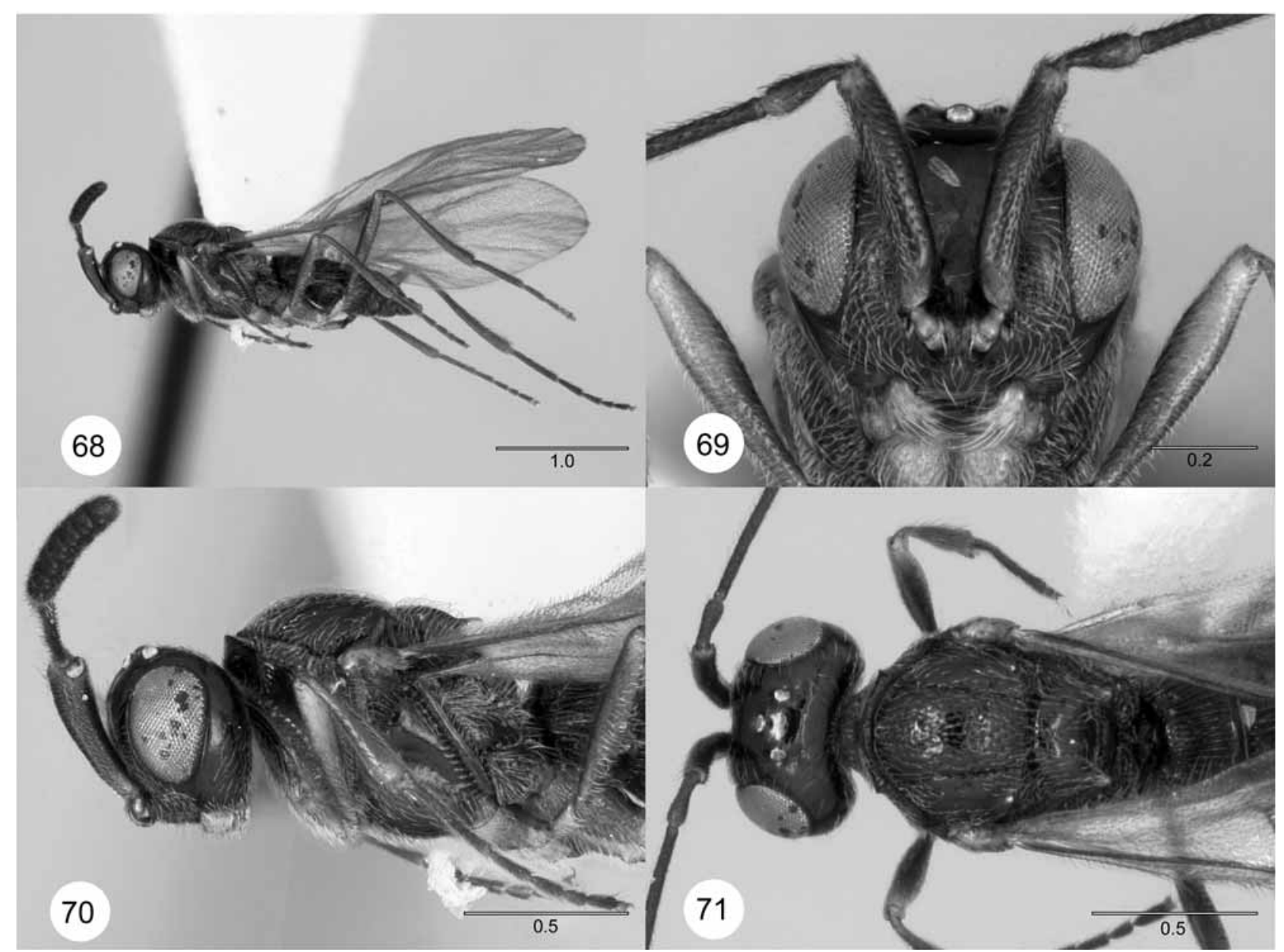

FIGURES 68-71. Archaeoteleia simulans, n.sp., paratype female (OSUC 146493) 68, Lateral habitus; 69, head, frontal view; 70, head and mesosoma, lateral view; 71, head and mesosoma, dorsal view. Scale bars in millimeters. 
Metasoma (Figs. 68, 71) relatively short, length 2.4 times width, most terga with rather long, scattered, semierect hairs; T1 entirely longitudinally costate except for narrow, smooth band along posterior margin, horn not or only weakly developed, anterior margin with only moderate elevation, length of T1 0.5 times width; length of T2 0.5 times width, strongly costate throughout; length of T3 0.4 times width, costae finer than on T2, both T2, T3 with narrow smooth band along posterior margin; length of T4 0.5 times width, with finer longitudinal costae, larger smooth area posteriorly; length of T5 0.5 times width, predominantly with very short longitudinal rugulosity anteriorly, mostly smooth in posterior half; T6 very short, bluntly triangular, length 0.8 times width.

Male. Differing from the female in the following characters: both A4 and A5 with keels, keels not exceeding basal third of antennomere; length of A1 4.3 times width; length of A2 1.3 times width; length of A3 1.8 times length of A1; propodeal keels less pronounced than in female; all metasomatic terga longitudinally costate, but progressively finer, on T4 only anterior half with longitudinal sculpture.

Diagnosis. Most similar to A. araucana, distinguished by the even coverage of distinct setigerous punctures on the entire middle lobe of the mesoscutum, and the low and completely striate bulge on T1 in the female.

Etymology. The specific epithet simulans, derived from Latin for imitate or copy, refers to the similarity of this species to Archaeoteleia araucana.

Link to Distribution Map. [http://atbi.biosci.ohio-state.edu:210/hymenoptera/eol_scelionidae.content _page?page_level=3\&page_id=taxon_page_data\&page_version=190989\&page_option1=M]

Material examined. Holotype female: CHILE: Los Lagos, Antillanca, 1300 m, Nothofagus tree line, Puyehue N.P., Osorno Prov., 16.II.1988, L. Masner, OSUC 174423. Deposited in CNCI.

Paratypes: CHILE: Araucanía, Monte Verde, Carahue, Prov. de Cautín, 29.I-2.II.1993, L.E. Peña, female, OSUC 146493 (CNCI); Nahuelbuta National Park, forest, 9.II.2005, L. Masner, 2 females, OSUC 203943, 203944 (CNCI).

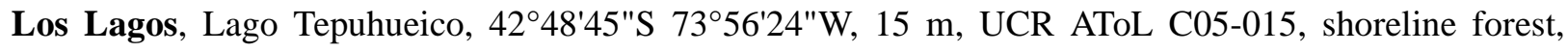
Miraflores, Chiloé Isl., 13.II.2005, male, OSUC 174444 (CNCI); Las Trancas, 500 m, Nothofagus, $30 \mathrm{~km} \mathrm{~W}$ La Unión, Valdivia Prov., 7-12.II.1988, L. Masner, 4 males, 1 female, OSUC 203936-203939, 203945 (CNCI); Petrohué, Llanquihue Prov. (old), 26-29.III.1968, L.E. Peña, male, OSUC 151832 (AEIC); Puntra River, 100 m, Nothofagus forest, Route 5, Chiloé Isl., Los Lagos Reg., Chile, 24.II.1988, L. Masner, 2 males, OSUC 203941 (CNCI).

\section{Archaeoteleia submetallica Masner, new species}

Figures 72-75

Description: Female. Length 3.1-3.2 mm. Color: castaneous brown, mesoscutum, sometimes T6 with slight purplish metallic tinge; antenna abruptly bicolored, A1-A5 bright yellow, A6-A12 nearly black; legs, including coxae, entirely yellow; dorsal part of pronotum, including epomial corners, yellow; lower portion of pronotum, mesopleuron, metapleuron, S1-S2 dark brown to nearly black.

Head (Figs. 73-75): vertex, occiput, upper frons rugose punctate, punctures bearing short, appressed setae; sculpture along inner orbits with longitudinal rugulosity, central part of frons punctate; upper gena rugose punctate, sparsely setose above, longitudinally rugulose punctate below; eye glabrous; LOL greater than OOL; occipital carina fine, complete, not distinctly crenulate; frons with strong median keel running slightly over half distance from interantennal process to median ocellus; striae of cheeks and face strong, reaching inner orbits; clypeus strongly transversely striate, anterolateral corners strongly projecting, with long erect setae; toruli contiguous with upper margin of clypeus; A1 5.7 times as long as wide; A2 2.9 times as long as wide; A3 1.1-1.2 times as long as A2; flagellum with moderately dense, suberect setae, length subequal to width of A3; claval formula A6-A12/2-2-2-2-2-2-1. 
Mesosoma (Figs. 74-75): transverse pronotal carina extremely sharp, bladelike, produced medially into broad point, with anterolateral corners sharply produced, pointed; vertical epomial carina absent; horizontal epomial carina close to mesoscutum, and shoulders narrow, maximum width about 0.5 tegula width, space between horizontal epomial carina and mesoscutum rather broad, carina turning downwards on pronotal side; lateral pronotum predominantly smooth, highly shining, largely glabrous, area above fore coxa with irregular, large, transverse rugulae; netrion not well defined; mesoscutum highly convex, with dense, fine pilosity, interspersed with few, long erect setae, densely punctured, interstices smooth, without microsculpture; admedian lines absent; notaulus absent; parapsidal line absent; transscutal articulation absent; scutellum broadly transverse, almost striplike, length 0.4 times length of mesoscutum, densely punctate, with dense pilosity and few erect bristles; scutellar spines strong, straight, sharply pointed, semierect; mesopleural carina present, running almost in middle of mesopleuron, smooth and shining above; mesopleuron almost entirely glabrous, smooth, shining, without microsculpture, with row of deep foveolae along posterior margin; mesepisternum below mesopleural carina almost glabrous, smooth and shining; acetabular carina present, crenulate; metapleuron densely hairy, with rough rugulosity and deep punctures, without glabrous area; propodeum with shallow excavation medially, punctured, with distinctly finer sculpture than lateral propodeum; submedial carinae present, not projecting, not sharp; tegula absent; wings entirely absent; legs relatively short, robust; pretarsal claws very strongly developed.

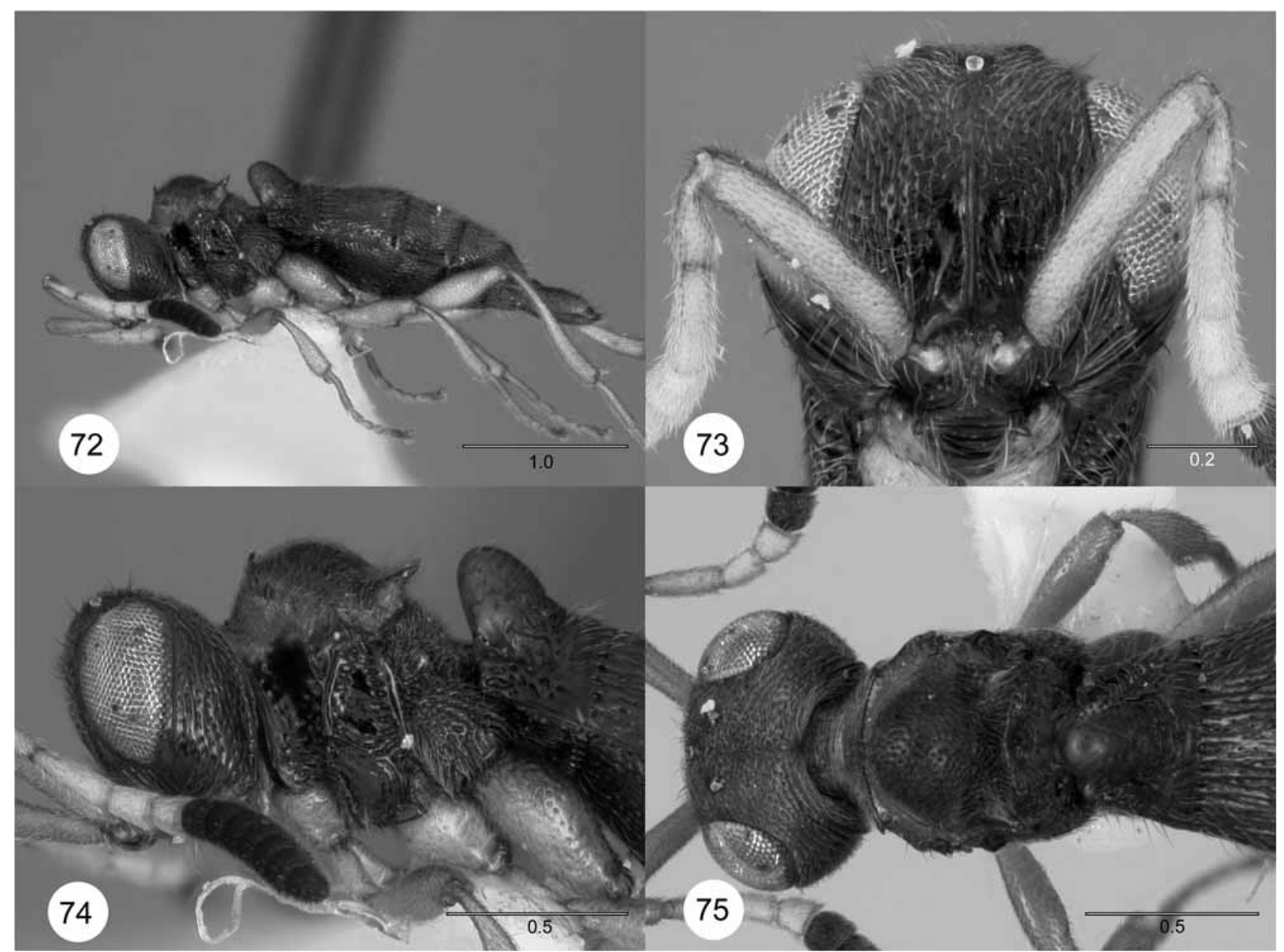

FIGURES 72-75. Archaeoteleia submetallica, n.sp., holotype female (OSUC 146616). 72, Lateral habitus; 73, head, frontal view; 74, head and mesosoma, lateral view; 75, head and mesosoma, dorsal view. Scale bars in millimeters.

Metasoma (Figs. 72, 75) convex laterally, length 2.9-3.0 times width; T1 with massive horn, leaning forward, top of horn clearly higher than level of mesoscutum, anterior face and top of horn, smooth, glabrous, posterior part of horn rugose punctate, with dense pilosity, rest of T1 rugose punctate, with abundant pilosity, 
length of T1 0.8 times width; length of T2 0.7 times width, covered with strong longitudinal rugulae interspersed with punctures, dense semidecumbent pilosity, scattered erect long bristles; length of T3 0.5 times width, sculpture and setation similar to T2, slightly finer; length of T4 0.4 times width, sculpture and pilosity similar to T3; length of T5 0.3 times width, with finer longitudinal rugulae and pilosity; T6 distinctly elongate, 2.0-2.3 times width, basally with short longitudinal rugulae, otherwise deeply punctate, with pilosity and scattered bristles similar to other tergites.

Male unknown.

Diagnosis. These three females are truly apterous, with no rudiments of tegula or wings present; in this character this species can only be confused with A. pygmea and A. dispar. Archaeoteleia submetallica may be differentiated by the rugose punctate gena; straight scutellar spines; top of horn on T1 exceeding level of mesoscutum (in lateral view); and T6 distinctly elongate, at least twice as long as wide. It may also be distinguished from A. dispar by the complete absence of even the rudiments of wings. This is the only species of Archaeoteleia with parts of body with submetallic purplish tinge.

Etymology. The specific epithet submetallica refers to the coloring of the body.

Link to Distribution Map. [http://atbi.biosci.ohio-state.edu:210/hymenoptera/eol_scelionidae.content _page?page_level=3\&page_id=taxon_page_data\&page_version=190987\&page_option1=M]

Material examined. Holotype female: CHILE: Bío-Bío, Arauco, E. Contulmo, Pata de Gallina, 1025.I.1989, pan trap, P. Salinas, OSUC 174165. Deposited in CNCI.

Paratypes: CHILE: Bío-Bío, Arauco, E. Contulmo, Pata de Gallina, 10-25.I.1989, pan trap, P. Salinas, OSUC 146616 (CNCI); Arauco, Pata de Gallina, 12.IV.1997, T. Cekalovic, TC-544 Berlese, female, OSUC 185479 (UCDC).

Comments. Twenty-four males of Archaeoteleia were also collected at the type locality, most at same time, but we cannot distinguish these from the males of A. pygmea. Therefore, we believe that the males of $A$. submetallica either are indistinguishable from A. pygmea, they have not yet been collected, the species is thelytokous, or the differences observed in the females may fall within the range of variation of a single species.

\section{ACKNOWLEDGMENTS}

We thank L. Musetti and J. Cora for their invaluable support and assistance, G.A.P. Gibson for his careful review of the manuscript and A. Ashworth for information on his collecting localities. We also thank the Auckland Institute for a grant to enable J. Early to visit the Canadian national Collection of Insects. This material is based upon work supported in part by the National Science Foundation under grant Nos. DEB0344034 and DEB-1614764.

\section{REFERENCES}

Austin, A.D. \& Field, S.A. (1997) The ovipositor system of scelionid and platygastrid wasps (Hymenoptera: Platygastroidea): comparative morphology and phylogenetic implications. Invertebrate Taxonomy, 11, 1-87.

Austin, A.D., Johnson, N.F. \& Dowton, M. (2005) Systematics, evolution and biology of scelionid and platygastrid wasps. Annual Review of Entomology, 50, 553-582.

Bin, F. (1981) Definition of female antennal clava based on its plate sensilla in Hymenoptera Scelionidae Telenominae. Redia, 64, 245-261.

Chambers, F. (1982) Archaeoteleia novaezealandiae Masner (Hymenoptera, Scelionidae). The Weta, 5(2), 44.

Crosby, T.K., Dugdale, J.S. \& Watt, J.C. (1976) Recording specimen localities in New Zealand: an arbitrary system of areas and codes defined. New Zealand Journal of Zoology, 3, 69.

Johnson, N.F. (1992) Catalog of world Proctotrupoidea excluding Platygastridae. Memoirs of the American Entomological Institute, 51, 1-825.

Johnson, N.F., Musetti, L. \& Masner, L. The Cretaceous scelionid genus Proteroscelio (Hymenoptera: Platygastroidea). 
American Museum Novitates, in press.

Kozlov, M.A. (1970) [Supergeneric groupings of Proctotrupoidea (Hymenoptera).] Entomologicheskoye Obozreniye, 49, 203-226.

Kozlov, M.A. \& Kononova, S.V. (1990) [Scelioninae of the Fauna of the USSR (Hymenoptera, Scelionidae, Scelioninae).] Nauka, Leningrad. 344 pp.

Loiácono, M.S. \& Díaz, N.B. (1977) Anotaciones sobre himenópteros proctotrupoideos y cynipoideos argentinos (Hymenoptera: Proctotrupoidea, Cynipoidea). Neotropica, 23, 95-102.

Masner, L. (1968) A new genus of Scelionidae (Hymenoptera) with austral disjunctive distribution. New Zealand Journal of Science, 11, 652-663.

Masner, L. (1976) Revisionary notes and keys to world genera of Scelionidae (Hymenoptera: Proctotrupoidea). Memoirs of the Entomological Society of Canada, 97, 1-87.

Masner, L. (1980) Key to genera of Scelionidae of the Holarctic region, with descriptions of new genera and species (Hymenoptera: Proctotrupoidea). Memoirs of the Entomological Society of Canada, 113, 1-54.

Masner, L. \& Huggert, L. (1989) World review and keys to genera of the subfamily Inostemmatinae with reassignment of the taxa to the Platygastrinae and Sceliotrachelinae (Hymenoptera: Platygastridae). Memoirs of the Entomological Society of Canada, 147, 1-214.

Mikó, I., Vilhelmsen, L, Johnson, N.F., Masner, L. \& Pénzes, Z. (2007) Skeletomusculature of Scelionidae (Hymenoptera: Platygastroidea): head and mesosoma. Zootaxa, 1571, 1-78.

Murphy, N.P., Carey, D., Castro, L.R., Dowton, M. \& A.D. Austin. (2007) Phylogeny of the platygastroid wasps (Hymenoptera) based on sequences from the 18S rRNA, 28S rRNA and CO1 genes: implications for the evolution of the ovipositor system and host relationships. Biological Journal of the Linnean Society, 91, 653-669.

Nel, A. \& Azar, D. (2005) The oldest parasitic Scelionidae: Teleasinae (Hymenoptera: Platygastroidea). Polskie Pismo Entomologiczne, 74, 333-338.

Richards, A.O. (1959) Revision of the Rhaphidophoridae (Orthoptera) of New Zealand. Part IV - The Rhaphidophoridae of the Thames gold mines. Transactions of the Royal Society of New Zealand, 87, 27-33.

Sarazin, M. J. (1986) Primary types of Ceraphronoidea, Evaniodea, Proctotrupoidea, and Trigonaloidea (Hymenoptera) in the Canadian National Collection. The Canadian Entomologist, 118, 957-989. 